\title{
High speed silicon wet anisotropic etching for applications in bulk micromachining: a review
}

\author{
Prem Pal ${ }^{1 *}$, , Veerla Swarnalatha ${ }^{1}$, Avvaru Venkata Narasimha Rao ${ }^{1}$, Ashok Kumar Pandey ${ }^{2}$, Hiroshi Tanaka ${ }^{3}$ \\ and Kazuo Sato ${ }^{4}$
}

\begin{abstract}
Wet anisotropic etching is extensively employed in silicon bulk micromachining to fabricate microstructures for various applications in the field of microelectromechanical systems (MEMS). In addition, it is most widely used for surface texturing to minimize the reflectance of light to improve the efficiency of crystalline silicon solar cells. In wet bulk micromachining, the etch rate is a major factor that affects the throughput. Slower etch rate increases the fabrication time and therefore is of great concern in MEMS industry where wet anisotropic etching is employed to perform the silicon bulk micromachining, especially to fabricate deep cavities and freestanding microstructures by removal of underneath material through undercutting process. Several methods have been proposed to increase the etch rate of silicon in wet anisotropic etchants either by physical means (e.g. agitation, microwave irradiation) or chemically by incorporation of additives. The ultrasonic agitation during etching and microwave irradiation on the etchants increase the etch rate. However, ultrasonic method may rupture the fragile structures and microwave irradiation causes irradiation damage to the structures. Another method is to increase the etching temperature towards the boiling point of the etchant. The etching characteristics of pure potassium hydroxide solution $(\mathrm{KOH})$ is studied near the boiling point of $\mathrm{KOH}$, while surfactant added tetramethylammonium hydroxide (TMAH) is investigated at higher temperature to increase the etch rate. Both these studies have shown a potential way of increasing the etch rate by elevating the temperature of the etchants to its boiling point, which is a function of concentration of etch solution. The effect of various kinds of additives on the etch rate of silicon is investigated in $\mathrm{TMAH}$ and $\mathrm{KOH}$. In this paper, the additives which improve the etch rate have been discussed. Recently the effect of hydroxylamine $\left(\mathrm{NH}_{2} \mathrm{OH}\right)$ on the etching characteristics of TMAH and $\mathrm{KOH}$ is investigated in detail. The concentration of $\mathrm{NH}_{2} \mathrm{OH}$ in $\mathrm{TMAH} / \mathrm{KOH}$ is varied to optimize the etchant composition to obtain improved etching characteristics especially the etch rate and undercutting which are important parameters for increasing throughput. In this article, different methods explored to improve the etch rate of silicon have been discussed so that the researchers/scientists/engineers can get the details of these methods in a single reference.
\end{abstract}

Keywords: Wet anisotropic etching, Silicon, Micromachining, $\mathrm{TMAH}, \mathrm{KOH}, \mathrm{NH}_{2} \mathrm{OH}, \mathrm{MEMS}$

\footnotetext{
*Correspondence: prem@iith.ac.in

${ }^{1}$ MEMS and Micro/Nano Systems Laboratory, Department of Physics,

Indian Institute of Technology Hyderabad, Hyderabad, India

Full list of author information is available at the end of the article
}

\begin{abstract}
Introduction
Etching is one of the major processes employed in the fabrication of microstructures. It is classified into two categories: wet etching and dry etching as presented in Fig. 1 [1-4]. Wet etching is further subdivided into two parts namely anisotropic and isotropic etching. Silicon wet anisotropic etching is extensively used in silicon
\end{abstract}




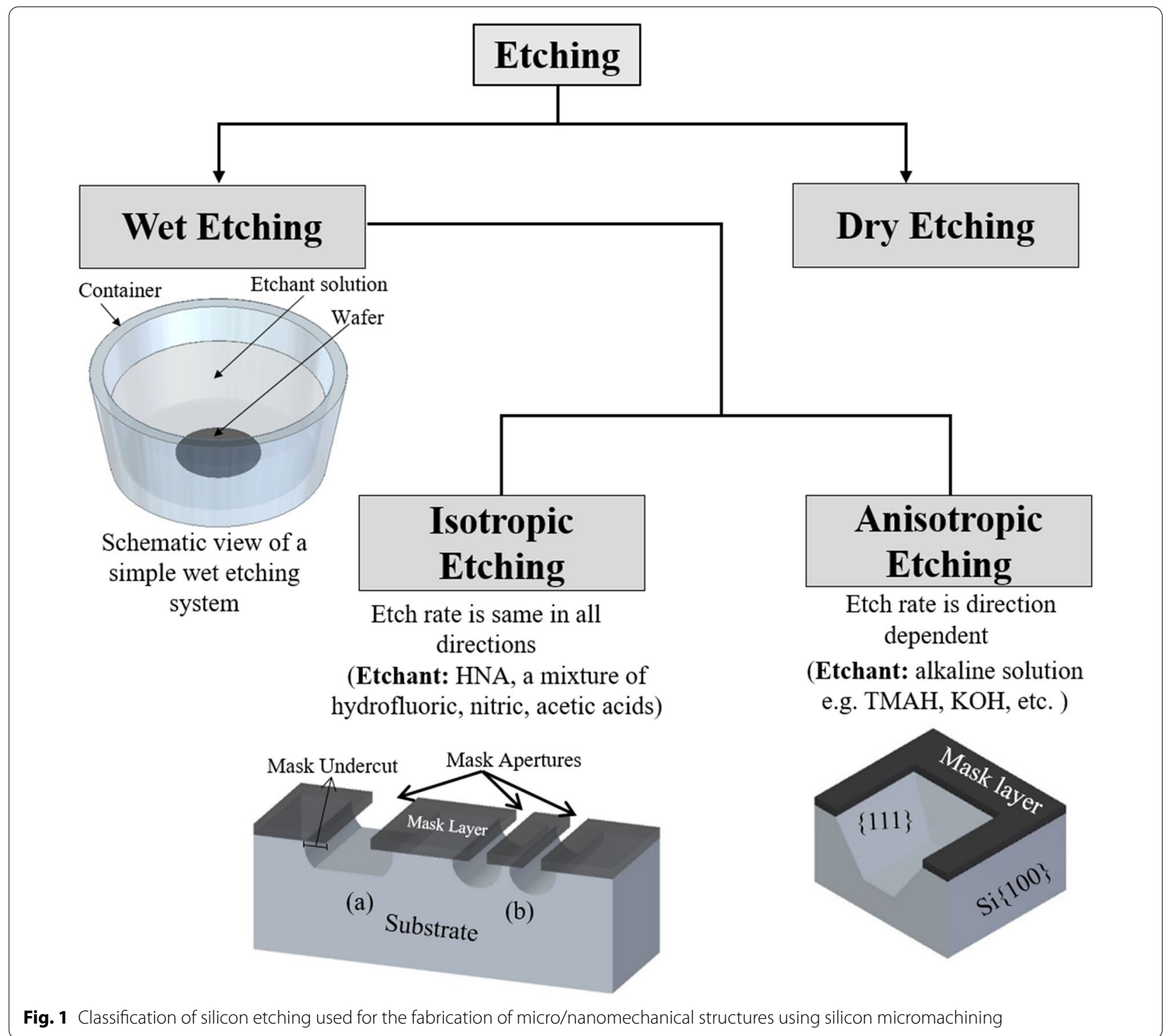

bulk micromachining for the fabrication of microelectromechanical systems (MEMS) and the surface texturing for solar cell applications [1-10]. Figure 2 presents the examples of a few microstructures which are fabricated using wet anisotropic etching for applications in MEMS. The etch rate of silicon is usually the strong function of the orientation, etchant type, concentration, and etching temperature. Moreover, the etch rate is significantly affected by the impurities (or additives) in the etchant. Different kinds of anisotropic etchants such as potassium hydroxide solution (KOH) [11-24], tetramethylammonium hydroxide (TMAH) [24-36], ethylenediamine pyrocatechol water (EDP or EPW) [37-39], hydrazine $\left(\mathrm{N}_{2} \mathrm{H}_{4}\right)$ [40, 41], ammonium hydroxide $\left(\mathrm{NH}_{4} \mathrm{OH}\right)$ [42,
43], cesium hydroxide ( $\mathrm{CsOH})$ [44], etc. have been investigated and employed for the fabrication of microstructures. However, TMAH and $\mathrm{KOH}$ are most widely used for the formation of microstructures in silicon wet bulk micromachining $[1-8,19,28,29,34,36,45-48]$. Both etchants have their own pros and cons. $\mathrm{KOH}$ solution provides higher etch rate and better anisotropy between $\{100\} /\{110\}$ and $\{111\}$ planes, whereas TMAH is a solution compatible for CMOS (complementary metaloxide-semiconductor) process and exhibits high etch selectivity between silicon and silicon dioxide.

Silicon wafers are available in a variety of sizes from $25.4 \mathrm{~mm}$ (1 inch) to $300 \mathrm{~mm}$ (11.8 inches) as shown in Fig. 3. The size has gradually increased to improve 


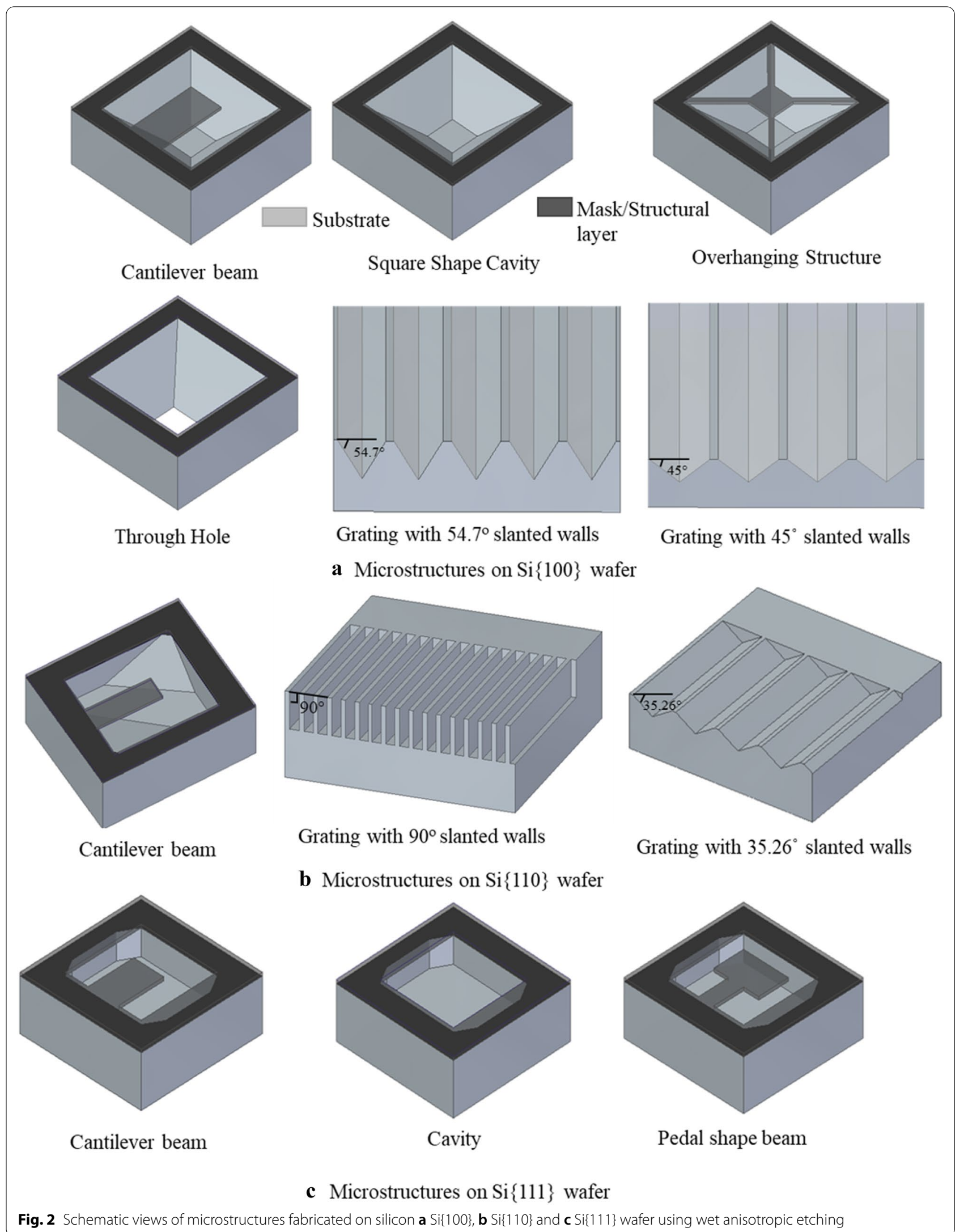




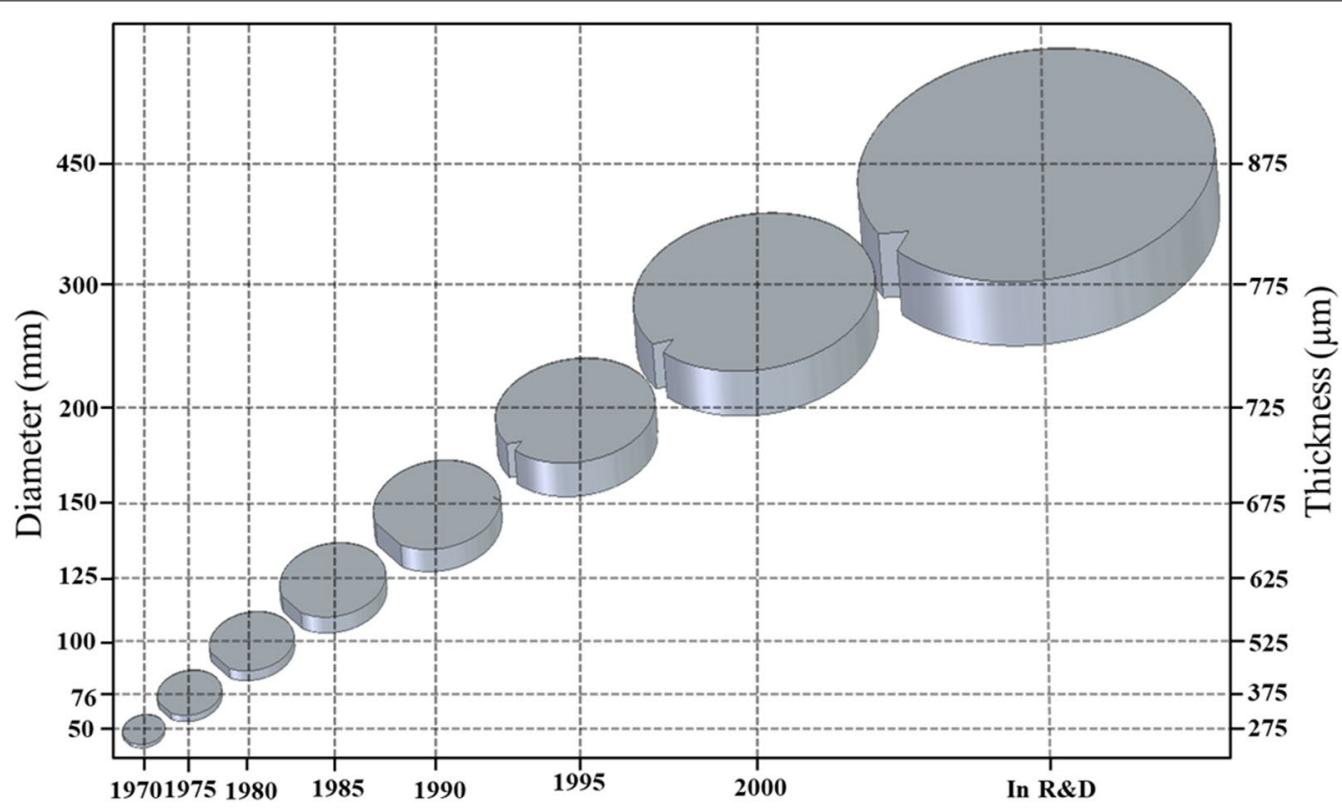

Fig. 3 Historical trend of the size of the silicon wafer

Table 1 Wafer size vs thickness

\begin{tabular}{ll}
\hline Wafer size & Standard thickness \\
\hline 2 inch (50.8 mm) & $275 \mu \mathrm{m}$ \\
$76 \mathrm{~mm}(3$ inch) & $375 \mu \mathrm{m}$ \\
$100 \mathrm{~mm}(4$ inch) & $525 \mu \mathrm{m}$ \\
$125 \mathrm{~mm}$ (5 inch) & $625 \mu \mathrm{m}$ \\
$150 \mathrm{~mm}$ (6 inch) & $675 \mu \mathrm{m}$ \\
$200 \mathrm{~mm}$ (8 inch) & $725 \mu \mathrm{m}$ \\
$300 \mathrm{~mm}$ (12 inch) & $775 \mu \mathrm{m}$ \\
$450 \mathrm{~mm}$ (18 inch), future & $925 \mu \mathrm{m}$ \\
\hline
\end{tabular}

throughput and to reduce the production cost of semiconductor devices. Presently $300 \mathrm{~mm}$ ( 12 inch) diameter is the largest size wafer used in fab industry. Different wafer manufacturing companies are involved in the development of $450 \mathrm{~mm}$ (or 18-inch) diameter wafer [49]. The thickness of the wafers depends upon the size of the wafer to provide adequate mechanical support during device fabrication. It increases with increase of wafer diameter. The standard thickness versus wafer diameter as per semiconductor equipment and materials international (SEMI) is given in Table 1. In the wet chemicalbased bulk micromachining, the industrial throughput is a strong function of the etch rate. Wafer thickness versus etching time for $\mathrm{Si}\{100\}$ in $5 \mathrm{wt} \% \mathrm{TMAH}$ and 20 $\mathrm{wt} \% \mathrm{KOH}$ at $70{ }^{\circ} \mathrm{C}$ is shown in Fig. 4. The etch rate of silicon at $70{ }^{\circ} \mathrm{C}$ in $5 \mathrm{wt} \% \mathrm{TMAH}$ and $20 \mathrm{wt} \% \mathrm{KOH}$ is about $29 \mu \mathrm{m} / \mathrm{h}$ and $40 \mu \mathrm{m} / \mathrm{h}$, respectively $[50,51]$, which is

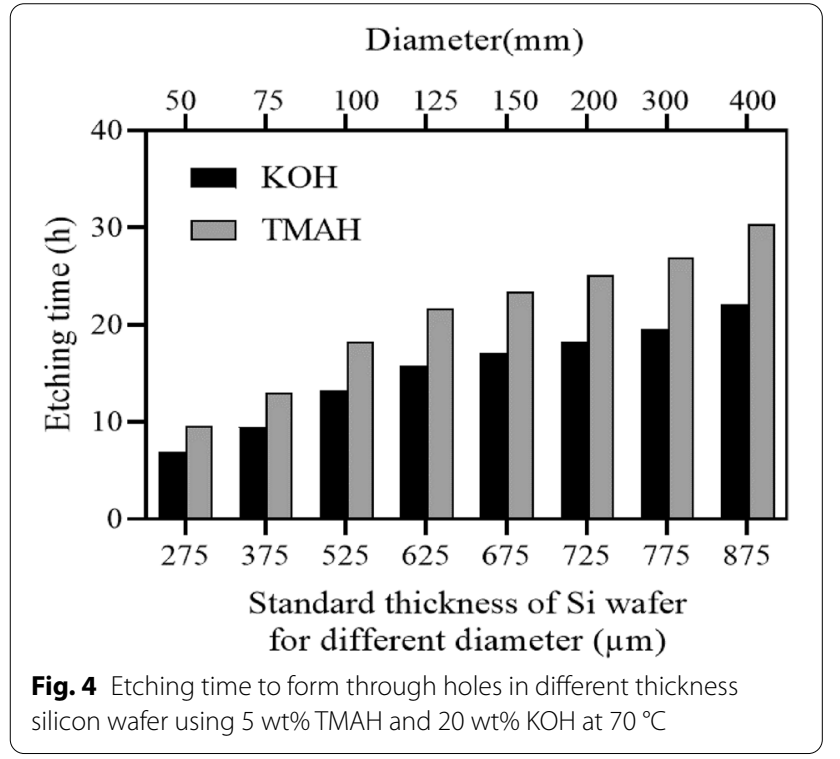

moderate (or low) if larger thickness wafers are etched to form through holes and diaphragms. Slower etch rate not only limits the throughput but also affects the frequently used masking layer (e.g. $\mathrm{SiO}_{2}$ ) due to increased time of exposure with the etchants (say $\mathrm{KOH}$ ), The etching of $775 \mu \mathrm{m}$ thickness (standard thickness of $300 \mathrm{~mm}$ diameter wafers) of $\mathrm{Si}\{100\}$ in $5 \mathrm{wt} \%$ TMAH and $20 \mathrm{wt} \% \mathrm{KOH}$ at $70{ }^{\circ} \mathrm{C}$ requires about $27 \mathrm{~h}$ and $19 \mathrm{~h}$, respectively. Further increases in the thickness and the size of the wafer will lead to an increase in the etching time. Hence, there 
has been a strong demand to develop a solution or technique to attain high etch rate to reduce etching time that will eventually help for enhancing the industrial production. Several methods have been reported to improve the etch rate including the addition of certain additives [5065], ultrasonic agitation [66], microwave irradiation [67, 68] and etching at (or near) the boiling point of the etchant $[18,69]$. The addition of certain kinds of additives to the etchant solution introduces other species which can enhance the etch rate. Recently, $\mathrm{NH}_{2} \mathrm{OH}$-added TMAH and $\mathrm{KOH}$ solutions, which provide very high etch rate in comparison to pure $\mathrm{KOH}$ and TMAH, are explored for applications in wet bulk micromachining for the formation of MEMS structures [50, 51, 59-65].

In this article, several methods employed to improve the etch rate of silicon have been reviewed and discussed in detail. It is aimed at providing a single reference to understand different methods explored to increase the etch rate of silicon and the underlying etching mechanism behind each technique. The advantages and disadvantages of each approach are briefly explicated. This paper is intended to serve as a guide on silicon etch rate enhancement for applications in silicon wet bulk micromachining for the fabrication of microstructures.

\section{Silicon etching mechanism in alkaline solution}

The chemical reaction governing the etching process in alkaline solution is investigated by many researchers and several models have been proposed [70-76]. Among the different models, Gosalvez et al. model is more appropriate to explain the etching mechanism in alkaline solution [76]. Anisotropic etching consists of two alternating reactions, namely, (i) oxidation (ii) etching with the peculiarity that oxidation is very slow as compared to etching. Generally, silicon surface atoms are terminated by hydrogen. Hydroxide $\left(\mathrm{OH}^{-}\right)$ions and water $\left(\mathrm{H}_{2} \mathrm{O}\right)$ molecules are the chemically reactive species in the alkaline solution (KOH, TMAH). Figure 5 presents the etching mechanism in pure alkaline solution. The oxidation step can occur through either chemical oxidation and/or electrochemical oxidation. In the chemical oxidation step, the $\mathrm{H}$ atoms of $\mathrm{Si}-\mathrm{H}$ surface bonds are replaced by $\mathrm{OH}^{-}$ions due to the higher electronegativity of oxygen compared to hydrogen. Here, $\mathrm{OH}^{-}$ion acts as a catalyst while $\mathrm{H}_{2} \mathrm{O}$ is the reactive molecule. As a result, the surface $\mathrm{Si}$ atoms are oxidized. The chemical reaction for the process on $\mathrm{Si}\{100\}$, which has two dangling and two back bonds, is given by the following equation.

$$
\begin{gathered}
(=\mathrm{Si})_{2} \mathrm{SiH}_{2}+2 \mathrm{OH}^{-}+2 \mathrm{H}_{2} \mathrm{O} \rightarrow \\
\quad(=\mathrm{Si})_{2} \mathrm{Si}(\mathrm{OH})_{2}+2 \mathrm{H}_{2}+2 \mathrm{OH}^{-}
\end{gathered}
$$

In electrochemical oxidation, the surface $\mathrm{Si}-\mathrm{H}$ bond is broken due to thermal dissociation. This leaves two electrons in the conduction band of Si. The $\mathrm{OH}^{-}$ions, being negatively charged, cannot be adsorbed on to the Si surface. $\mathrm{H}_{2} \mathrm{O}$ molecules, which are near the Si surface will accept that two electrons resulting in its dissociation into $\mathrm{H}^{+}$and $\mathrm{OH}^{-}$ions. These $\mathrm{OH}^{-}$ions are adsorbed on the $\mathrm{Si}$ surface forming $\mathrm{Si}-\mathrm{OH}$ bonds and lead to the weakening of $\mathrm{Si}-\mathrm{Si}$ back bonds (Fig. $5 \mathrm{~b}$ ). The chemical reaction for the same is shown in Eq. (2)

$$
\left(=\mathrm{Si}_{2} \mathrm{SiH}_{2}+2 \mathrm{H}_{2} \mathrm{O} \rightarrow(=\mathrm{Si})_{2} \mathrm{Si}(\mathrm{OH})_{2}+4 \mathrm{H}^{+}+4 e^{-}\right.
$$

The higher electronegativity of oxygen on the surface $\mathrm{Si}$ atom leads to the weakening of $\mathrm{Si}-\mathrm{Si}$ back bonds. The polar water molecules in the solution attack the weakened $\mathrm{Si}-\mathrm{Si}$ back bonds and self- dissociated into $\mathrm{H}^{+}$ and $\mathrm{OH}^{-}$ions. The $\mathrm{OH}^{-}$ions formed get attached to the $\mathrm{Si}$ atom that is being etched out forming orthosilicic acid $\left(\mathrm{Si}(\mathrm{OH})_{4}\right)$. The $\mathrm{H}^{+}$ions form a Si-H bond with the $\mathrm{Si}$ atoms in the next layer of the substrate (Fig. 5c). The etching reaction is as shown in following equation

$$
(=\mathrm{Si})_{2} \mathrm{Si}(\mathrm{OH})_{2}+2 \mathrm{H}_{2} \mathrm{O} \rightarrow 2(=\mathrm{SiH})+\mathrm{Si}(\mathrm{OH})_{4}
$$

The chemical/electrochemical reactions (1), (2) and (3) need to take place in a short time period in order to achieve high etch rate. In addition, reactants in chemical process must be sufficiently supplied to etching front, and etched products must be smoothly removed from etched surface. When any of them meet difficulties to advance in the etching process, etch rate decreases as a result. In other words, etch rate can be enhanced in many ways, such as by accelerating the chemical reactions themselves, by enhancing the supply of reactants, or by removing etched products from etching front. Several methods have explored to increase the etch rate which are discussed in subsequent sections.

\section{Etching with ultrasonic agitation}

In anisotropic wet etching of silicon, ultrasonic agitation applied to etching solution is effective to enhance the etch rate. In this etching method, ultrasonic vibrational force helps to remove the etched products from Si surface. As discussed in previous section, the etched products are hydrogen ion $\left(\mathrm{H}^{+}\right)$, hydrogen gas $\left(\mathrm{H}_{2}\right)$, and $\mathrm{Si}(\mathrm{OH})_{4} \cdot \mathrm{H}^{+}$makes a new $\mathrm{Si}-\mathrm{H}$ bond with a Si atom on the next layer of the crystal surface waiting for the next chemical reactions to start. $\mathrm{H}_{2}$ can dwell on the etched surface and can be an obstacle for the etching front exposed to fresh reactants. $\mathrm{Si}(\mathrm{OH})_{4}$ is ionized as dihydroxidodioxidosilicate (2-) $\left(\mathrm{SiO}_{2}(\mathrm{OH})_{2}{ }^{2-}\right)$ in alkaline solution according to the following sequence. 


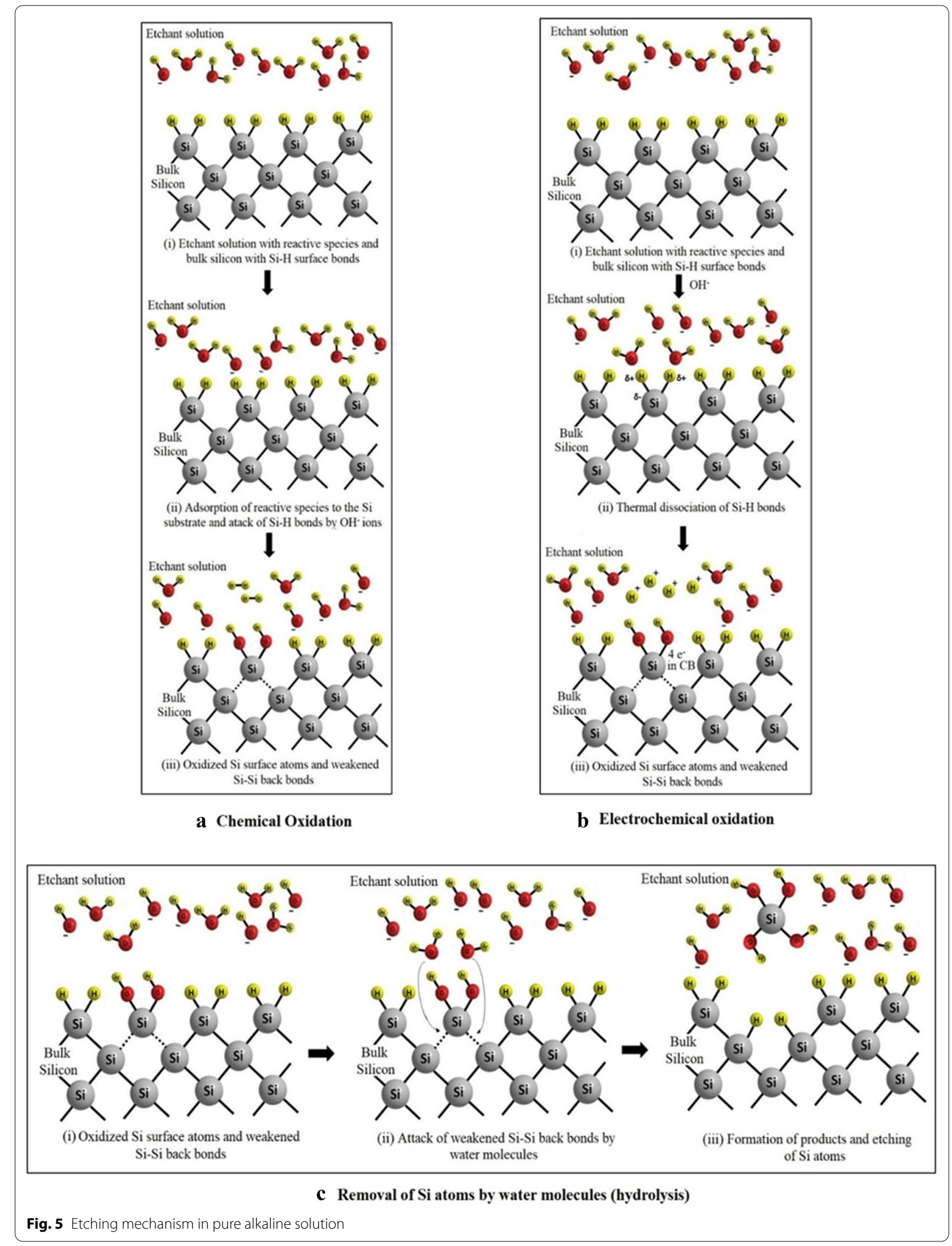




$$
\mathrm{Si}(\mathrm{OH})_{4}+2 \mathrm{OH}^{-} \rightarrow \mathrm{SiO}_{2}(\mathrm{OH})_{2}^{2-}
$$

However, silicate $\mathrm{Si}(\mathrm{OH})_{4}$ still can stay on $\mathrm{Si}$ surface in the shape of polymer $[41,42]$ in diluted alkaline solutions. Ultrasonic vibration applied to the solution enhances the detachment of $\mathrm{H}_{2}$ bubbles as well as silicate $\mathrm{Si}(\mathrm{OH})_{4}$ from Si surface allowing a fresh etch solution get contact to the surface.

Chen et al. [66] measured the average etch rate as a function of ultrasonic agitation power for $33 \mathrm{wt} \% \mathrm{KOH}$ and $5 \mathrm{wt} \%$ TMAH water solutions. The results are shown in Fig. 6. Average etch rate increases according to the increase of ultrasonic power input in a range of 0 to $400 \mathrm{~W}$ with a single frequency of $40 \mathrm{kHz}$. Etch rate is saturated at the power of $350 \mathrm{~W}$. The ratio of increase of etch rate between with and without agitation for $33 \mathrm{wt} \%$ $\mathrm{KOH}$ at $80{ }^{\circ} \mathrm{C}$ is 1.2 , while for $5 \mathrm{wt} \% \mathrm{TMAH}$ at $70{ }^{\circ} \mathrm{C}$ it is

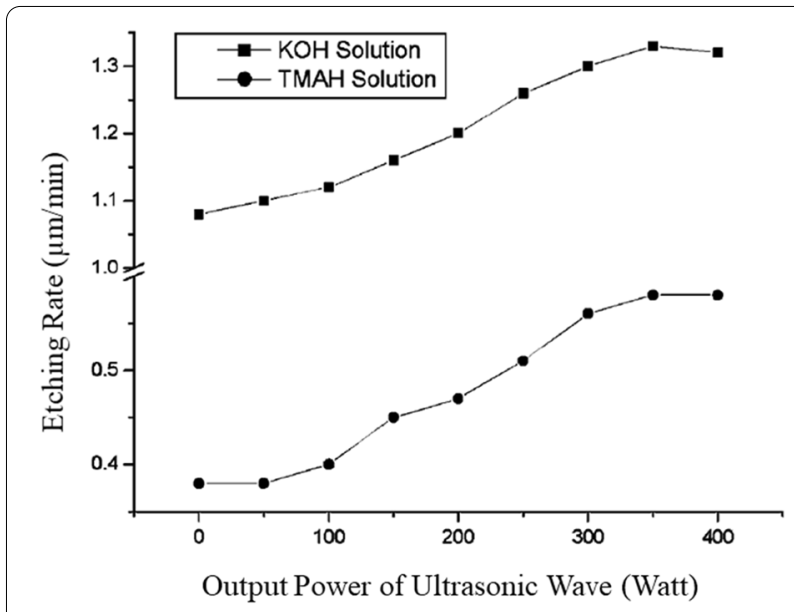

Fig. 6 Etching rate of $\mathrm{Si}\{100\}$ as a function of the power of ultrasonic waves [66], ( ) 2002, Elsevier
1.6. The results are not much attractive from a viewpoint of the etch rate enhancement compared to the effect of etching temperature and the addition of oxidizers as will be discussed in next sections.

Most attractive effect of the ultrasonic agitation to etching solution is an improvement of etched surface morphology due to the conquest of micro-pyramids emerging on the etched surface. The study of the etched surface morphology is mostly done on $\operatorname{Si}\{100\}$ wafers as this orientation is most widely used in MEMS and semiconductor industries. In pure alkaline solution, the etched surface morphology primarily depends on etchant concentration and etching temperature. In the case of $\mathrm{KOH}$ solution, when the concentration is diluted less than $8 \mathrm{M}$ (30 wt\%), micro-pyramids start to appear on $\mathrm{Si}\{100\}$ as shown in Fig. 7 [77]. Various models have been proposed to explain the main reasons behind the formation of hillocks during etching process. Palik et al. [78] argued that the micro-pyramids are originated due to the attachment of etched products (e.g. $\mathrm{H}_{2}$ gas and silicate) on silicon surface during etching process. Both can dwell on the Si surface acting as micro-mask sitting on every apex of the pyramids. Schiffrin's group investigated the suppression of micro-pyramids assuming that the $\mathrm{H}_{2}$ bubbles are the source of micro-pyramids $[79,80]$. They added oxygen gas as an oxidizer to a saturation level, and isopropylalcohol (IPA) to $3.6 \mathrm{M} \mathrm{KOH}$ solution for weakening surface tension of the $\mathrm{H}_{2}$ bubbles. They found the decrease in the generation of $\mathrm{H}_{2}$ bubbles and consequently the number of hillocks [79]. They further applied ultrasonic agitation to $2 \mathrm{M} \mathrm{KOH}$ solution (again with saturated $\mathrm{O}_{2}$ and IPA), for minimizing the dwelling time of $\mathrm{H}_{2}$ bubbles on Si surface [80]. They obtained a pyramidfree etched surface on $\mathrm{Si}\{100\}$ as shown in Fig. 8. They obtained a root mean square roughness less than $20 \mathrm{~nm}$.

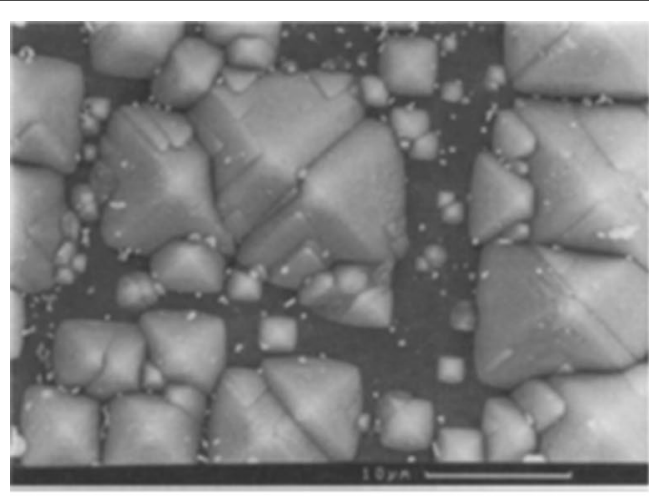

a

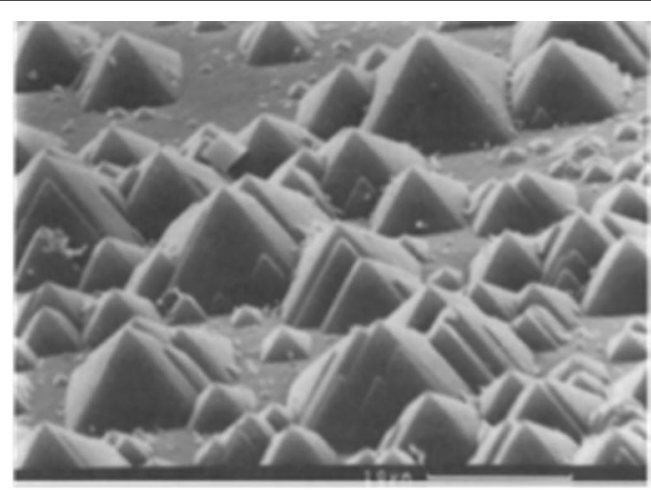

b

Fig. 7 SEM images of micro-pyramids on Si $\{100\}$ surface after 30 min etching in $4.0 \mathrm{M} \mathrm{KOH}$ at $70{ }^{\circ} \mathrm{C}$ : $\mathbf{a}$ top view and $\mathbf{b}$ tilted view at $30^{\circ}$ from $\{100\}$ surface [77], @ 1996 IOP Publishing 


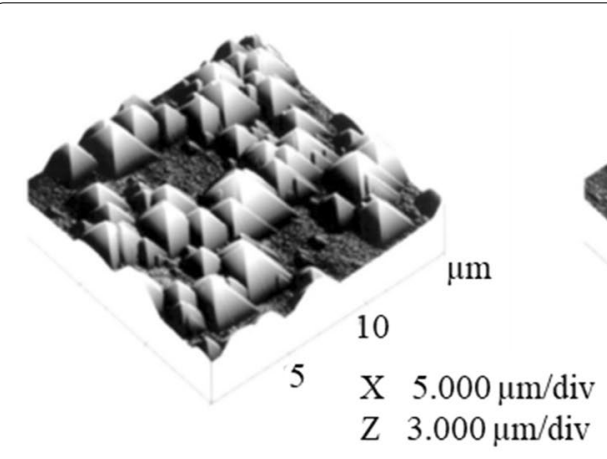

a

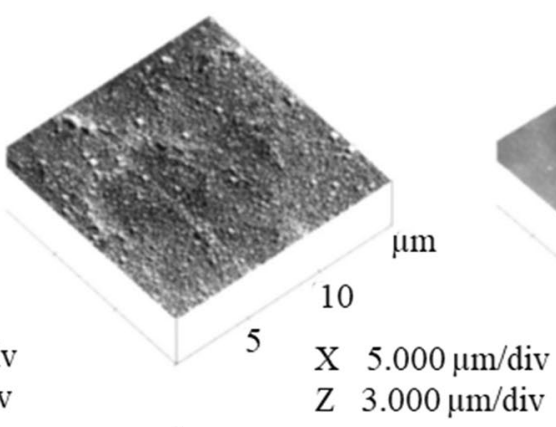

b

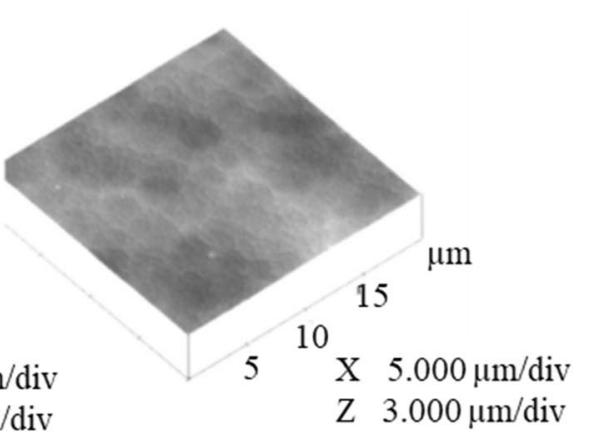

c

Fig. 8 AFM images of Si\{100\} surface etched in $2 \mathrm{M} \mathrm{KOH}$ solution at $60{ }^{\circ} \mathrm{C}$ for 60 min under three different conditions: a solution saturated with $\mathrm{Ar}$ gas, b ultrasonic agitation applied to the solution (a), c solution saturated with $\mathrm{O}_{2}$ gas [80], @ 1997 IOP Publishing

Elwenspoek's group separately investigated the minimization of micro-pyramidal structures and found that the effective conditions are correlated to etch rate enhancement by means of adding oxidation agent (e.g., ferricyanide $\mathrm{K}_{3} \mathrm{Fe}(\mathrm{CN})_{6}$ ) in etchant solution, or applying biased potential slightly higher than open circuit potential (OCP) to Si substrate [77]. They concluded that the silicon oxidation enhancement is effective to minimize the pyramidal structures and also for etch rate enhancement, though excessive oxidation resulted in etch stop by full passivation of $\mathrm{Si}$ surface with an oxide film.

The growth of micro-pyramids and their stability in size was discussed by Elwenspoek [81]. There was no direct evidence that the $\mathrm{H}_{2}$ worked as a micro-mask because he noticed that the pyramidal structures in $\mathrm{KOH}$ are less than that in TMAH, though $\mathrm{H}_{2}$ bubbles are generated much more with $\mathrm{KOH}$ than with TMAH. Hence it cannot firmly be claimed that $\mathrm{H}_{2}$ bubbles are the only source of micro-pyramids. Hence there is a room here to consider another etched product silicate $\mathrm{Si}(\mathrm{OH})_{4}$ as a source of micro-pyramid at etching front throughout deep etching process. The presence of silicate on etching front was recognized during Si etching in $\mathrm{KOH}, \mathrm{NH}_{4} \mathrm{OH}$, $\mathrm{N}_{2} \mathrm{H}_{4}$ (Hydrazine), and TMAH solutions. Schnakenberg et al. [42] suggested that the etched product $\mathrm{Si}(\mathrm{OH})_{4}$ became polymerized and worked as a protection mask in $\mathrm{NH}_{4} \mathrm{OH}$ solution. Gajda et al. [41] further claimed that the polymerized $\mathrm{Si}(\mathrm{OH})_{4}$ takes a shape of silica gels in $\mathrm{N}_{2} \mathrm{H}_{4}$ solution. Veenendaal et al. [82] proposed a model of silicate micro-mask assuming the presence of $\mathrm{Si}(\mathrm{OH})_{4}$ particles on the etching front. Two models of micro-pyramid growth due to micro-masking by $\mathrm{H}_{2}$ and $\mathrm{Si}(\mathrm{OH})_{4}$ are compared in Fig. 9. Difficulty in $\mathrm{H}_{2}$ model lies on the instable presence of bubbles on the apex of micro-pyramids. On the other hand, silicate model allows $\mathrm{Si}(\mathrm{OH})_{4}$ cluster persistently staying on an apex during etching process. The cluster may be semi-permeable against etching species. It is easier for the silicate model to explain stable shape and size of pyramid during deep etching of Si.

Mechanical agitation means for suppressing micropyramids was studied by Chen et al. [66]. They compared the effects of mechanical stirring and ultrasonic agitation, and concluded that the latter is superior for suppressing micro-pyramids. Figure 10 compares the SEM images of $\mathrm{Si}\{100\}$ surfaces etched in 5\% TMAH solution. In the case of etching without any agitation, $\mathrm{Si}\{100\}$ etched surface is fully covered by pyramidal structures (i.e. hillocks). The number of hillocks are significantly reduced when the etchant is mechanically agitated using magnetic stirrer and ultrasonic waves. However, it cannot be claimed unquestionably whether the attachment of $\mathrm{H}_{2}$ bubbles is the main origin of the micro-pyramids or it is caused by silicates. Hence it can be concluded that the ultrasonic agitation mechanically helps to detach the etched products from etching front, and suppresses the emergence of pyramids.

The emergence of micro-pyramids does not directly decrease average etch rate, because footprint of the micro-pyramids is much less than the total etched surface area. However, when micro-pyramids densely emerges and fully covers the $\mathrm{Si}\{100\}$ surface (see Fig. 10 Sample A), substrate orientation (i.e. $\{100\}$ ) disappears from the top surface and pyramidal facet and its ridge orientations start to dominate the average etch rate of the substrate. Physical detachment of etched products (i.e. $\mathrm{H}_{2}$ and/or silicate) in the etching process can contribute to enhance the etch rate, by indirectly enhancing the access of reactants to etching front.

In MEMS device fabrication, ultrasonic agitation needs more issues to consider than that mentioned above. As MEMS requires the fabrication of a varieties of $3 \mathrm{D}$ 

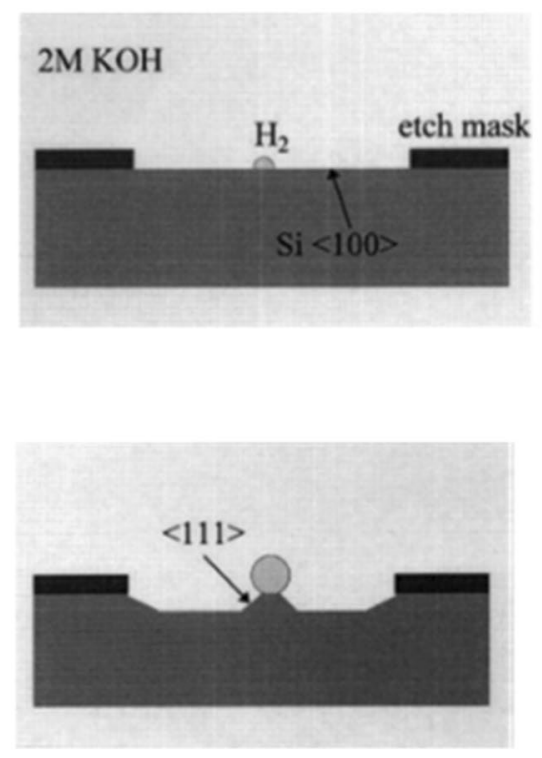

a

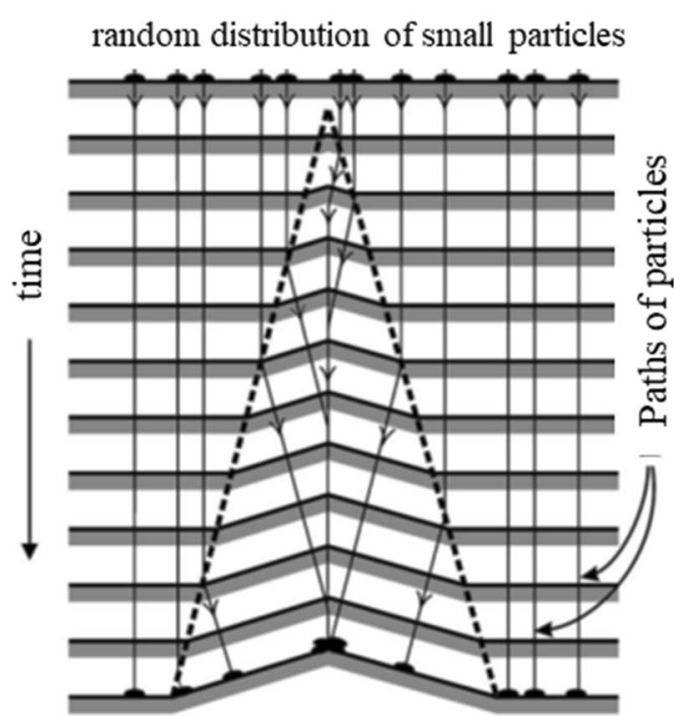

Particles accumulated on protruding edge

b

Fig. 9 Two models of micro-pyramid growth, both assuming etched products as micro-masking materials: $\mathbf{a} \mathrm{H}_{2}$ bubble sticks/grows on etched surface randomly [80], ( 1997 IOP Publishing, and b Silicate particles accumulated on protruding edges according to a time sequence of etching [82], ( 2001 Elsevier

shapes such as deep narrow grooves and the large volume cavities etched from small-sized apertures on a $\mathrm{Si}$ wafer, etch rates can be much less than that expected from the etch rate obtained from flat wafers having mask apertures of large area. Use of ultrasonic agitation is one of the solutions to this issue. Ohwada et al. etched arrayed deep grooves on a $\mathrm{Si}\{110\}$ wafer [83]. As the sidewalls of the grooves are perpendicular to the wafer surface and the groove aperture width is narrow down to $1 \mu \mathrm{m}, \mathrm{H}_{2}$ bubbles as an etched product easily clog up in the etched groove cross-section, restricting fresh etching solution flowing into the groove. In order to let the bubbles out from the groove before growing in size, they applied ultrasonic agitation in the etching bath. The cross-sectional views of etched grooves are shown in Fig. 11. The grooves formed without ultrasonic agitation could not achieve uniform etch depth, while the etch depth of the grooves with wider spacing fabricated with ultrasonic agitation increases. Although the ultrasonic agitation of a single frequency of $28 \mathrm{kHz}$ with an output power of $600 \mathrm{~W}$ had improved groove depth to some extent, but non-uniformity in etch depths among grooves is remained there. They argued that it is due to a standing wave developed in the silicon wafer by a single frequency of ultrasonic waves. They further employed a new ultrasonic oscillator sequentially generating three different frequencies of 28,45 , and $100 \mathrm{kHz}$ with time duration of $1 \mathrm{~ms}$ each and succeeded in obtaining grooves with uniform depth as shown in Fig. 11c. This is an example of ultrasonic agitation employed to remove $\mathrm{H}_{2}$ bubbles (etched products) from narrow apertures on a wafer surface for fabricating semi-closed etched cavities.

The optimization of ultrasonic agitation power is not yet quantitatively investigated. Schiffrin's group just claimed "a moderate power" of ultrasound [79]. Though Ohwada et al. [83] and Chen et al. [66] reported the output power of the oscillators, those values are just input power applied to the etching bath walls. Effective sonic energy applied to the etching front needs a modelling tailored for each etching facility in relation to bath size, liquid level and wafer positions.

While the ultrasonic agitation of etchant solution helps to remove the etched products, in case of microfabrication of MEMS structures, there is a risk that the excessive ultrasonic agitation causes a fracture of thin film structure such as diaphragm. This is one of the main reasons that the ultrasonic agitation did not become popular in MEMS industry.

\section{Microwave irradiation during etching}

It was first reported by Dziuban that the etch rate of silicon in $\mathrm{KOH}$ water solution is enhanced by the assistance of microwave irradiation [67]. He designed an etching apparatus equipped with a microwave generator having 

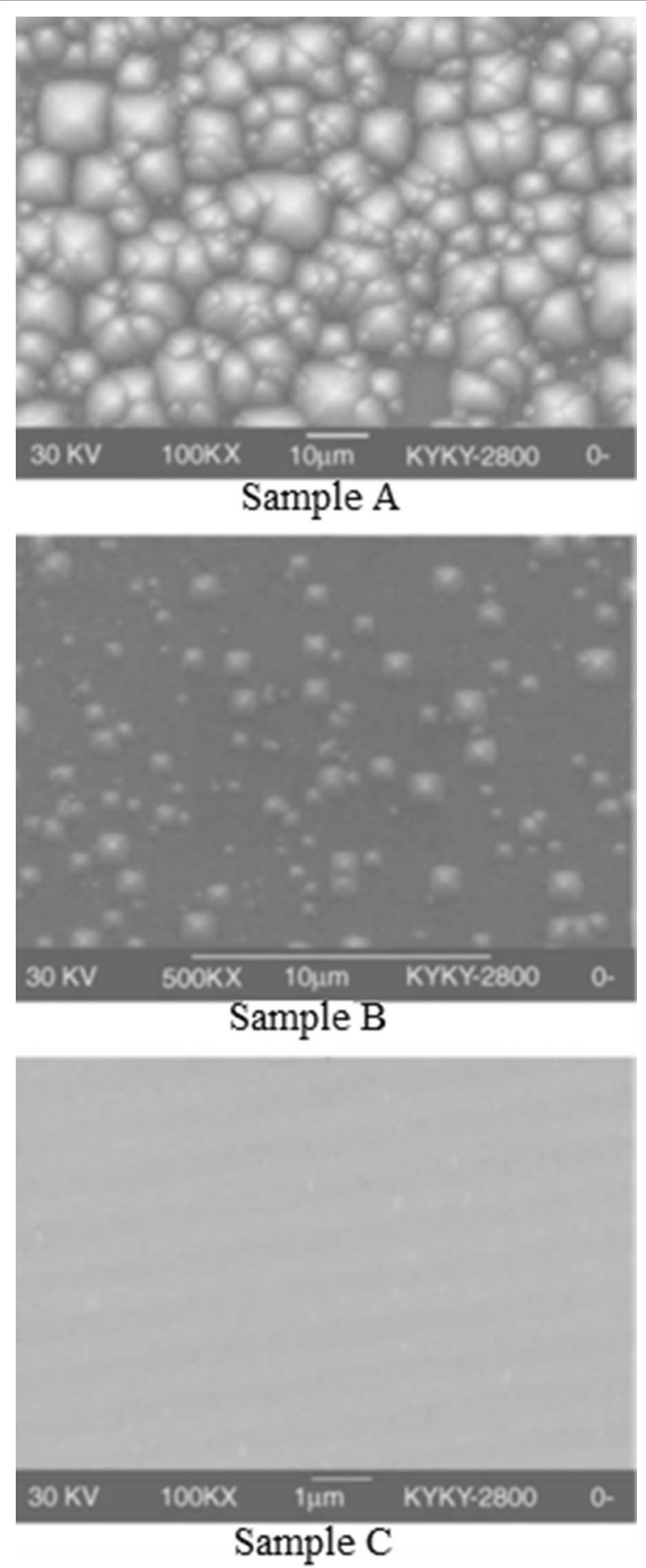

Fig. 10 SEM images of Si\{100\} surface etched in 5 wt\% TMAH under three different agitation conditions: a Sample A: without agitation, b Sample B: with rotational stirrer agitation, and c Sample C: with ultrasonic agitation of 300 W [66], () 2002, Elsevier an output power of $100 \mathrm{~W}$ and a frequency of $2.54 \mathrm{GHz}$. Microwave was irradiated into the etching chamber from the bottom. Etchant temperature in the chamber is measured and controlled by chopping the microwave power. Two types of etching chamber were prepared: one was an open chamber for $100 \mathrm{~mL}$ of etchant at atmospheric pressure, and another was a closed chamber containing $30 \mathrm{~mL}$ of etchant whose interior could passively reach high pressure up to $4 \mathrm{MPa}$ (40 bar). The system was named as EMMA-EMSi (etching machine for anisotropic etching of monocrystalline silicon). Etch rate of $\mathrm{Si}\{100\}$ in $10 \mathrm{M} \mathrm{KOH}$ water solution in open air chamber was about $8 \mu \mathrm{m} / \mathrm{min}$ regardless of the solution temperature in a range of $70-100{ }^{\circ} \mathrm{C}$ as presented in Fig. 12. Etch rates were enhanced by a factor of $10-30$ by microwave irradiation. Etching was possible even in pure DI water under the microwave irradiation in the closed pressure chamber. Etch rate of $\mathrm{Si}\{100\}$ is reached $0.2 \mu \mathrm{m} / \mathrm{min}$, where temperature and pressure were $180{ }^{\circ} \mathrm{C}$ and $4 \mathrm{MPa}$, respectively.

Dziuban admitted that the mechanism of etch rate enhancement is not clear. He speculated that the microwave irradiation dissociated water molecules, and increased an amount of active $\mathrm{OH}^{-}$in the solution, which can enhance the attachment of $\mathrm{OH}$ to $\mathrm{Si}$ surface atoms. The most interesting results with this work are that the $\mathrm{Si}$ was etched by DI water at $180{ }^{\circ} \mathrm{C}$ and $4 \mathrm{MPa}$ pressure. It is not clear if microwave irradiation contributed to change in the state of water, because no evidence was presented.

The major weakness of the work was that the author neither measured nor estimated the local temperature rise at solid-liquid interface during etching. It is concerned that the microwave had induced quite local heat generation on the surface of conductive solid Si, i.e. the etching front, in addition to heat bulk liquid solution which is measured during etching process. The results are shown in Fig. 12a can be understood that the temperature of solid-liquid interface already reached to a boiling point of $10 \mathrm{M} \mathrm{KOH}$ solution regardless of the controlled temperature measured apart from the etching front in a range $70-100{ }^{\circ} \mathrm{C}$. Obtained constant etch rates are equivalent to the values at boiling point of the $10 \mathrm{M} \mathrm{KOH}$ solution. There is a concern that the etching temperature measured by the etching microwave silicon (EMSi) system is not the temperature of solid-liquid interface but of the bulk solution. Real etching front temperature seems much underestimated. In addition, we think that an increase in etching rate with the increase of $\mathrm{KOH}$ concentration shown in Fig. 12b is not an effect of 


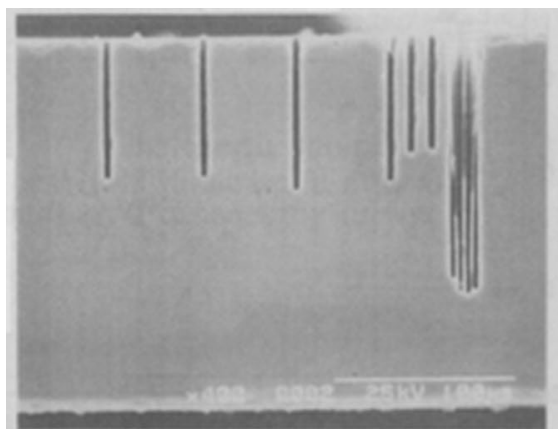

a

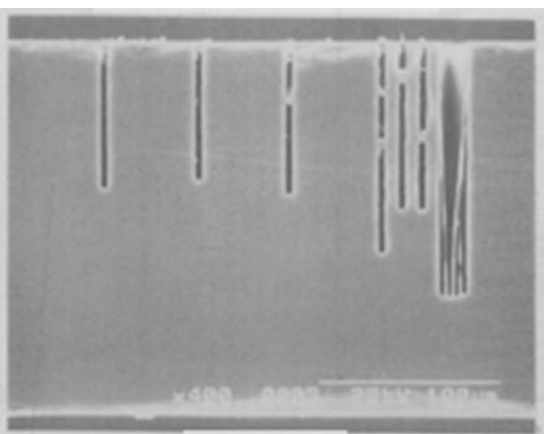

b

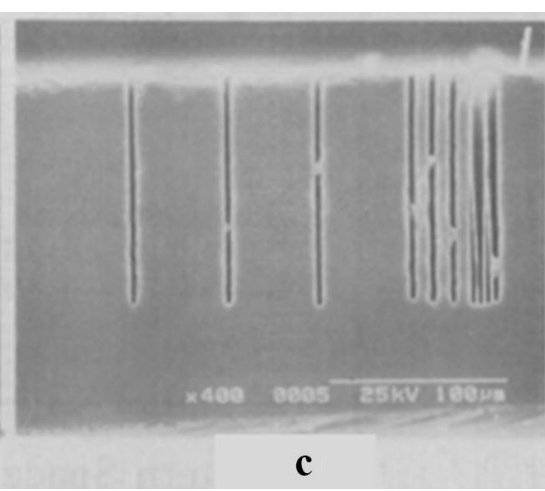

Fig. 11 SEM images of $1 \mu \mathrm{m}$ wide deep grooves showing the comparison of etch uniformity under three etching conditions in $41 \mathrm{wt} \% \mathrm{KOH}$ at $60^{\circ} \mathrm{C}$ for $6 \mathrm{~h}$ : a no agitation, $\mathbf{b}$ ultrasonic agitation with a single frequency of $28 \mathrm{kHz}$, and $\mathbf{c}$ ultrasonic agitation with $28,45,100 \mathrm{kHz}$ frequencies applied sequentially for 1 ms duration [83], () 1995, IEEE

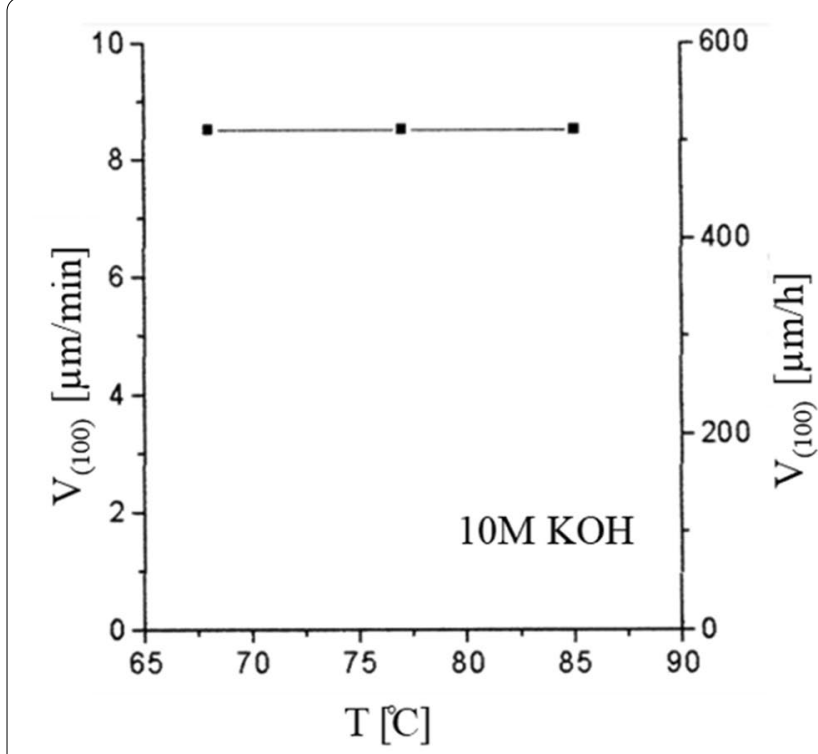

a

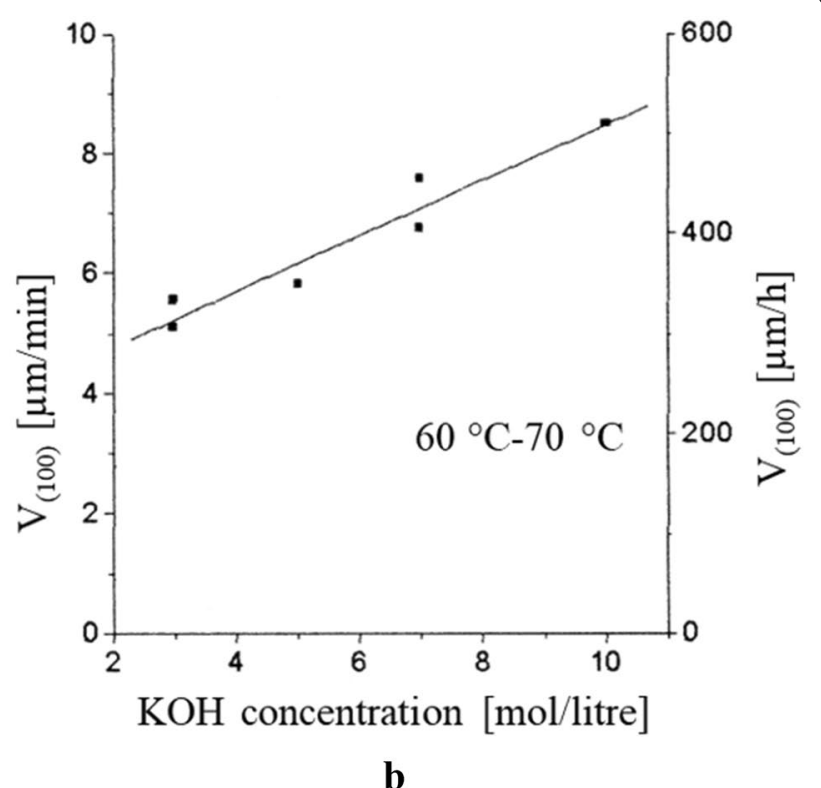

b

Fig. 12 Etch rate of $\mathrm{Si}(100)$ in $\mathrm{KOH}$ solution under microwave irradiation at atmospheric pressure: $\mathbf{a}$ effect of etchant temperature and $\mathbf{b}$ effect of $\mathrm{KOH}$ concentration [67], @ 2000, Elsevier

the concentration but a consequence of the difference in the boiling point of $\mathrm{KOH}$ solutions due to the change in concentration. The etch rate increase depending on the increase of concentration is quite reasonable, assuming that etching front temperature always reached a boiling point in the EMSi system. The rise of boiling point with highly concentrated solutions utilized in etch rate enhancement is quantitatively discussed in the next section. We think that the reported etch rates enhancement argued in Fig. 12 is not due to the decomposition of water molecule, but mainly due to the local heating at etching front to the boiling point of etching solutions accelerating oxidation reaction described by Eq. (1) in previous section.

Dziuban's group further developed a new apparatus named extended etching microwave silicon (E2MSi) aiming at separating the etching chamber from microwave irradiation processing of solution as shown in Fig. 13 [84]. It has two vessels connected in series by tubing. One vessel is for microwave irradiation processing of etching solution, and the other is for Si etching using the activated solution. Microwave power was in a range of $0-3000 \mathrm{~W}$, and frequency was $2.45 \mathrm{GHz}$. Etching solution was firstly processed by microwave irradiation for $30 \mathrm{~s}$, 


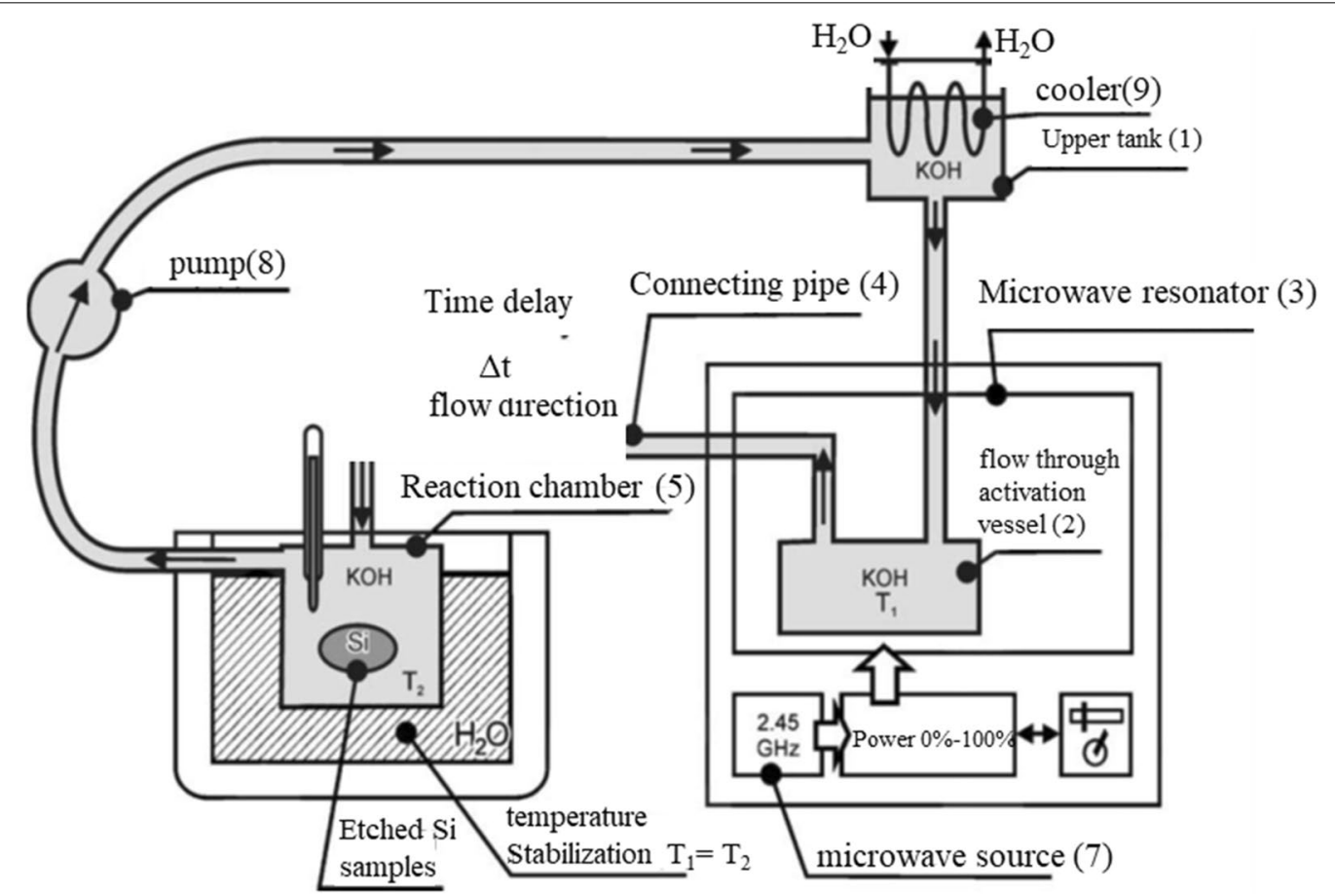

Fig. 13 Experimental set-up of the modified E2MSi stand with closed loop etchant circulation, where etching chamber is separated from solution agitation chamber [84], ( 2004, Elsevier

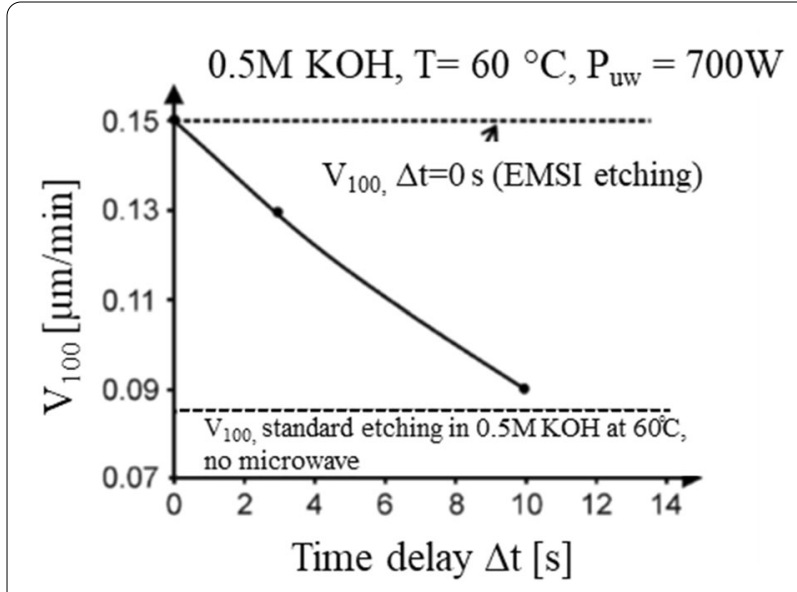

Fig. 14 Etch rate of Si\{100\} quickly decayed depending on time delay for introducing a microwave-irradiated solution to the etching chamber of E2MSi. Etch rates are compared between time delay of $3 \mathrm{~s}$ and $10 \mathrm{~s}$ [84], @ 2004, Elsevier

and then quickly introduced to etching vessel in a short time delay. Etch rate of $\mathrm{Si}\{100\}$ in $0.5 \mathrm{M} \mathrm{KOH}$ solution at $60{ }^{\circ} \mathrm{C}$ was measured as a function of applied microwave power. Etch rate increment, roughly proportional to the input power, is $0.44 \mathrm{um} / \mathrm{min}$ when microwave power was $3000 \mathrm{~W}$. The obtained etch rate was 5 times higher than that without agitation. Etch rate enhancement effect of microwave was quickly decayed in less than $10 \mathrm{~s}$ after microwave irradiation as shown in Fig. 14 [84]. Time delay for the irradiated solution reaches to the wafer in the etching vessel was adjusted by the length of connecting tubes between two vessels. When the time delay was $10 \mathrm{~s}$, the etch rate enhancement was almost disappeared.

Dziuban' group illustrated a model of microwave irradiation effects in the vicinity of $\mathrm{Si}$ surface as shown in Fig. 15. They claimed that the $\mathrm{H}_{2} \mathrm{O}$ molecules in normal state are making clusters each containing hundreds of molecules bound to each other by weak hydrogen bonds. This makes the number of $\mathrm{H}_{2} \mathrm{O}$ molecules effectively contacting Si surface far less than that in case all the $\mathrm{H}_{2} \mathrm{O}$ molecules randomly approach to $\mathrm{Si}$ surface. Microwave irradiation destroys the water cluster in pieces and many of the $\mathrm{H}_{2} \mathrm{O}$ molecules should be isolated from cluster as shown in Fig. 15b. Such an activated state of water should have an increased number of contacting points on $\mathrm{Si}$ surface. This enhances the adsorption of water molecules ready for reaction. It is regarded as one of the etch rate enhancement means, by enhancing adsorption of reactant $\mathrm{H}_{2} \mathrm{O}$ to $\mathrm{Si}$ surface. This could be a reason for an increase in etch rate. When microwave irradiation stops, the finely randomized water molecules gradually rebuild larger sized clusters as shown in Fig. 15c, losing the activeness. Dziuban's explanation seems acceptable on the activation and its decay of the water molecules by 


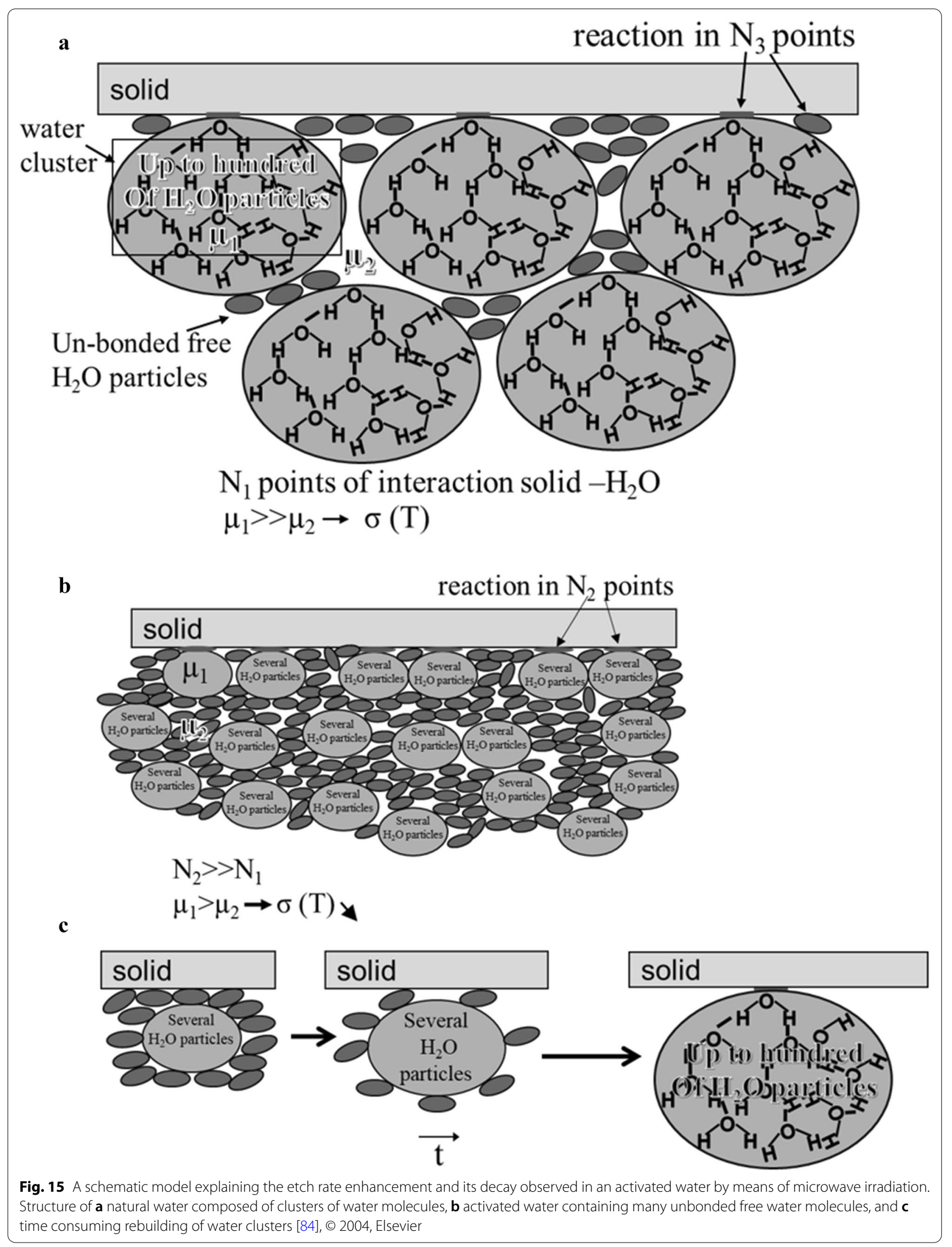


switching the microwave irradiation. He measured electric conductivity of water with and without microwave irradiation, and found that the irradiated water shows a conductivity $40 \%$ less than that for non-irradiated water. Recovery in conductivity was observed with water after microwave irradiation. These results together with FTIR absorption spectrum change, stimulation of water cluster may be possible for enhancing etching rate to some extent, though time decay of irradiation effect still could not be explained.

We think that Dziuban's experimental proofs seem insufficient in terms of accuracy and repeatability of experimental data. Firstly, the way they evaluated the time decay in etch rate (Fig. 14) is questionable. They plotted etch rate values at $\mathrm{t}=3$ and $10 \mathrm{~s}$ showing a time decay with E2MSi apparatus. As the etch rate measurement needs to etch Si typically for more than minutes, it seems hard to distinguish the etch rates taken by time difference of 7 s. Secondly, Fig. 14 contains a data taken by their first apparatus EMSi [67] which had a problem underestimating etching temperatures as mentioned before. Hence the mechanism of etch rate enhancement by microwave irradiation is still on a level of speculation. If the etch rate enhancement works according to Dziuban's model, it can be categorized as an enhancement of reactants supply to the etching front mentioned in previous section. It may be emphasized here that this study was not carry forwarded by any other research group. Hence the etching mechanism behind the increase in etch rate due to microwave irradiation presented by Dziuban cannot be corroborated.

\section{Etching at boiling point of the etchant}

It is known that the anisotropic etching is a time-consuming reaction because the oxidation reaction in Eq. (1) is the slowest reaction throughout the etching process. The oxidation reaction demands high activation energies $[13,25]$. It is reasonable to etch silicon at high temperature to accelerate the process by the aid of thermal energy. Seidel et al. reported the temperature dependence of silicon etching rate in $\mathrm{KOH}$ aqueous solutions in a concentration range of $10-50 \mathrm{wt} \%$ [13]. The etching rate followed the Arrhenius equation, and the activation energies for the etching reaction calculated for $20 \mathrm{wt} \% \mathrm{KOH}$ are $0.57 \mathrm{eV}(55 \mathrm{~kJ} / \mathrm{mol})$ on $\mathrm{Si}\{100\}$ and $0.59 \mathrm{eV}(57 \mathrm{~kJ} / \mathrm{mol})$ on $\mathrm{Si}\{110\}$. Considering the band model, density of state diagram for silicon, and the value of activation energy obtained from the Arrhenius equation, it was claimed that the etching rate is determined by the transfer of electrons in the case of $\mathrm{KOH}$ aqueous solution. Similarly, the temperature dependent etch rates were also investigated with TMAH solutions. Tabata et al. [25] reported the etching rates of silicon in TMAH aqueous solution in a concentration range of 5-40 $\mathrm{wt} \%$. The activation energies of the etching rate are 0.5 to $0.7 \mathrm{eV}$ (48 to $67 \mathrm{~kJ} / \mathrm{mol}$ ) on $\mathrm{Si}\{100\}$ and $0.4 \mathrm{eV}(39 \mathrm{~kJ} / \mathrm{mol})$ on $\mathrm{Si}\{110\}$. These results consistently support the etching mechanism proposed by Seidel et al. [13]. Such large values of activation energy with $\mathrm{KOH}$ and TMAH solutions suggest that the etching at high temperature is effective to enhance the etch rate. In wet etching system, achievable maximum temperature is limited by the boiling point of the etching solution.

Tanaka et al. investigated the etch rates in high concentration $\mathrm{KOH}$ solutions at the temperature near to the boiling point of the solution aiming to obtain high etching rate with smooth etched surface $[18,85]$. Figure 16 shows the etch rates of $\operatorname{Si}\{100\}$ and $\operatorname{Si}\{110\}$ at different temperatures as a function of $\mathrm{KOH}$ concentration ranging from 20 to $50 \mathrm{wt} \%$. The etch rate for each concentration decreases with increase of $\mathrm{KOH}$ concentration,
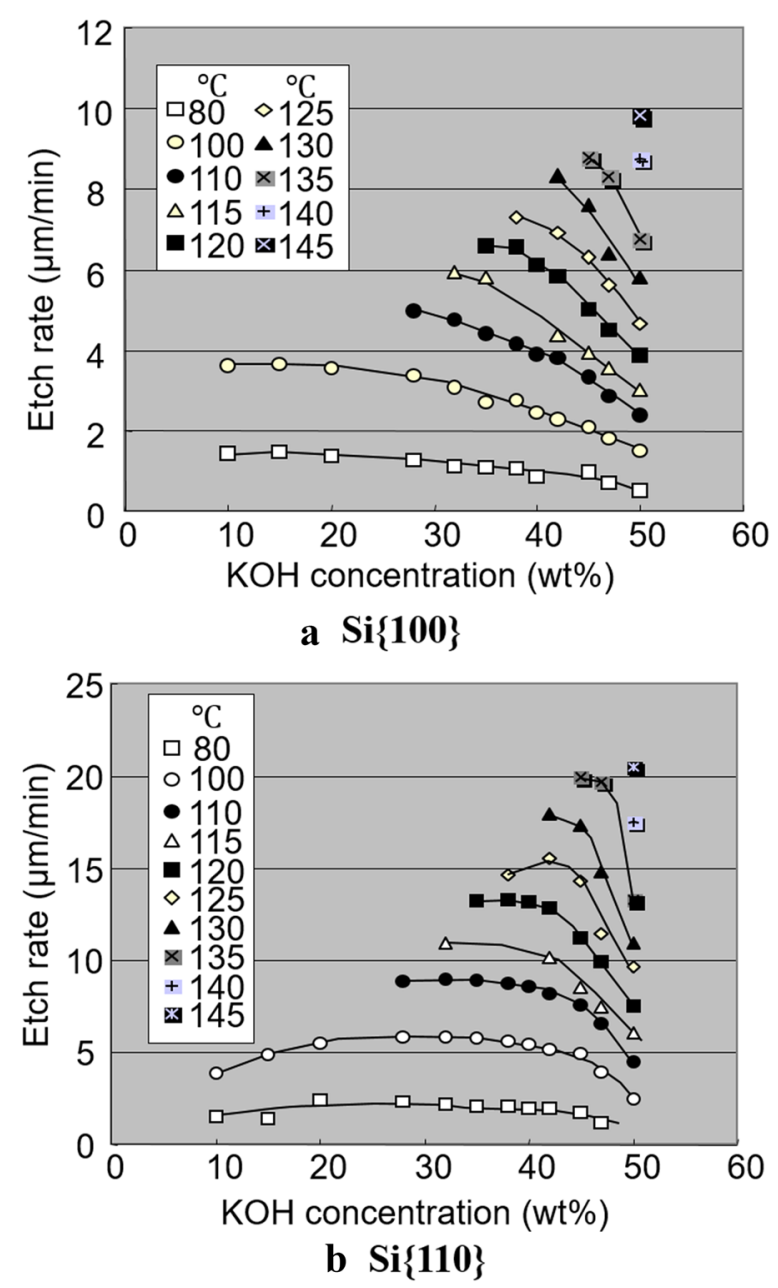

Fig. 16 Etch rate of $\mathrm{Si}\{100\}$ and $\mathrm{Si}\{110\}$ as a function of $\mathrm{KOH}$ concentration. Highly concentrated solutions can reach higher temperatures allowing high speed etching [18, 85], (c) 2004, Elsevier 
which is due to the shortage of the reactant $\mathrm{H}_{2} \mathrm{O}$ in the concentrated solution. The boiling point of the $\mathrm{KOH}$ solution increases with its concentration. Henceforth, the etching temperature of concentrated $\mathrm{KOH}$ can go much higher than the less concentrated $\mathrm{KOH}$. As a matter of fact, boiling point of $50 \mathrm{wt} \% \mathrm{KOH}$ solution is 145 ${ }^{\circ} \mathrm{C}$, while that of $28 \mathrm{wt} \% \mathrm{KOH}$ solution is $110{ }^{\circ} \mathrm{C}$. Achievable etching rate for $\mathrm{Si}\{100\}$ shown in Fig. 16a is $10 \mu \mathrm{m} /$ min with $50 \mathrm{wt} \% \mathrm{KOH}$ solution, while that with $28 \mathrm{wt} \%$ $\mathrm{KOH}$ solution is $5 \mu \mathrm{m} / \mathrm{min}$. Similarly, for $\mathrm{Si}\{110\}$ shown in Fig. 16b, 50wt\% KOH solution achieved etching rate of $21 \mu \mathrm{m} / \mathrm{min}$, while $28 \mathrm{wt} \% \mathrm{KOH}$ solution achieved $8 \mu \mathrm{m} /$ min. If the etch rates are compared with $80{ }^{\circ} \mathrm{C}$ etching temperature, the etch rates in $50 \mathrm{wt} \% \mathrm{KOH}$ are increased by $5-9$ times for $\operatorname{Si}\{100\}$ and $4-20$ times for $\operatorname{Si}\{110\}$ when the etching temperature increase upto the boiling point of the etchant. Figure 17 shows the Arrhenius plots of $\operatorname{Si}\{100\}$ and $\operatorname{Si}\{110\}$ etching rates for different $\mathrm{KOH}$ concentrations ranging from 10 to $50 \mathrm{wt} \%$. The Arrhenius plots are nearly linear from $80{ }^{\circ} \mathrm{C}$ to near the boiling point. This means that the activation process in the high temperature region is almost the same as that in the lower temperature region.

Figure 18 shows the etched surface roughness of $\mathrm{Si}\{100\}$ and $\mathrm{Si}\{110\}$ in $\mathrm{KOH}$ with a concentration range of $15-50 \mathrm{wt} \%$. It is apparent that the $\mathrm{Si}\{100\}$ etched surfaces are consistently smooth when etched with $\mathrm{KOH}$ solutions whose concentration is higher than $28 \mathrm{wt} \%$ as presented in Fig. 18a. On the other hand, the etched surface roughness results of $\mathrm{Si}\{100\}$ presented in Fig. 18b do not show any concentration range where smoother surface can be obtained. Optical microscope images of the etched $\mathrm{Si}\{110\}$ surface presented in Fig. 19 indicate that the smooth etched surface without hillocks can be obtained in $45 \mathrm{wt} \% \mathrm{KOH}$ at $135{ }^{\circ} \mathrm{C}$. Therefore, the results presented in Figs. 16, 17, 18, 19 should be used as reference to find the optimal etching condition to obtain highspeed etching with smoother etched surface.

Tang et al. studied the etch rate of $\mathrm{Si}\{100\}$ in surfactant added TMAH at high temperature [69]. Etching temperature is varied from 80 to $115{ }^{\circ} \mathrm{C}$, which is close to the boiling point of the etchant solution. Figure 20 shows the temperature dependence etch rate of $\mathrm{Si}\{100\}$ in Triton-X-100 added $25 \mathrm{wt} \%$ TMAH. It is reported that the etching rate above $100{ }^{\circ} \mathrm{C}$ is increased 3 to 4 times that in $80{ }^{\circ} \mathrm{C}$ solution. The effect of etching temperature on the etched surface roughness is presented in Fig. 21. The surface roughness is improved as the etching temperature approaches towards the boiling point of the etchant solution.

It is concluded that the etching at the temperature near to the boiling point of the etchant solution is an effective way of enhancing the etching rate. In addition, the

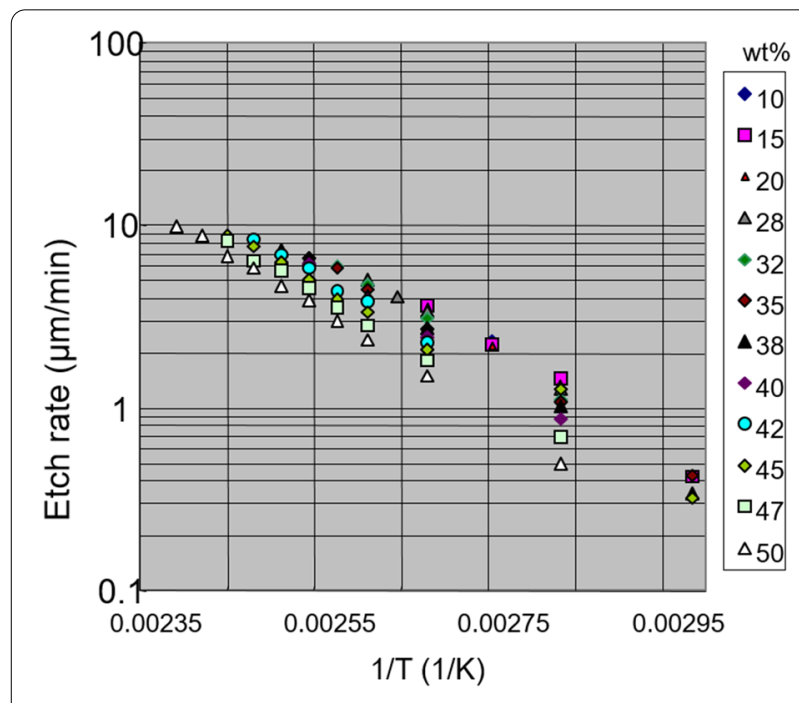

a $\operatorname{Si}\{\mathbf{1 0 0}\}$

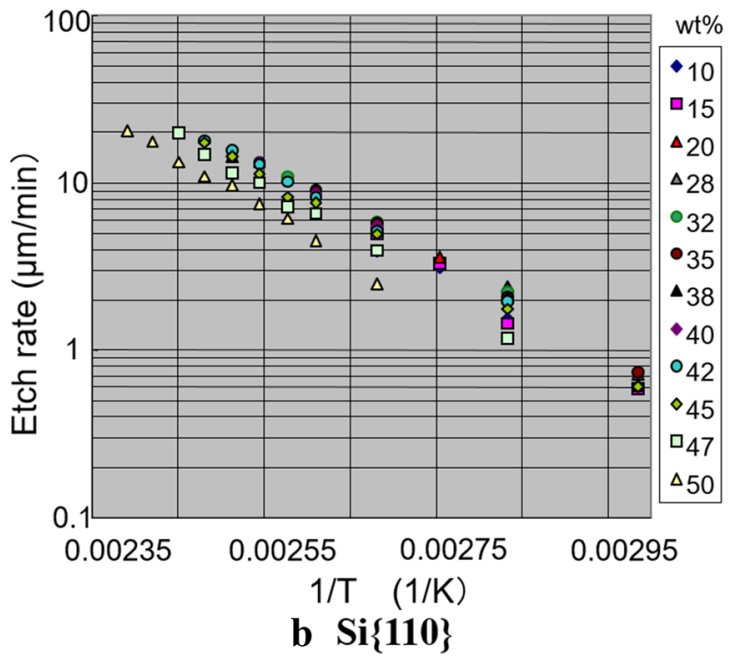

Fig. 17 Arrhenius plots of $\mathrm{Si}\{100\}$ and $\mathrm{Si}\{110\}$ etching rates for different concentrations of $\mathrm{KOH}$ aqueous solutions [85]

etched surfaces are smoother compared to that etched at lower temperatures. However, when applying the high temperature etching technologies to real production, it is necessary to keep the solution composition constant by compensating selective evaporation among components. When looking at Figs. 20 and 21, there is a significant shift in experimental curves between 100 and $105{ }^{\circ} \mathrm{C}$. Such an event might be caused by a change in the composition during etching due to selective evaporation or decomposition of any component in the solution, such as Triton-X-100 which is a component to suppress etching rate.

A bottle neck step dominating the etching rate of silicon is the oxidation of silicon among all steps in the 


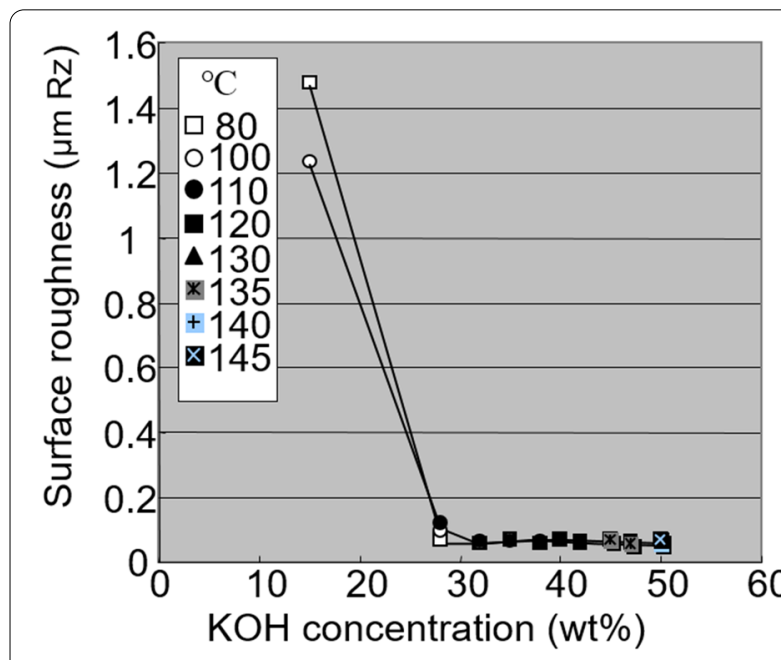

a $\mathrm{Si}\{\mathbf{1 0 0}\}$

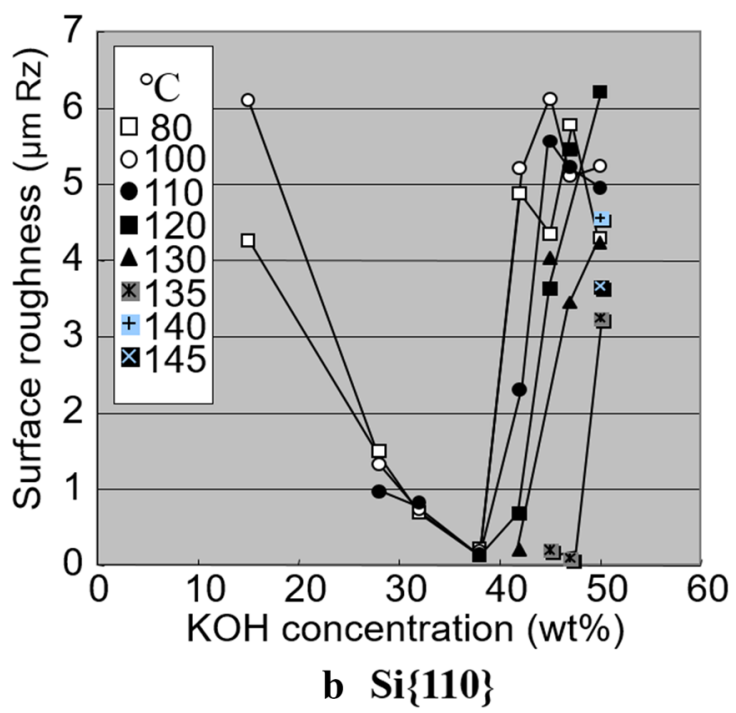

Fig. 18 Etched surface roughness of a Si\{100\} and $\mathbf{b} \operatorname{Si}\{110\}$ in $\mathrm{KOH}$ solutions in a concentration range from 15 to 50 wt\% [18], (C 2004, Elsevier

etching system. This is the reason why high temperature etching is so effective to achieve high speed etching. In comparison, stirring motion of the solution is less necessary for enhancing etching rate, but necessary only for improving uniformity in temperature of the etching solution in the bath. This is quite a contrast to chemical isotropic etching of silicon using hydrofluoric acid (HF) and nitric acid $\left(\mathrm{HNO}_{3}\right)$ water solution that aggressively reacts with $\mathrm{Si}$. The isotropic etching is a typical diffusionlimited reaction process whose etched shape is strongly influenced by a weak flow and diffusion of the solution. In actual high-speed etching processing, swiftness and

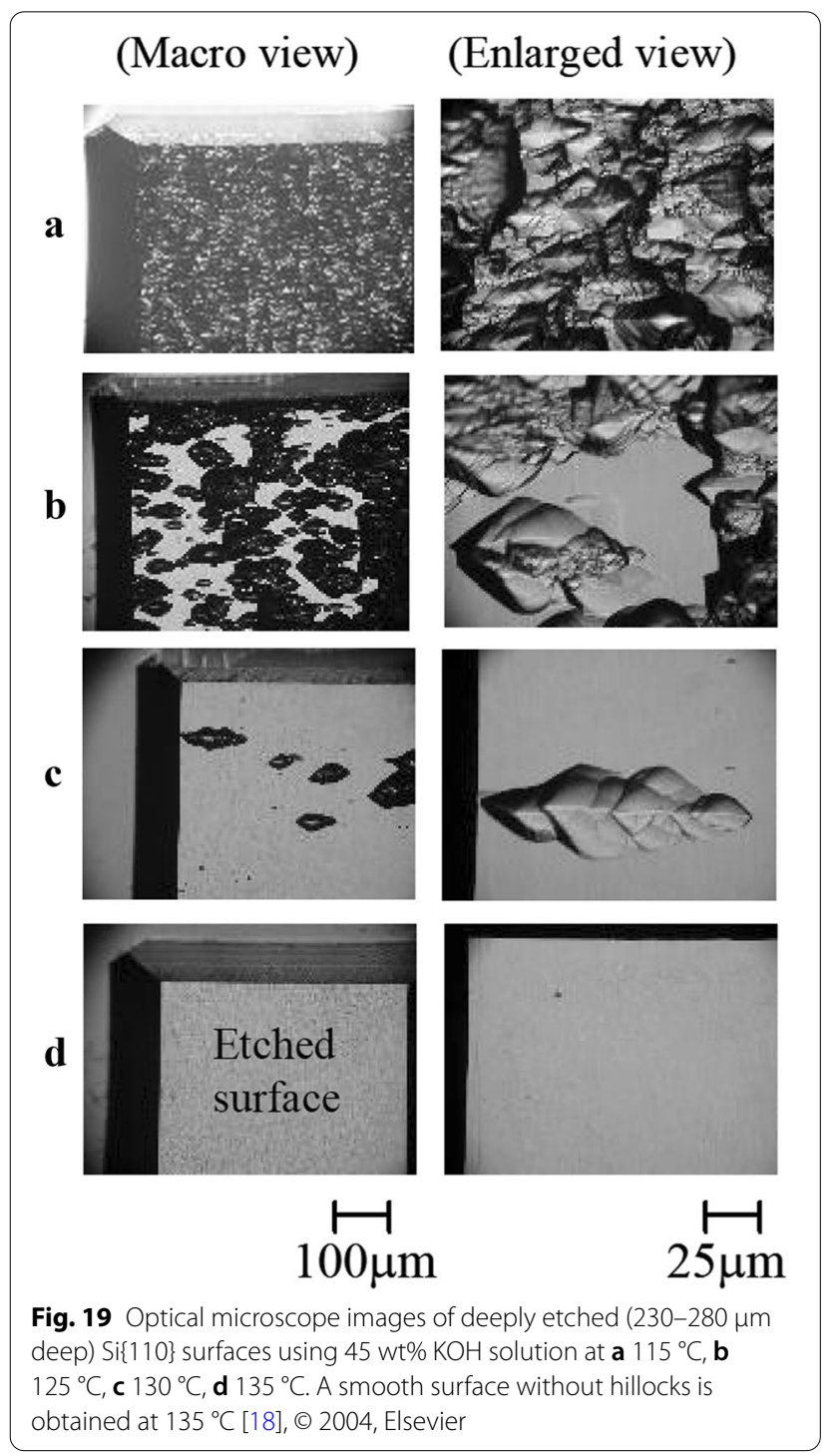

stability of wafer handling is also required until etching process is carried out at high temperature. The etch selectivity between silicon and silicon dioxide decreases with etching temperature. Hence it is necessary to use a etch mask which has high etch selectivity with silicon such as silicon nitride $\left(\mathrm{Si}_{3} \mathrm{~N}_{4}\right), \mathrm{Cr}-\mathrm{Au}$, etc.

\section{Incorporation of different kinds of additives}

To alter the etching characteristics (e.g. etch rate, surface morphology, undercutting) of pure alkaline solution, especially $\mathrm{KOH}$ and TMAH, the effect of different kinds of additives has been investigated [1, 7, 23, 27, 30, 50-65, 85-105]. Some additives modify all three etching characteristics (i.e. etch rate, surface morphology, undercutting), while others change one or two etching characteristics. In this article, the additives (e.g. oxidizing 


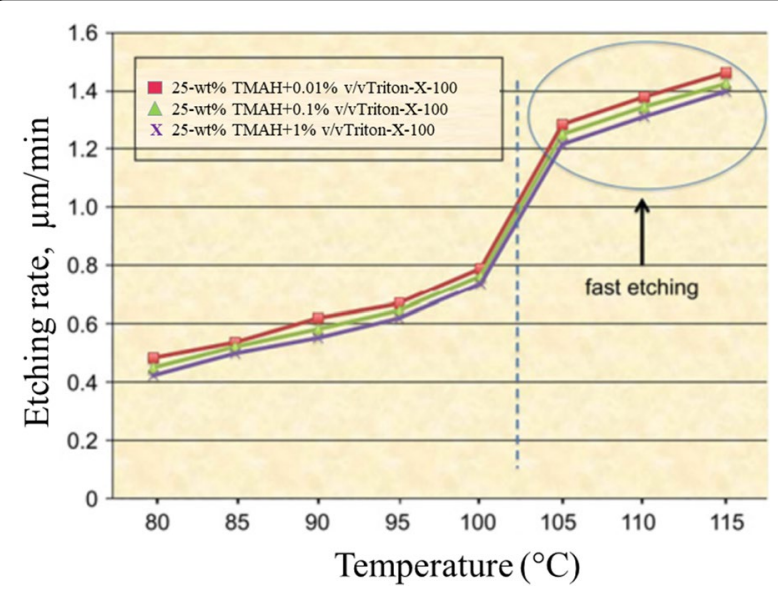

Fig. 20 Etch rate of $\mathrm{Si}\{100\}$ as a function of etching temperature in $25 \mathrm{wt} \%$ TMAH with a surfactant Triton-X-100 in a volume fraction of $0.01-1 \%$ [69], @ 2014, IET

agents, various ion-typed surfactants, ammonium persulfate, $\mathrm{NH}_{2} \mathrm{OH}$ ) which increase the etch rate of silicon, especially $\mathrm{Si}\{100\}$, have been discussed [50-52, 55, 56, 59-65, 106-111]. Moldovan et al. investigated the effect of redox $\left(\mathrm{K}_{3}\left[\mathrm{Fe}(\mathrm{CN})_{6}\right] 0.1 \mathrm{M}, \mathrm{K}_{4}\left[\mathrm{Fe}(\mathrm{CN})_{6}\right] 0.3 \mathrm{H}_{2} \mathrm{O}\right.$ $0.1 \mathrm{M}, \mathrm{KNO}_{3} 0.1 \mathrm{M}$ ) and complexant (ether-crown, calix[4]arenes, phenols) [52], whereas Yang et al. studied the impact of very small amount of anionic surfactant sodium dihexyl sulfosuccinate (SDDS) [56]. Several oxidizing agents such as ammonium persulfate (APS or AP, $\left.\left(\mathrm{NH}_{4}\right)_{2} \mathrm{~S}_{2} \mathrm{O}_{8}\right)$ Oxygenate $\left(\mathrm{H}_{2} \mathrm{O}_{2}\right)$, ammonium nitrate $\left(\mathrm{NH}_{4} \mathrm{NO}_{3}\right)$, ammonium acetate $\left(\mathrm{CH}_{3} \mathrm{COONH}_{4}\right)$, thiamine mononitrate $\left(\mathrm{C}_{12} \mathrm{H}_{17} \mathrm{~N}_{5} \mathrm{O}_{4} \mathrm{~S}\right)$ have been explored to modify TMAH solution to protect the aluminium metal patterns on silicon surface during etching process [106-111]. Out of these additives, AP is most effective to achieve a high etch rate with smooth etched surface, and most importantly the complete protection of the exposed Al. Sotoaka studied the effect of various kinds of additives on the etch rate of silicon and the hydroxylamine $\left(\mathrm{NH}_{2} \mathrm{OH}\right)$ is presented as more effective additive [55]. Swarnalatha et al. and Narasimha et al. systematically investigated the effect of different concentrations of hydroxylamine $\left(\mathrm{NH}_{2} \mathrm{OH}\right)$ on all three etching characteristics (i.e. etch rate, etched surface morphology, and undercutting) in TMAH and $\mathrm{KOH}$ [50, 51, 60-65]. In addition, the etch rate of $\mathrm{SiO}_{2}$ and its selectivity with silicon are investigated. The etching characteristics are studied on principal crystallographic planes (i.e. $\{100\}$, $\{110\}$ and $\{111\})$. Various kinds of mask patterns are used to investigate the undercutting and to demonstrate the applicability in MEMS fabrication.

\section{Etch rate}

Moldovan et al. investigated wet anisotropic etching of $\mathrm{Si}\{100\}$ in $4.5 \mathrm{M} \mathrm{KOH}$ with addition of redox system $\left(\mathrm{K}_{3}\left[\mathrm{Fe}(\mathrm{CN})_{6}\right] 0.1 \mathrm{M}, \mathrm{K}_{4}\left[\mathrm{Fe}(\mathrm{CN})_{6}\right] 0.3 \mathrm{H}_{2} \mathrm{O} 0.1 \mathrm{M}, \mathrm{KNO}_{3}\right.$ $0.1 \mathrm{M}$ ) and/or a complexant (ether-crown, calix[4]arenes) [52]. The results are shown in Fig. 22. The addition of redox system increases the etch rate of $\mathrm{Si}\{100\}$ by $25 \%$ of that in pure $4.5 \mathrm{M} \mathrm{KOH}$. The proposed solution is not toxic, but it is corrosive. The incorporation of ether crown complexant increases the etch rate by $25 \%$, while the addition of calix[4]arene complexant improves it by $50 \%[52]$.

Yang et al. studied the effect of three ion-typed surfactants including anionic SDSS, cationic ASPEG and non-ionic PEG on the etch rate of $\operatorname{Si}\{100\}$ in $30 \mathrm{wt} \%$ $\mathrm{KOH}$ and $10 \mathrm{wt} \% \mathrm{TMAH}$ solutions [56]. The etch rate of $\mathrm{Si}\{100\}$ at different temperatures in pure and surfactant added 30 wt\% $\mathrm{KOH}$ is shown in Fig. 23a, while Fig. 23b presents the same for pure and surfactant added $10 \mathrm{wt} \%$ TMAH. It can easily be noticed from Fig. 23 that the anionic SDSS is the most effective additive to increase the etch rate. The effect SDSS on etch rate increases as the etching temperature increases.

Yan et al. studied the modified TMAH by addition of ammonium persulfate (APS or AP, $\left.\left(\mathrm{NH}_{4}\right)_{2} \mathrm{~S}_{2} \mathrm{O}_{8}\right)$ to protect the aluminium layer during the etching silicon [106]. They achieved zero etching rate of $\mathrm{Al}$ when adequate amounts of AP and silicon are added to TMAH solution. Figure 24 shows the etch rate of aluminium as a function of AP concentration at $85{ }^{\circ} \mathrm{C}$. The amount of dissolved silicon in 5 and $10 \mathrm{wt} . \%$ TMAH are 1.6 and 3.2 wt.\%, respectively. The etch rate of $\mathrm{Al}$ decreases to zero when the concentration of AP reaches $0.4 \mathrm{wt} \%$ and 1.2 wt $\%$ in $5 \mathrm{wt} \%$ and $10 \mathrm{wt} \% \mathrm{TMAH}$, respectively. Figure 25 shows the etch rate and surface roughness of $\mathrm{Si}\{100\}$ as a function of AP concentration in $10 \mathrm{wt} \% \mathrm{TMAH}$ with dissolved $3.2 \mathrm{wt} \%$ silicon at $85{ }^{\circ} \mathrm{C}$. The etch rate of silicon increases from $0.4 \mu \mathrm{m} / \mathrm{min}$ to $0.85 \pm 0.9 \mu \mathrm{m} / \mathrm{min}$ when AP concentration is in the range between 0.6 and $2.0 \mathrm{wt} \%$ [106]. Fujitsuka et al. studied different kinds of additives in $10 \mathrm{wt} \%$ TMAH to protect the $\mathrm{Al}$ during silicon anisotropic etching [108]. Figure 26 shows the etch rates of $\mathrm{Al}-\mathrm{Si}$ and $\mathrm{Si}\{100\}$ as a function of ammonium persulfate (AP) concentration in $3.2 \mathrm{wt} \%$ Si dissolving 10 wt.\% TMAH at $80{ }^{\circ} \mathrm{C}$ [108]. Si anisotropic etching without $\mathrm{Al}$ etch is achieved by dissolving $\mathrm{Si}$ and $\mathrm{AP}$ in TMAH. Jun et al. investigated the effect of ammonium persulfate (AP), pyrazine, ammonium hydrogen sulfate (AHS), and isopropyl alcohol (IPA) in $10 \mathrm{wt} \% \mathrm{TMAH}$ at $70{ }^{\circ} \mathrm{C}$ [109]. The addition of AP, pyrazine, AHS increases the etch rate as shown in Fig. 27. It can be easily noticed that AP and pyrazine are more effective additives to increase the etch rate. Hence it can be stated that the ammonium 


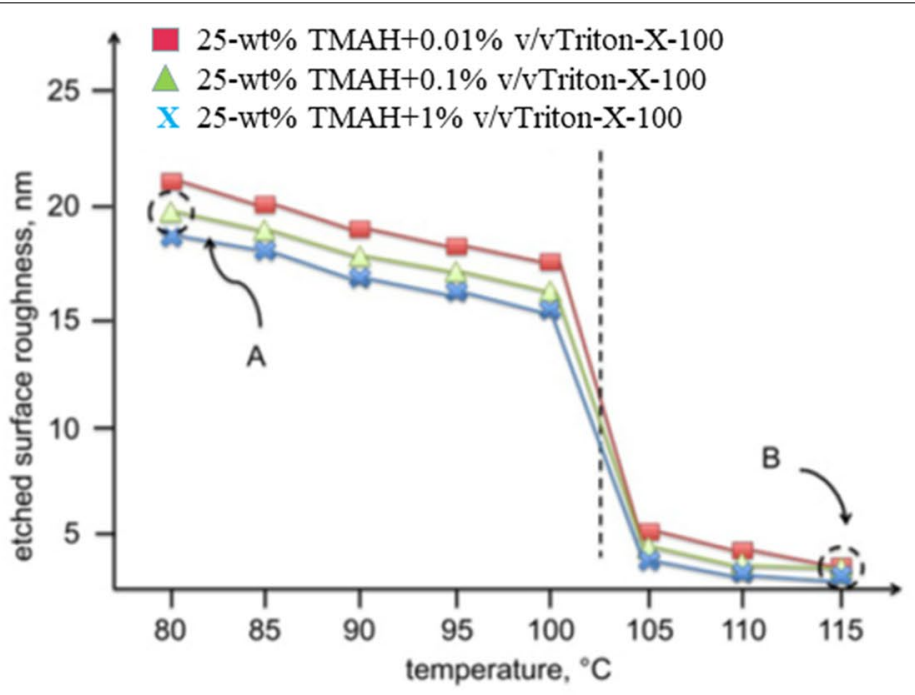

a
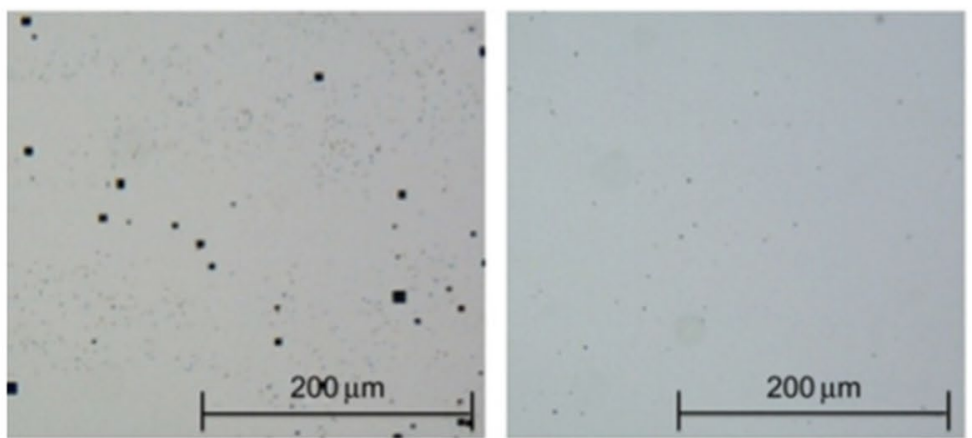

b
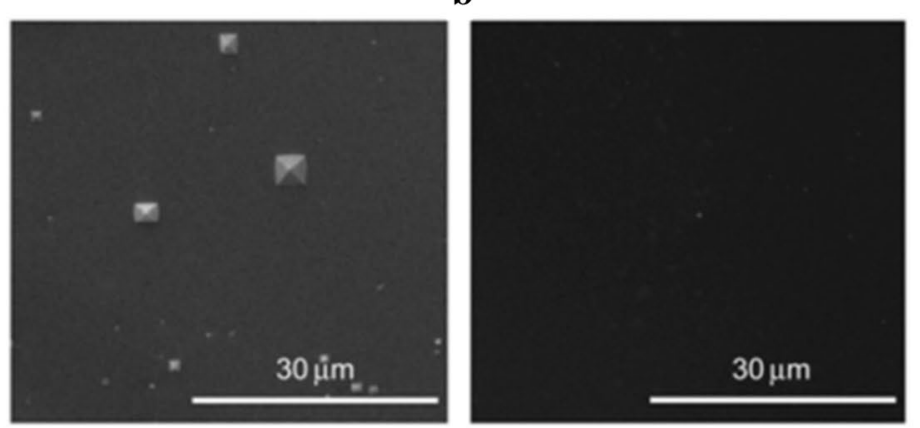

c
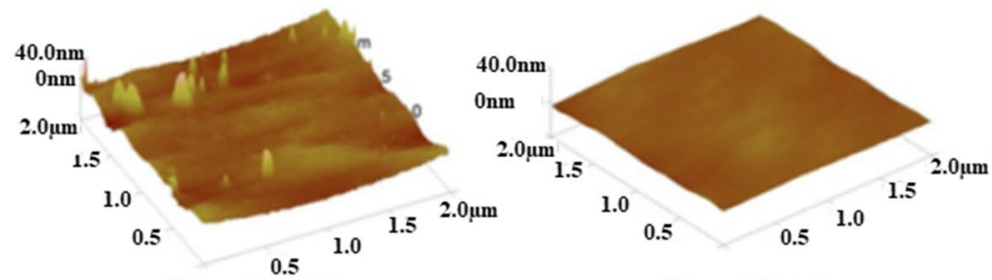

$\mathrm{Ra}=19.4 \mathrm{~nm}$

d

$\mathrm{Ra}=1.2 \mathrm{~nm}$

Fig. 21 a Temperature dependent etched surface roughness of Si\{100\} in 25 wt\% TMAH with Triton-X-100 in a volume fraction from 0.01-1\%. Etched surface morphologies of the samples corresponding to points A and B: b optical micrographs, c SEM images and d AFM results [69], @ 2014, IET 

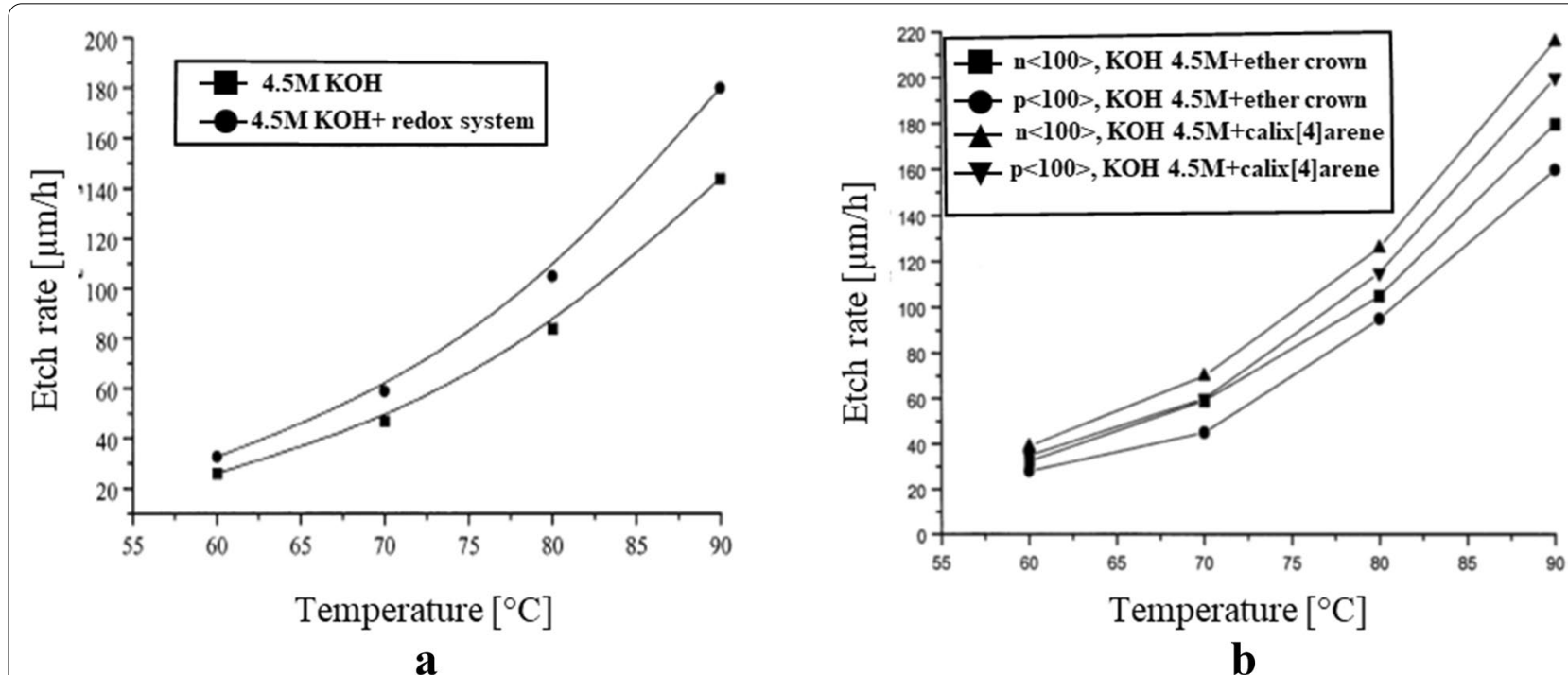

Fig. 22 Etch rate of $\mathrm{Si}\{100\}$ in $4.5 \mathrm{M} \mathrm{KOH}$ with a redox $\left(\mathrm{K}_{3}\left[\mathrm{Fe}(\mathrm{CN})_{6}\right] 0.1 \mathrm{M}, \mathrm{K}_{4}\left[\mathrm{Fe}(\mathrm{CN})_{6}\right] .3 \mathrm{H}_{2} \mathrm{O} 0.1 \mathrm{M}, \mathrm{KNO}_{3} 0.1 \mathrm{M}\right)$ and b complexants (ether-crown, calix[4]arenes) [52], ( ) 1999, Elsevier

persulfate (Synonym: AP, APS, ammonium peroxodisulfate) is the best additive to protect $\mathrm{Al}$ in TMAH and to obtain higher etch rate of silicon.

Swarnalatha et al. [50, 60-62] and Narasimha et al. [51, 63-65] investigated the effect of different concentrations of hydroxylamine $\left(\mathrm{NH}_{2} \mathrm{OH}\right)$ on the etch rates of principal crystallographic planes (i.e. $\{100\},\{110\}$ and $\{111\}$ ) in 5 wt\% TMAH and $20 \mathrm{wt} \% \mathrm{KOH}$. In addition, the etch rate of $\mathrm{SiO}_{2}$ and its selectivity with silicon are investigated. 5 wt\% TMAH is selected because the lower concentration TMAH (2-5 wt\%) provides greater etch rate in comparison to higher concentration TMAH (20-25 wt\%). Similarly, $20 \mathrm{wt} \% \mathrm{KOH}$ is chosen to obtain higher etch rate. In both etchants, the concentration of $\mathrm{NH}_{2} \mathrm{OH}$ is varied from 5 to $20 \%$ in step of $5 \%$ to obtain the optimum concentration for achieving improved chemical etch rate. Figures 28 and 29 present the etch rates of different orientation silicon surfaces in $5 \mathrm{wt} \% \mathrm{TMAH}$ and $20 \% \mathrm{KOH}$ without and with addition of different concentrations of $\mathrm{NH}_{2} \mathrm{OH}$, respectively. Standard deviation in etch rate is determined by taking four measurements on the same chip at different locations. In both cases, the etch rate of silicon increases significantly as the concentration of $\mathrm{NH}_{2} \mathrm{OH}$ increases. In the case of TMAH, $10 \% \mathrm{NH}_{2} \mathrm{OH}$ is an optimal concentration to obtain the highest etch rate, while $15 \% \mathrm{NH}_{2} \mathrm{OH}$ is an appropriate concentration for $\mathrm{KOH}$ to achieve maximum etch rate of silicon.

Silicon etching process takes place in three major steps: (1) diffusion of the reactants to the silicon surface, (2) chemical reaction between etchant and silicon atoms, and (4) diffusion/dissolution of reaction products into the bulk etchant [3, 56, 92]. Factors (1) and (3) are termed "diffusion-limited dissolution", while factor (2) is termed "reaction rate limited dissolution", which depend on the etching temperature, types and concentrations of etchants and additives and crystallographic directions. The chemical activities of the etching solutions induced by additive and types of etchant strongly affect the etching rate for a fixed etching temperature. If an additive improves the wettability of the etchant, the etchant can easily diffuse to the silicon surface and the reaction products can quickly diffuse to the bulk etchant that results in higher etch rate. The etch rate may increase if the chemical activities of the etchant are improved by the incorporation of the additive. So, it can be stated that an additive in alkaline solution can increase the etch rate if it increases diffusivity or reactivity or both. The addition of complexant increases $\mathrm{OH}^{-}$free ions in the solution, resulting an increase of the etch rate [52]. The addition of SDSS improve the wettability in $\mathrm{KOH}$ and chemical activity in TMAH that results in increase of the etch rate [56].

The behaviour of $\mathrm{NH}_{2} \mathrm{OH}$ in alkaline solutions is extensively studied [112-116]. To explain the possible etching mechanism in $\mathrm{NH}_{2} \mathrm{OH}$-added alkaline solution a simple model was proposed by Swarnalatha et al. [117]. In this model, $\mathrm{NH}_{2} \mathrm{O}^{-}$and $\mathrm{OH}^{-}$ions are considered as catalysts, while $\mathrm{H}_{2} \mathrm{O}$ as the reactive molecule. When $\mathrm{NH}_{2} \mathrm{OH}$ is added to pure alkaline solutions, it reacts with $\mathrm{OH}^{-}$ions in the solution forming $\mathrm{NH}_{2} \mathrm{O}^{-}$ions and water molecules as shown in the following equations [112]: 


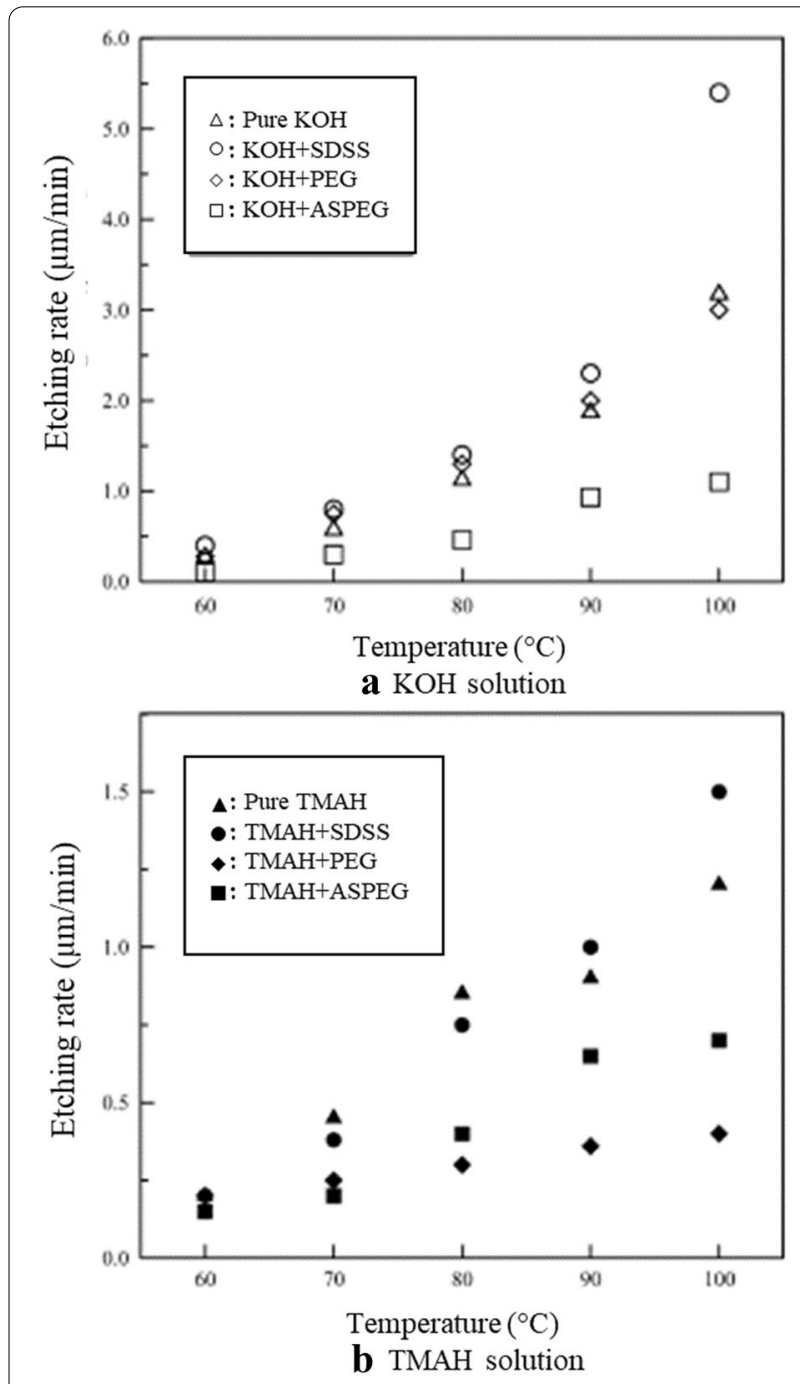

Fig. 23 Average etching rate of $\mathrm{Si}\{100\}$ in pure and surfactant-added a $30 \mathrm{wt} \% \mathrm{KOH}$ and $\mathbf{b} 10 \mathrm{wt} \% \mathrm{TMAH}$ at different etching temperatures [56], ( ) 2005, Elsevier

$$
\begin{aligned}
& \mathrm{NH}_{2} \mathrm{OH}+\mathrm{OH}^{-} \rightarrow \mathrm{NH}_{2} \mathrm{O}^{-}+\mathrm{H}_{2} \mathrm{O} \\
& \mathrm{NH}_{2} \mathrm{O}^{-}+\mathrm{NH}_{2} \mathrm{OH} \rightarrow \mathrm{NH}_{2} \mathrm{NHOH}+\mathrm{OH}^{-} \\
& \mathrm{NH}_{2} \mathrm{NHOH} \rightarrow \mathrm{HNO}+\mathrm{NH}_{3} \\
& \mathrm{HNO}+\mathrm{NH}_{2} \mathrm{OH} \rightarrow \mathrm{NH}_{2} \mathrm{O} \cdot+\mathrm{NH}_{2} \mathrm{O} . \\
& 2 \mathrm{NH}_{2} \mathrm{O} \cdot \rightarrow \mathrm{N}_{2}+2 \mathrm{H}_{2} \mathrm{O}
\end{aligned}
$$

The overall reaction of decomposition of $\mathrm{NH}_{2} \mathrm{OH}$ in alkaline solution is given by,

$$
3 \mathrm{NH}_{2} \mathrm{OH} \rightarrow \mathrm{N}_{2}+\mathrm{NH}_{3}+3 \mathrm{H}_{2} \mathrm{O}
$$

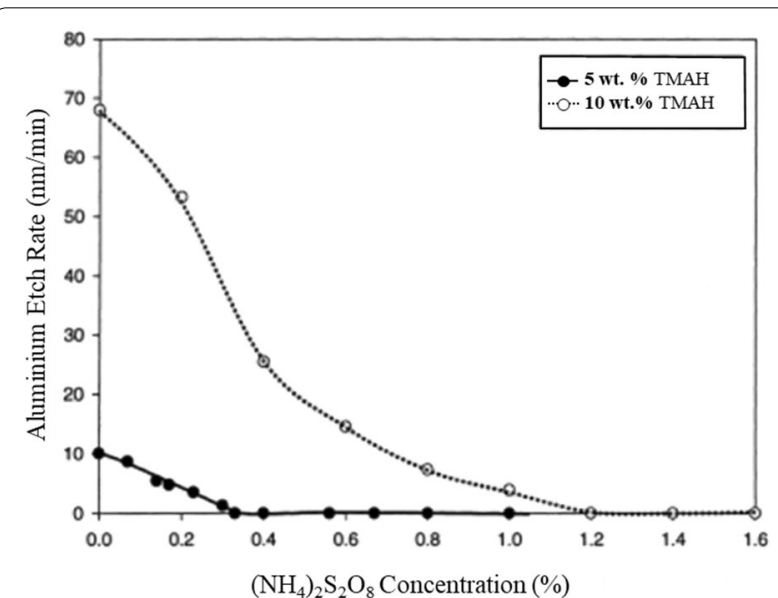

Fig. 24 Etch rate of aluminium as a function of $\left(\mathrm{NH}_{4}\right)_{2} \mathrm{~S}_{2} \mathrm{O}_{8}$ concentration at $85^{\circ} \mathrm{C}$. The amount of dissolved silicon in 5 and $10 \mathrm{wt}$ $\%$ TMAH are 1.6 and $3.2 \mathrm{wt} \%$, respectively [106], ๑ 2001, Elsevier

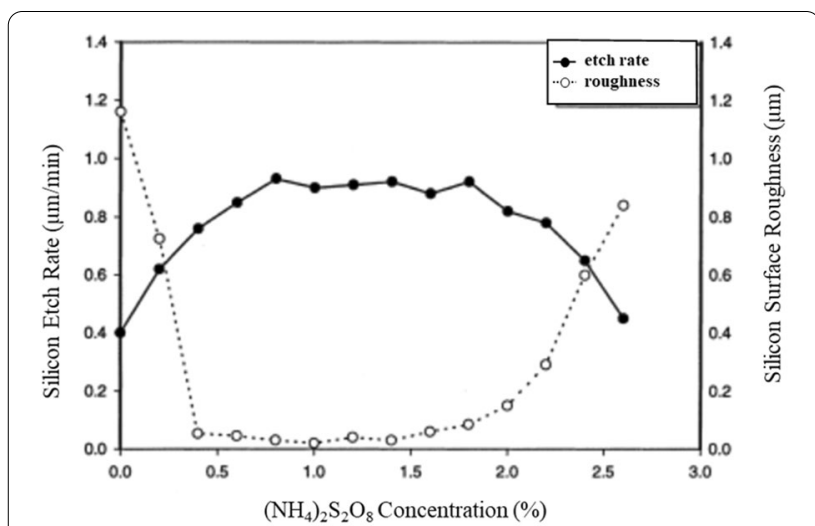

Fig. 25 Etch rate and surface roughness of $\mathrm{Si}\{100\}$ as a function of $\left(\mathrm{NH}_{4}\right)_{2} \mathrm{~S}_{2} \mathrm{O}_{8}$ concentration in $10 \mathrm{wt} \%$ TMAH with dissolved $3.2 \mathrm{wt} \%$ silicon at $85^{\circ} \mathrm{C}$ [106], @ 2001 , Elsevier

So, the reactive species, which are greatly accessible in $\mathrm{NH}_{2} \mathrm{OH}$-added alkaline solution, are $\mathrm{NH}_{2} \mathrm{O}^{-}$ions, $\mathrm{OH}^{-}$ions and $\mathrm{H}_{2} \mathrm{O}$ molecules. As the number of reactive species in $\mathrm{NH}_{2} \mathrm{OH}$-added alkaline solution is more in comparison to that in pure alkaline solution, the etch rate significantly increases in the presence of $\mathrm{NH}_{2} \mathrm{OH}$. In addition to these species, other intermediate compounds $\left(\mathrm{NH}_{2} \mathrm{NHOH}, \mathrm{HNO}\right.$ and $\mathrm{NH}_{2} \mathrm{O}$ radical $)$ may also participate in the etching reaction and might be helping to improve the etch rate. The etching mechanism proceeds through sequential oxidation and removal of surface silicon atoms by water molecules. The first step in the mechanism is the oxidation of surface silicon atoms. This can proceed through either chemical oxidation and/or electrochemical oxidation. 


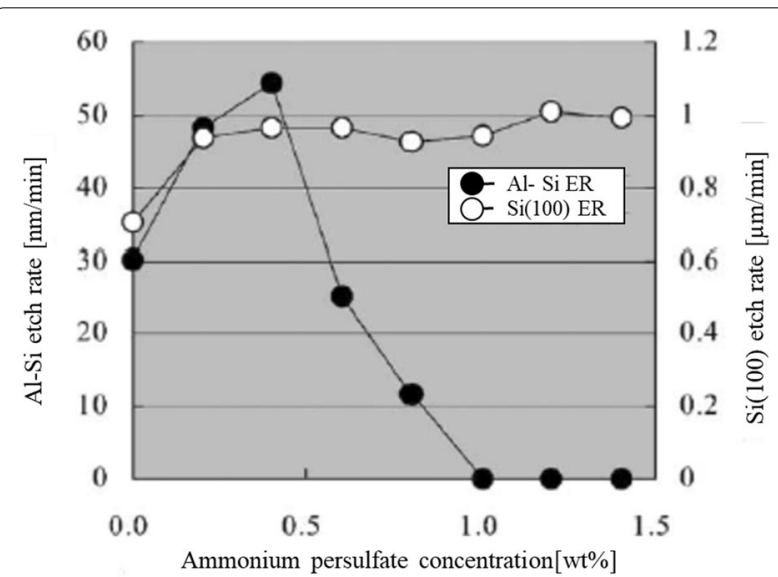

Fig. 26 Etch rate of Al-Si and $\mathrm{Si}\{100\}$ as a function of ammonium persulfate (AP) concentration in $3.2 \mathrm{wt} . \%$ Si dissolving $10 \mathrm{wt} \% \mathrm{TMAH}$ at $80^{\circ} \mathrm{C}[108]$, @ 2004, Elsevier

It may be emphasized here that the maximum etch rate is obtained when the concentration of $\mathrm{NH}_{2} \mathrm{OH}$ reaches to its optimal value. As per the experimental results, $\mathrm{NH}_{2} \mathrm{OH}$ concentration affects optimal balance of main active species in the etchant and therefore the etch rate decreases if $\mathrm{NH}_{2} \mathrm{OH}$ concentration is decreased/ increased below/above its most favorable value. A qualitative comparison of various kinds of additives that increase the etch rates of $\mathrm{Si}$ in TMAH and $\mathrm{KOH}$ solution is presented in Tables 2 and 3, respectively.

Hydroxylamine $\left(\mathrm{NH}_{2} \mathrm{OH}\right)$ is unstable in nature in the presence of alkaline solutions [115]. Therefore, it is important to study the influence of etchant age on the etch rate of silicon. $10 \% \mathrm{NH}_{2} \mathrm{OH}+5 \mathrm{wt} \% \mathrm{TMAH}$ and $15 \% \mathrm{NH}_{2} \mathrm{OH}+20 \mathrm{wt} \% \mathrm{KOH}$ are the optimal compositions to achieve the highest etch rate in comparison to pure TMAH and $\mathrm{KOH}$, respectively. Hence these compositions are employed to study the aging effect. In order to know the effect of etchant age on the etch rate of $\operatorname{Si}\{100\}, \operatorname{Si}\{110\}$, and $\operatorname{Si}\{111\}$, the same etchant solution is continuously used and the experiments are performed at different time interval in the same solution. Figure 30 shows the effect of etchant age for $10 \% \mathrm{NH}_{2} \mathrm{OH}+5 \mathrm{wt} \%$ TMAH, while Fig. 31 presents for $15 \% \mathrm{NH}_{2} \mathrm{OH}+20 \mathrm{wt} \%$ $\mathrm{KOH}$. It can easily be noticed that the etchant age considerably affects the etch rate. It is reduced with the age of the etchant. Hence it can be recommended here that the $\mathrm{NH}_{2} \mathrm{OH}$-added solution should be used immediately to achieve high etch rate. To fabricate the controlled depth cavities, etch depth must be measured in between etching process. The main cause of aging may be the selfdegrading behavior of $\mathrm{NH}_{2} \mathrm{OH}$ in TMAH/KOH solution [65].
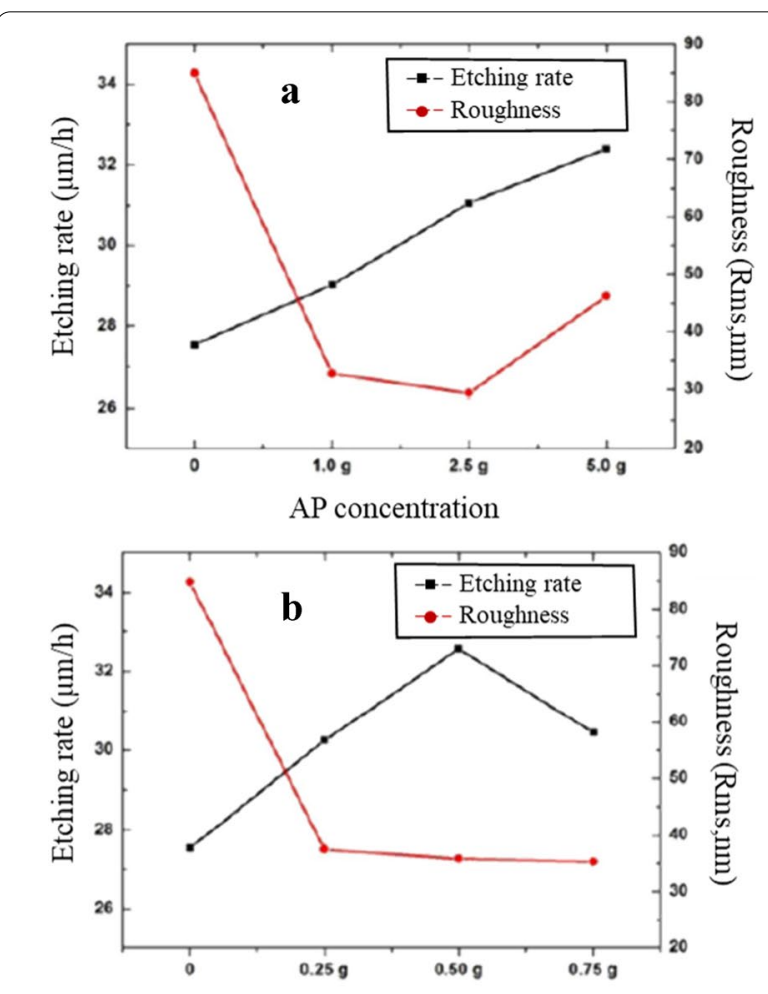

Pyrazine concentration

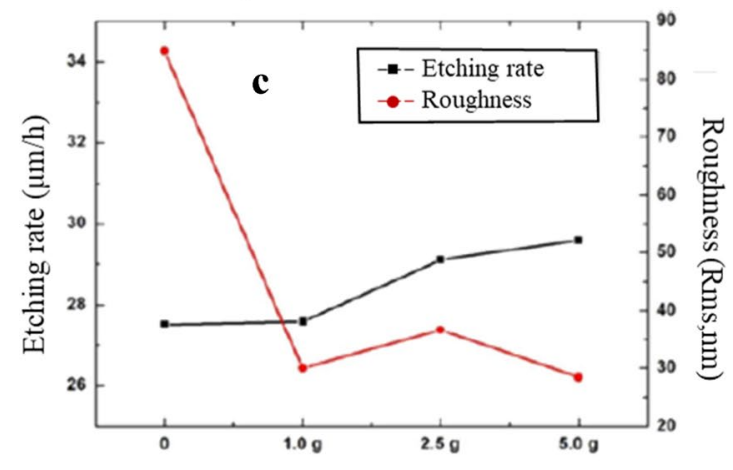

AHS concentration

Fig. 27 Etch rate and surface roughness of Si $\{100\}$ without and with addition of different amount of $\mathbf{a}$ ammonium persulfate (AP), $\mathbf{b}$ pyrazine, and c ammonium hydrogen sulfate (AHS) in per $500 \mathrm{~mL} 10$ wt $\%$ TMAH at $70{ }^{\circ} \mathrm{C}$ [109], ( 2015 , Springer

Silicon dioxide, especially thermally grown oxide, is extensively used in silicon micromachining as etch mask layer to create various kinds of grooves and cavities. Moreover, it is employed as structural layer for the fabrication of MEMS structures such as cantilever. Figure 32 presents the etch rate of thermally grown $\mathrm{SiO}_{2}$ and the etch selectivity between silicon and silicon dioxide. The etch selectivity is calculated using the etch rates of silicon and silicon dioxide in pure and different concentrations of $\mathrm{NH}_{2} \mathrm{OH}$-added TMAH. The same data for pure 

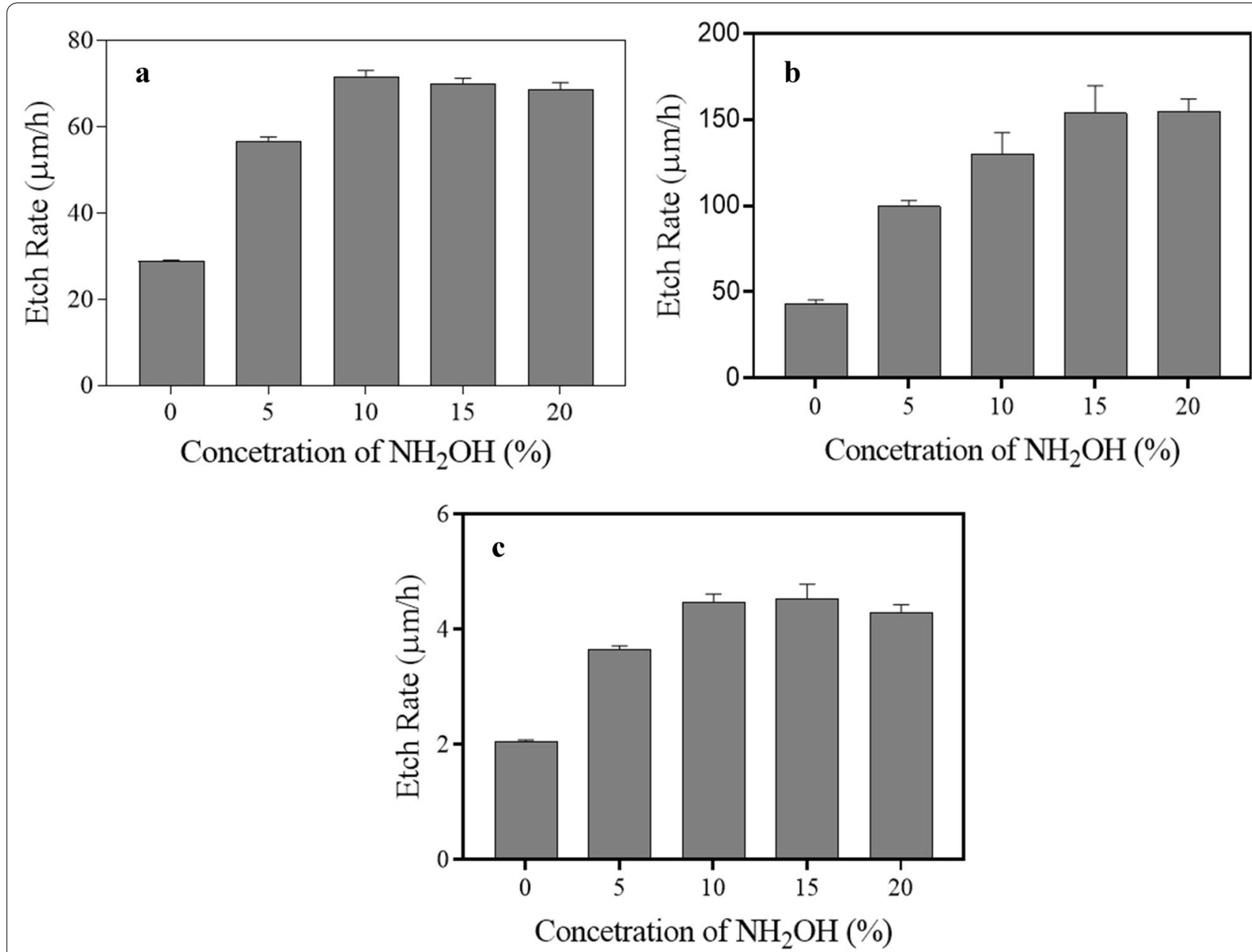

Fig. 28 Etch rates of $\mathbf{a} \mathrm{Si}\{100\} \mathbf{b} \mathrm{Si}\{110\}$ and $\mathbf{c} \mathrm{Si}\{111\}$ in 5 wt\% TMAH without and with varying concentrations of $\mathrm{NH}_{2} \mathrm{OH}$ at $70 \pm 1^{\circ} \mathrm{C}[50]$

and $\mathrm{NH}_{2} \mathrm{OH}$-added $\mathrm{KOH}$ are shown in Fig. 33. In both kinds of etchants, the etch rate of $\mathrm{SiO}_{2}$ increases as the concentration of $\mathrm{NH}_{2} \mathrm{OH}$ increases. In the fabrication of MEMS structures, the etch selectivity between silicon (or substrate) and mask/structural layer (e.g. $\mathrm{SiO}_{2}$ ) is an important concern and is defined as the ratio of the etch rate of silicon (substrate) to that of $\mathrm{SiO}_{2}$. If an etchant provides high etch selectivity, mask/structural layer can be exposed in the etchant for a longer time, which is needed to fabricate deep cavities/grooves or freestanding structures (e.g. cantilever) on silicon wafer. It can simply be noticed that the etch selectivity increases appreciably on the addition of $\mathrm{NH}_{2} \mathrm{OH}$, which is desirable to use oxide layer as a mask to form high depth cavities and/ or to fabricate suspended structures of silicon dioxide. It can be concluded that the addition of $\mathrm{NH}_{2} \mathrm{OH}$ not only increases the etch rate of silicon but also gives higher etch selectivity $\mathrm{Si}$ and $\mathrm{SiO}_{2}$ as compared to pure TMAH/ $\mathrm{KOH}$.

\section{Surface roughness and morphology}

Etched surface roughness and morphology are the important etching characteristics of an etchant. The requirement of smooth and textured surface morphology depends on the application. To fabricate uniform thickness suspended microstructure or uniform depth cavity/ groove or to achieve high reflectance for optical application smooth surface is needed, while in the case of solar cell application rough surface is required to reduce the reflectance of light. As discussed in "Etching with ultrasonic agitation" section, the main cause of surface roughness in the wet etching process is micromasking by the hydrogen bubbles and/or impurities on the surface during the etching process $[2,3,7,19,27,76-82,118-120]$. With an increase in hydrogen bubbles (or impurities or etching products) and their attachment with silicon surface during etching, surface roughness increases. The precise origin of most morphologic features is still under debate. However, in general, four simultaneous conditions are required to form hillocks on an etched surface. 

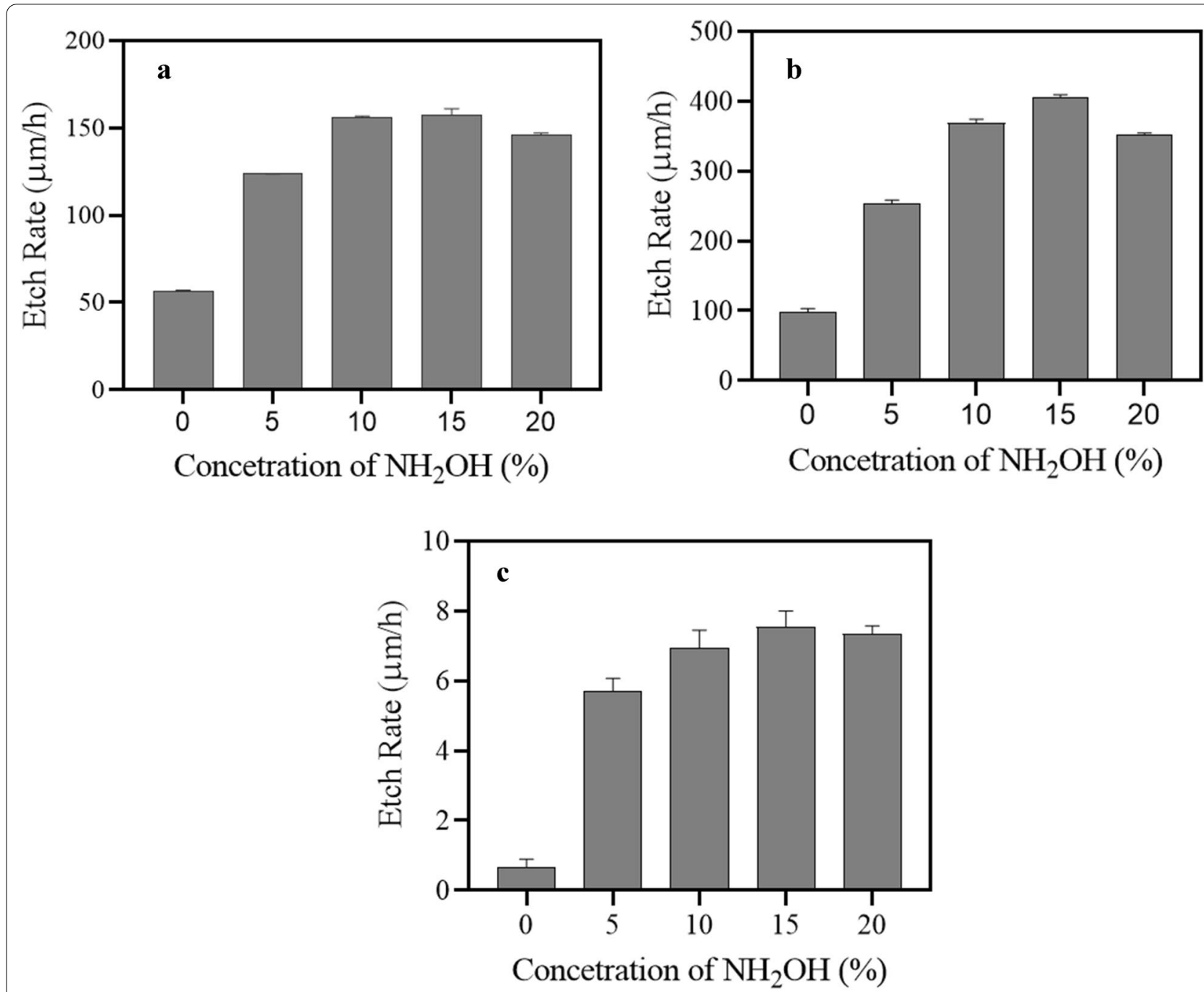

Fig. 29 Etch rate of $\mathbf{a} \mathrm{Si}\{100\} \mathbf{b} \mathrm{Si}\{110\}$ and $\mathbf{c} \mathrm{Si}\{111\}$ in $20 \mathrm{wt} \% \mathrm{KOH}$ without and with varying concentrations of $\mathrm{NH}_{2} \mathrm{OH}$ at $75 \pm 1{ }^{\circ} \mathrm{C}[51]$

Table 2 The effect of various kinds of additives on the etch rate of silicon in TMAH solution

\begin{tabular}{|c|c|c|c|c|c|}
\hline Authors & $\begin{array}{l}\text { Additive that improves the etch } \\
\text { rate }\end{array}$ & Orientation of silicon & TMAH Conc & Temp. $\left({ }^{\circ} \mathrm{C}\right)$ & Etch rate \\
\hline C-R Yang et al. [56] & $\begin{array}{l}\text { Anionic sodium dihexyl sulfosuc- } \\
\text { cinate (SDSS) }\end{array}$ & $\{100\}$ & 10 wt.\% & $60-100$ & Mild increase at 90 and $100 \mathrm{C}$ \\
\hline G Yan et al. [106] & Ammonium persulfate (AP) & $\{100\}$ & $5,10 w t \%$ & 85 & Effective increase \\
\hline N Fujitsuka et al. [108] & Ammonium persulfate (AP) & $\{100\}$ & 10 wt.\% & 80 & Effective increase \\
\hline K-H Jun et al. [109] & $\begin{array}{l}\text { Pyrazine, Ammonium persulfate } \\
\text { (AP) }\end{array}$ & $\{100\}$ & $10 \mathrm{wt} \%$ & 70 & Effective increase \\
\hline S. Birda et al. [107] & Ammonium persulfate (AP) & $\{100\}$ & $5-10$ wt.\% & $70-90$ & Effective increase \\
\hline E.H. Klaassen et al. [111] & Ammonium peroxydisulfate & $\{100\}$ & 5 wt.\% & $70-100$ & Effective increase \\
\hline R. Sotoaka [55] & $\begin{array}{l}\text { Maltose, Glucose, } \mathrm{NH}_{2} \mathrm{OH} \text {, Cel- } \\
\text { lobiose }\end{array}$ & $\{100\}$ & $10 \mathrm{wt} \%$ & 80 & $\begin{array}{l}\text { Significant increase in } \\
\mathrm{NH}_{2} \mathrm{OH} \text { added solution }\end{array}$ \\
\hline V. Swarnalatha et al.[50, 60-62] & $\mathrm{NH}_{2} \mathrm{OH}$ & $\{100\},\{110\}$ and $\{111\}$ & 5 wt $\%$ & 70 & Significant increase \\
\hline
\end{tabular}


Table 3 The effect of various kinds of additives on the etch rate of silicon in $\mathrm{KOH}$ solution

\begin{tabular}{|c|c|c|c|c|c|}
\hline Authors & Additive's name & Orientation of $\mathrm{Si}$ & KOH Conc & Temp. $\left({ }^{\circ} \mathrm{C}\right)$ & Effect on etch rate \\
\hline \multirow[t]{3}{*}{ C. Moldovan et al. [52] } & Redox system & $\{100\}$ & $4 \mathrm{M}$ & 80 & Mild increase \\
\hline & Ether crown complexant & $\{100\}$ & $4.5 \mathrm{M}$ & 80 & Mild increase \\
\hline & Calix[4]arene complexant & $\{100\}$ & $4.5 \mathrm{M}$ & 80 & Effective increase \\
\hline C-R Yang et al. [56] & Anionic sodium dihexyl sulfosuccinate (SDSS) & $\{100\}$ & $30 \mathrm{wt} \%$ & $60-100$ & Effective increase at $100^{\circ} \mathrm{C}$ \\
\hline R. Sotoaka [55] & Maltose, Glucose, $\mathrm{NH}_{2} \mathrm{OH}$, Cellobiose & $\{100\}$ & $25 w t \%$ & 80 & $\begin{array}{l}\text { Significant increase in } \\
\mathrm{NH}_{2} \mathrm{OH} \text { added solution }\end{array}$ \\
\hline $\begin{array}{l}\text { A. V. Narasimha Rao } \\
\text { et al. }[51,63-65]\end{array}$ & $\mathrm{NH}_{2} \mathrm{OH}$ & $\{100\},\{110\}$ and $\{111\}$ & $20 w t \%$ & 75 & Significant increase \\
\hline
\end{tabular}
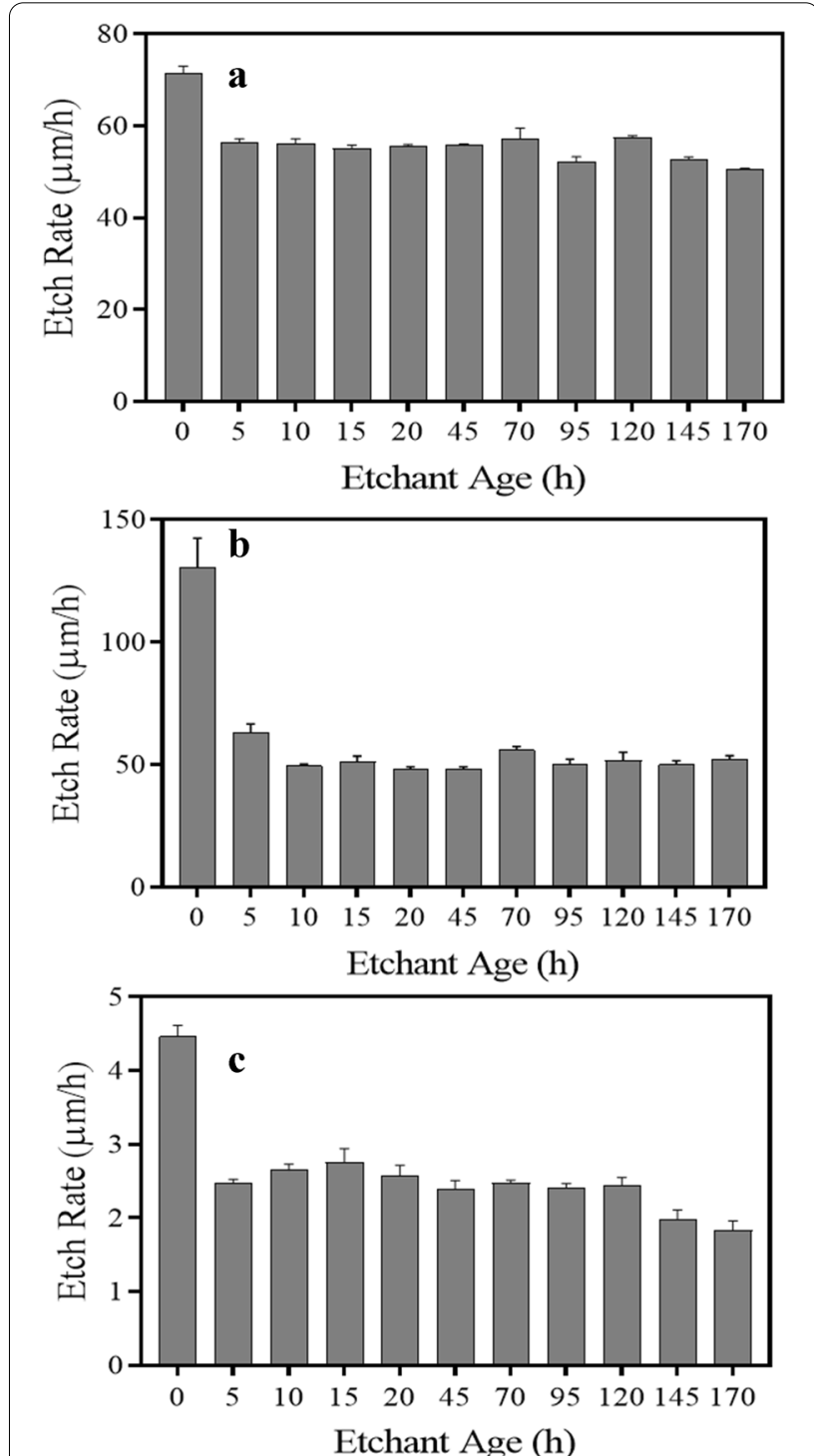

Fig. 30 Effect of aging of $10 \% \mathrm{NH}_{2} \mathrm{OH}+5 \mathrm{wt} \% \mathrm{TMAH}$ on the etch rates of (a) Si\{100\}, (b) Si\{110\}, and (c) Si\{111\} at $70 \pm 1^{\circ} \mathrm{C}[50]$
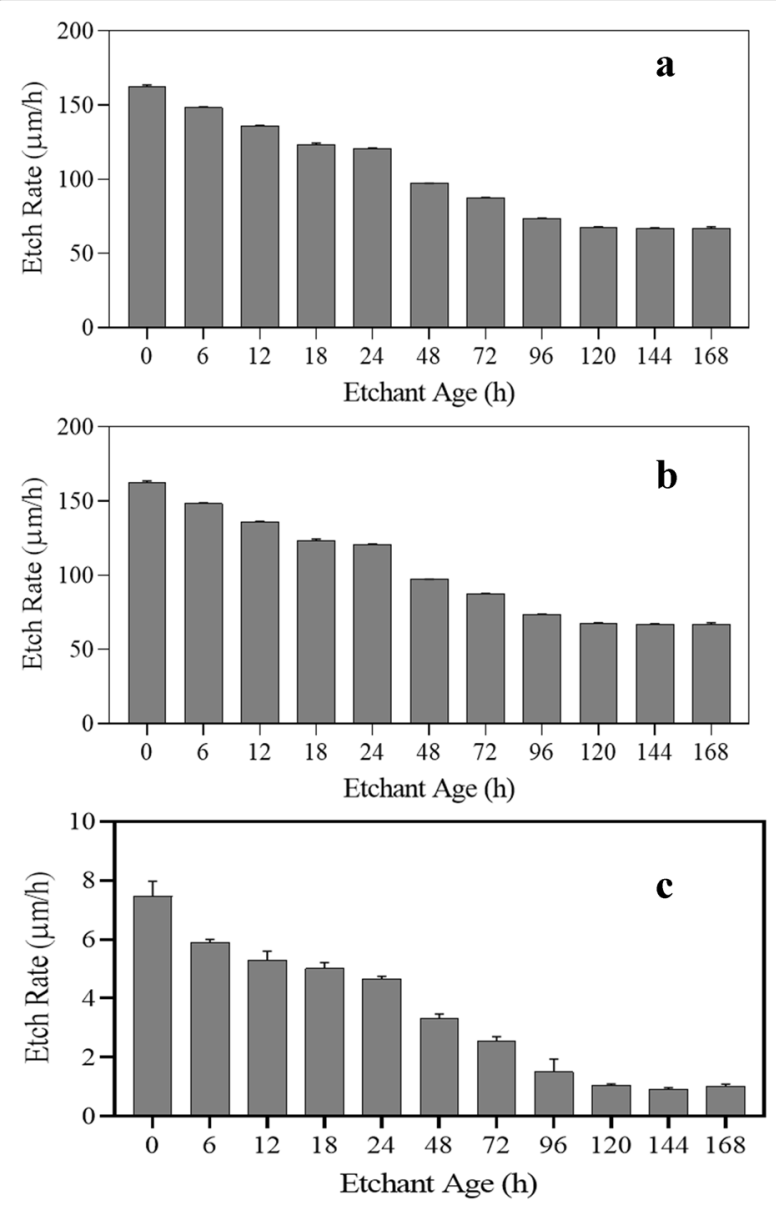

Fig. 31 Effect of aging of $15 \% \mathrm{NH}_{2} \mathrm{OH}+20 \mathrm{wt} \% \mathrm{KOH}$ on the etch rates of (a) Si\{100\}, (b) Si\{110\}, and (c) Si\{111\} at $75 \pm 1^{\circ} \mathrm{C}$ [51]

These conditions are the existence of a micromasking agent that stabilizes the apex atom/s, fast downward motion of the floor surface, stable side edges, and very stable lateral facets. The micromasking agent can be an insoluble reaction product, an etchant impurity, or an etchant inhomogeneity (such as a hydrogen bubble). The etchant inhomogeneities refer in general to the formation 


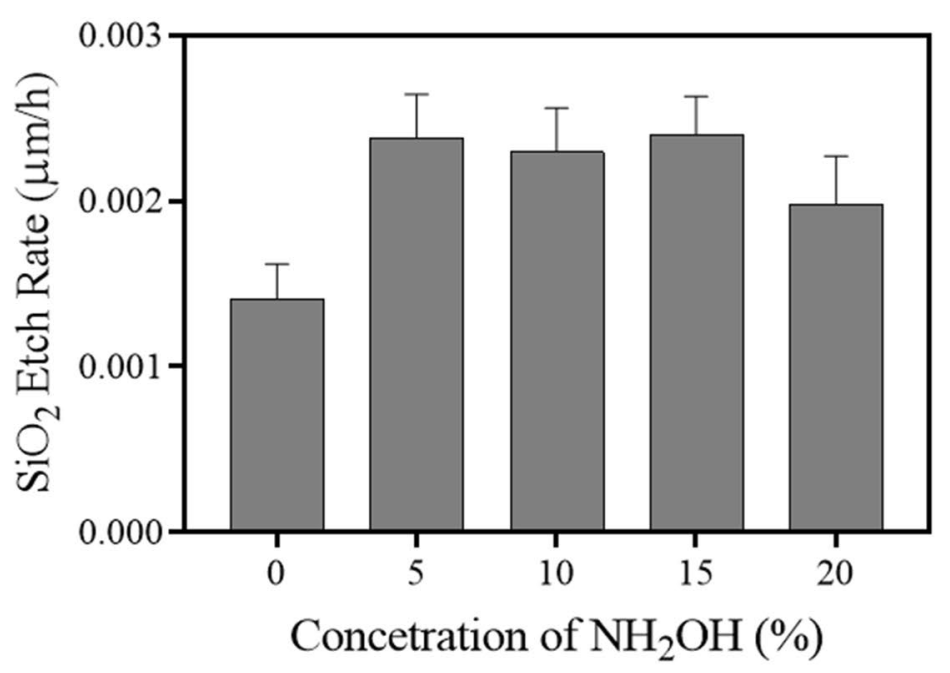

a
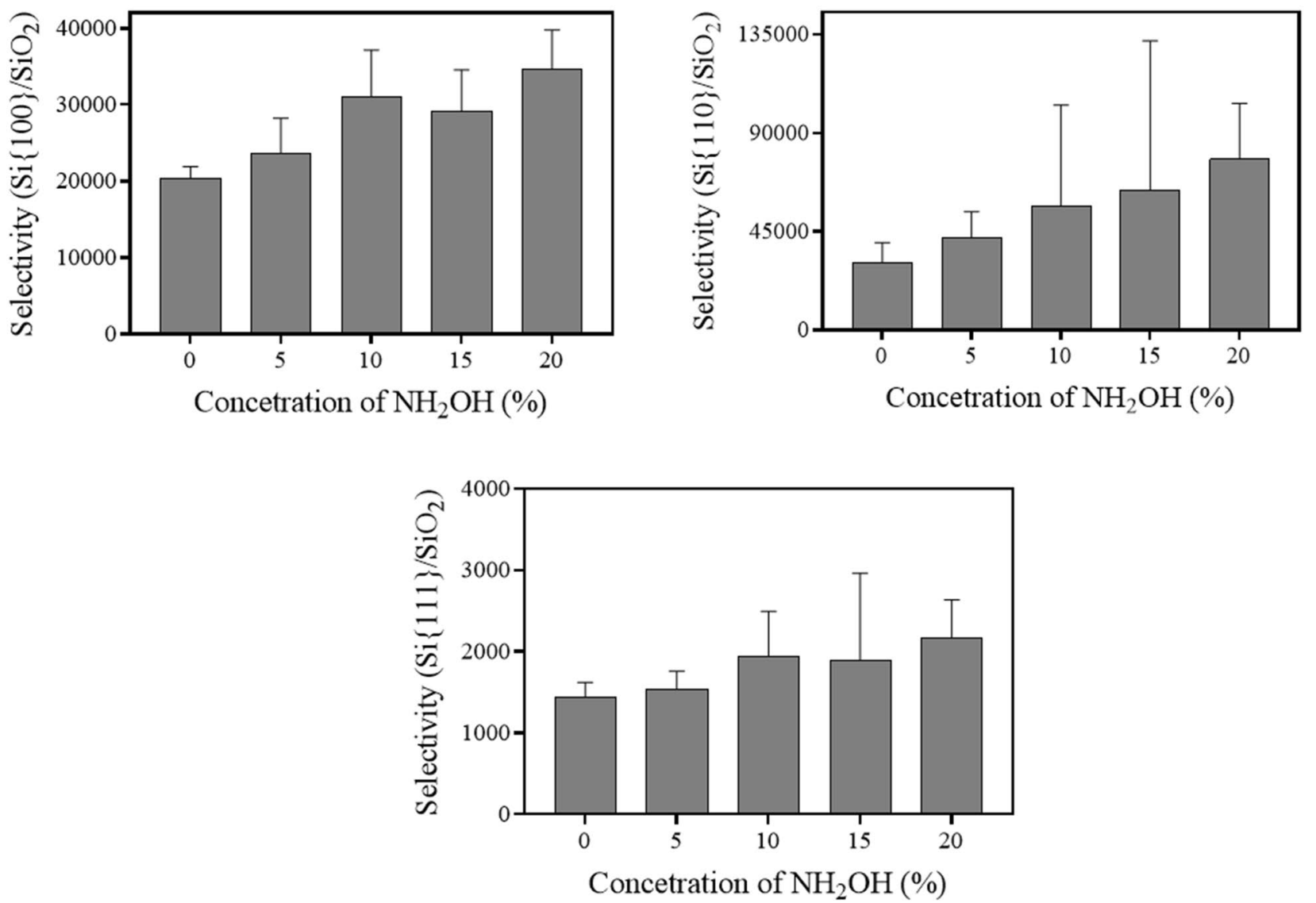

b

Fig. 32 a Etch rate of silicon dioxide and $\mathbf{b}$ the etch selectivity between silicon and silicon dioxide $\left(R_{\mathrm{Si}} / R_{\mathrm{SiO} 2}\right)$ in $5 \mathrm{wt} \% \mathrm{TMAH}$ at $70 \pm 1^{\circ} \mathrm{C}$ without and with addition of $\mathrm{NH}_{2} \mathrm{OH}[50]$ 


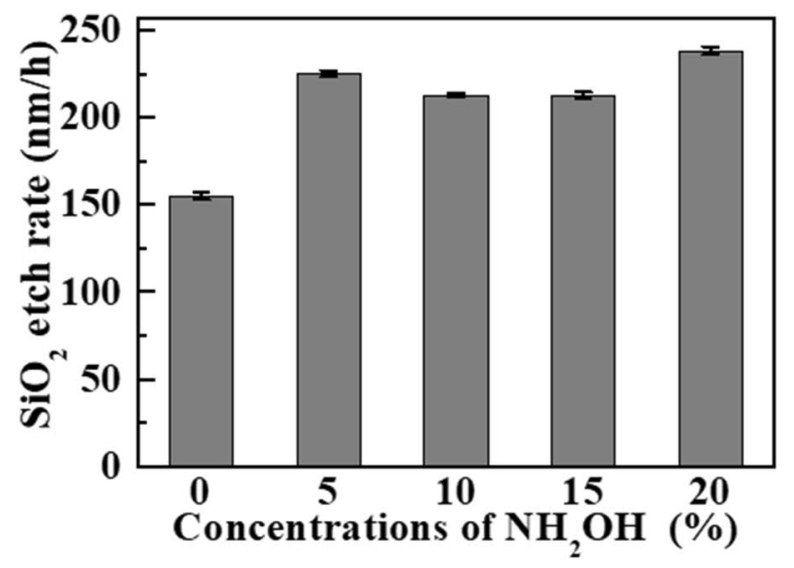

a
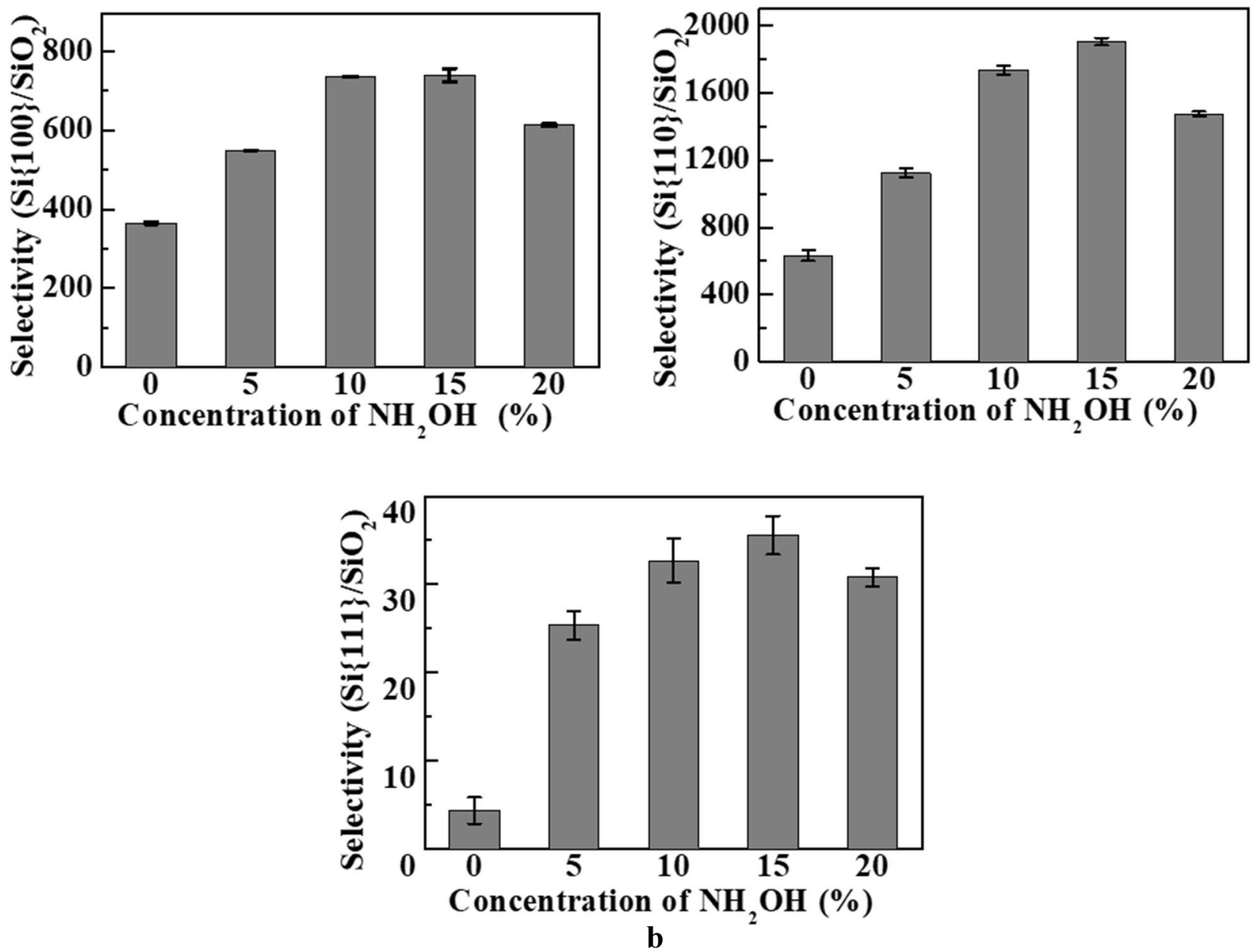

Fig. 33 a etch rate of silicon dioxide and $\mathbf{b}$ the etch selectivity between silicon and silicon dioxide $\left(R_{\mathrm{si}} / R_{\mathrm{siO} 2}\right)$ in 20 wt $\% \mathrm{KOH}$ at $75 \pm 1{ }^{\circ} \mathrm{C}$ without and with varying concentrations of $\mathrm{NH}_{2} \mathrm{OH}$ [51]

of inhomogeneous patterns due to the slow transport of the reactants and/or products. Surface morphology can be explained based on etch rate variation of the crystallographic orientation of silicon, which depends on the local neighbourhood of the exposed surface atoms, dangling bonds, and surface bonds [2]. Etched surface 
morphology and the surface roughness are influenced by the addition of an additive/s. Surfactant and isopropyl alcohol (IPA) are most extensively studied to improve etched surface morphology [3, 7, 27-30, 88-105]. The surfactant is commonly used as an additive in TMAH to obtain smooth etched surface morphology, while IPA is explored as most suitable additive in $\mathrm{KOH}$ to improve etched surface morphology. The present article is focused on the brief overview of etchants and the methods that provide higher etch rate in comparison to conventional etching method using pure alkaline solution. Hence the etched surface results obtained in the etchants providing higher etch rate have been included in this paper.

Figure 34 presents the surface roughness obtained in pure and redox + complexant added 4.5 M KOH [52]. It can easily be noticed that the roughness is reduced by one order of magnitude when redox + complexant is incorporated to $\mathrm{KOH}$. As discussed in previous section and Fig. 23, the addition of SDSS is more effective at higher temperature (i.e. $90-100{ }^{\circ} \mathrm{C}$ ). Figure 35 shows the SEM micrographs and corresponding average roughness of $\mathrm{Si}\{100\}$ surface etched in pure and SDSS added 30 wt $\% \mathrm{KOH}$ and $10 \mathrm{wt} \% \mathrm{TMAH}$ at $90{ }^{\circ} \mathrm{C}$. The addition of SDSS significantly affects the topology of the etched surface in $\mathrm{KOH}$ solution as can be seen in Fig. 35a, b, while it worsens the roughness when added to TMAH as can be observed in Fig. 35c, d.

The etched surface roughness of $\mathrm{Si}\{100\}$ as a function of ammonium persulfate (AP or APS, $\left.\mathrm{NH}_{4}\right)_{2} \mathrm{~S}_{2} \mathrm{O}_{8}$ ) concentration in $10 \mathrm{wt} \%$ TMAH is presented in Fig. 25 [106]. When AP concentration increases, etched surface roughness decreases. The surface roughness is less than $0.1 \mu \mathrm{m}$ when AP concentration in the range between 0.6 and 2.0 wt.\%. However, it becomes rougher if too much AP is incorporated. Figure 36 shows the SEM photographs of the silicon surface etched in $5 \mathrm{wt} \%$ TMAH without and with the addition of AP [106]. It can easily be noticed that the silicon surface improves significantly on the addition of AP. Figure 37 presents the etched surface morphology as a function of ammonium persulfate concentration in $3.2 \mathrm{wt} \%$ Si dissolving $10 \mathrm{wt} . \% \mathrm{TMAH}$ at $80{ }^{\circ} \mathrm{C}$ [108]. It can straightforwardly be noted that the addition of AP suppresses the formation of micropyramids. The effect of AP, pyrazine, and AHS on the etched surface roughness of $\mathrm{Si}\{100\}$ in $10 \mathrm{wt} \% \mathrm{TMAH}$ at $70{ }^{\circ} \mathrm{C}$ is presented in Fig. 27 [109]. The surface roughness is optimum when $2.5 \mathrm{~g} / 500 \mathrm{~mL}$ AP is added. When $0.75 \mathrm{~g}$ of pyrazine is added, the surface roughness is improved to $35.3 \mathrm{~nm}$. In the case of AHS, best surface roughness is obtained when $5.0 \mathrm{~g} / 500 \mathrm{~mL}$ AHS is added to $10 \mathrm{wt} \%$ TMAH. Figure 38 show the SEM images of etched surfaces of $\operatorname{Si}\{100\}$ with the addition of various concentration ammonium persulfate (AP) in $10 \mathrm{wt} \% \mathrm{TMAH}$ at $70{ }^{\circ} \mathrm{C}$ [109]. The number of hillocks decreased significantly when $1.0 \mathrm{~g}$ or $2.5 \mathrm{~g} / 500 \mathrm{~mL}$ AP is added. The cleanest etched surface is obtained when $2.5 \mathrm{~g}$ of AP is added. It can be emphasized here that the addition of ammonium peroxodisulfate (AP) helps to reduce hillocks and at the same time increase the silicon etching rate.

Figures 39, 40, 41 show the etched surface roughness and morphology of $\operatorname{Si}\{100\}, \operatorname{Si}\{110\}$, and $\operatorname{Si}\{111\}$, respectively, in pure and different concentrations of $\mathrm{NH}_{2} \mathrm{OH}$-added 5 wt\% TMAH [50, 60-62]. The surface roughness of $\mathrm{Si}\{100\}$ gradually decreases as the concentration of $\mathrm{NH}_{2} \mathrm{OH}$ increases. It decreases by an order of magnitude for $\mathrm{NH}_{2} \mathrm{OH}$ concentration of $10 \%$ or more. The surface roughness of $\mathrm{Si}\{110\}$ and $\mathrm{Si}\{111\}$ is not influenced significantly when $\mathrm{NH}_{2} \mathrm{OH}$ is added to TMAH. As $10 \% \mathrm{NH}_{2} \mathrm{OH}$-added TMAH provides maximum etch rate, the same etchant composition is suitable to obtain a smoother surface in comparison to pure TMAH.

Figures 42, 43, 44 present the etched surface roughness and morphology of $\mathrm{Si}\{100\}, \mathrm{Si}\{110\}$ and $\mathrm{Si}\{111\}$, respectively, in $20 \mathrm{wt} \% \mathrm{KOH}$ solution without and with addition of various concentrations of $\mathrm{NH}_{2} \mathrm{OH}$ [51, 63-65]. Although surface roughness of $\mathrm{Si}\{100\}$ reduces with increase of $\mathrm{NH}_{2} \mathrm{OH}$ concentration, it is not considerably changed in comparison to pure $\mathrm{KOH}$. The etched surface

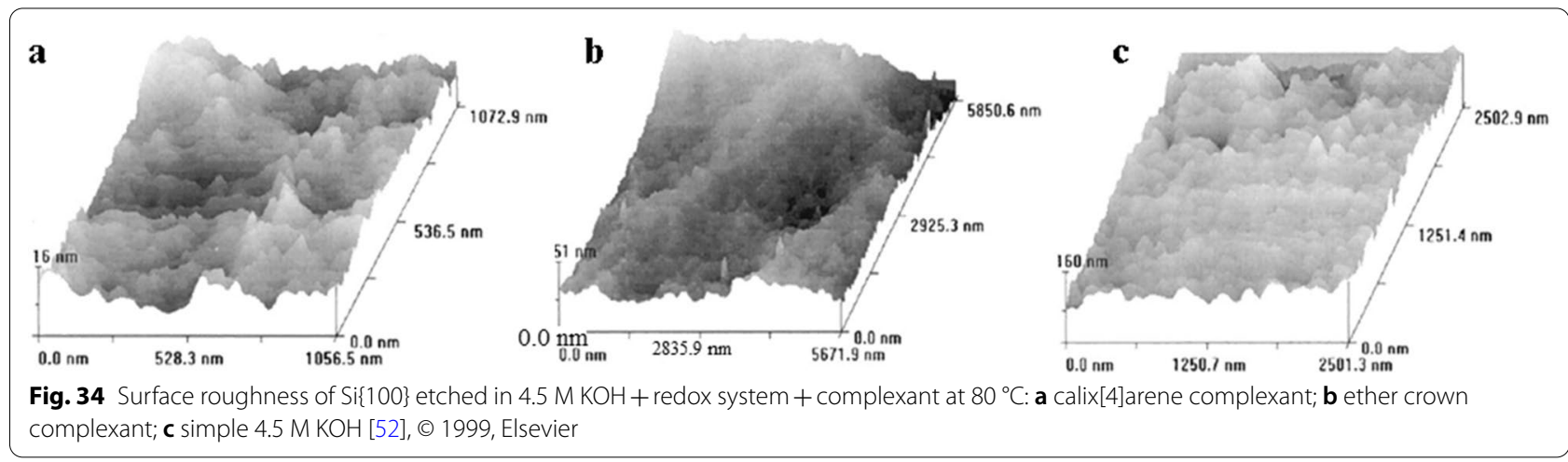




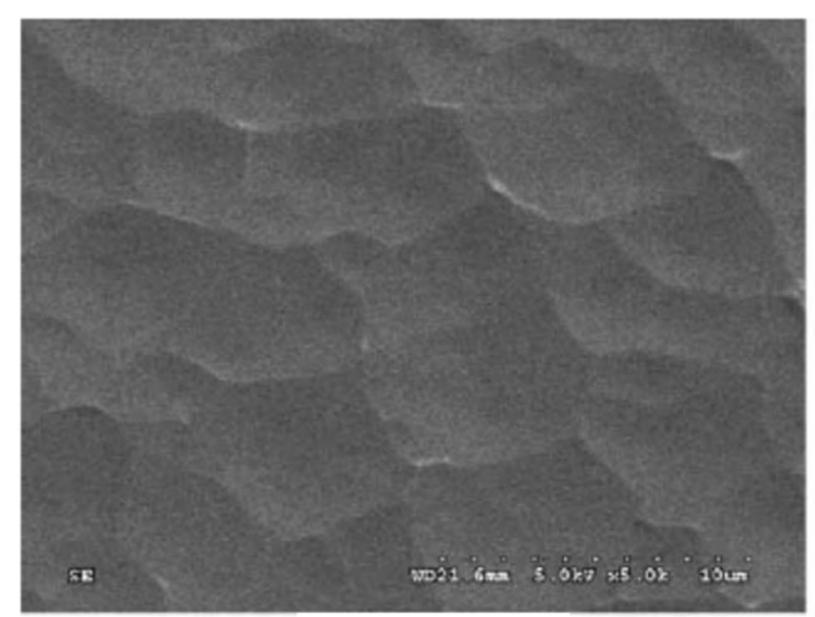

a $\operatorname{Ra} 58 \mathrm{~nm}$

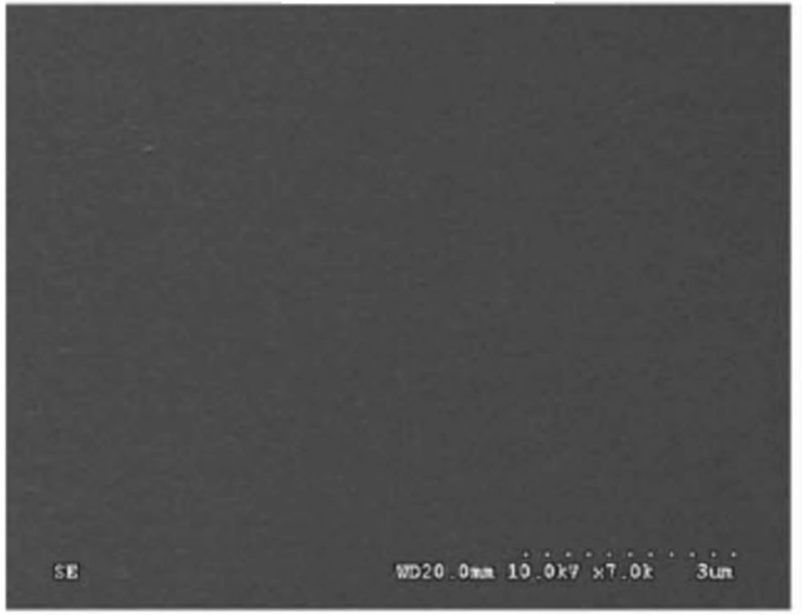

b $\operatorname{Ra} 7.6 \mathrm{~nm}$

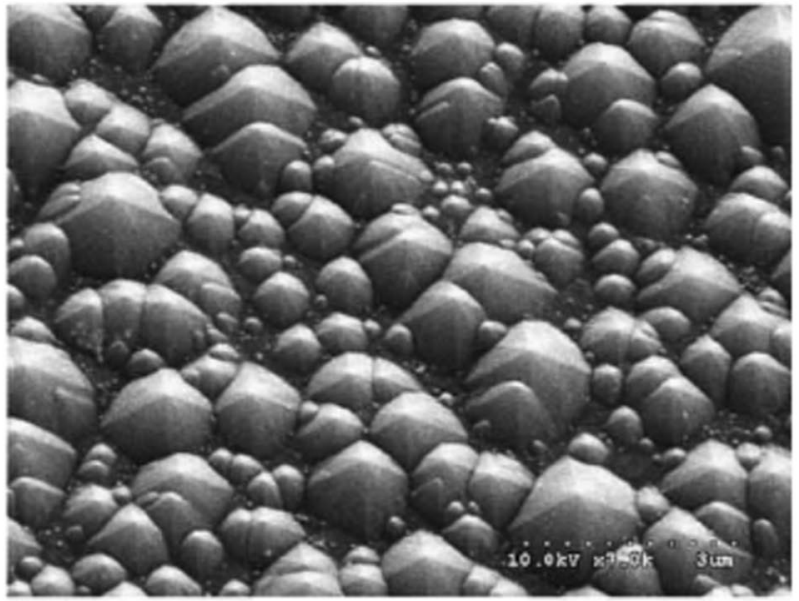

c $\mathrm{Ra} 100 \mathrm{~nm}$

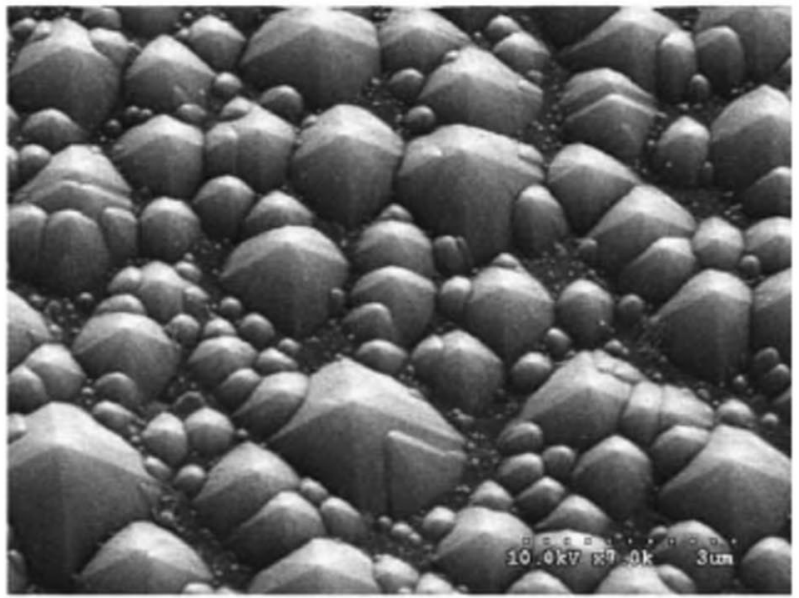

d Ra $200 \mathrm{~nm}$

Fig. 35 SEM micrographs and average roughness of etched surfaces in pure and SDSS-added $30 \mathrm{wt} \% \mathrm{KOH}$ and $10 \mathrm{wt} \% \mathrm{TMAH}$ at $90^{\circ} \mathrm{C}: \mathbf{a}$ pure $\mathrm{KOH}$, b $\mathrm{KOH}+$ SDSS, c pure TMAH, d TMAH + SDSS [56], ๑ 2005, Elsevier

of $\operatorname{Si}\{\{110\}$ is full of zig-zag patterns. Average surface roughness $(\mathrm{R} a)$ of the samples etched in $\mathrm{NH}_{2} \mathrm{OH}$-added $20 \mathrm{wt} \% \mathrm{KOH}$ solution is not significantly different as those are etched in pure $20 \mathrm{wt} \% \mathrm{KOH}$. It means that the etched surface of $\mathrm{Si}\{110\}$ is not affected considerably when $\mathrm{NH}_{2} \mathrm{OH}$ is added into $\mathrm{KOH}$ solution. The etched $\mathrm{Si}\{111\}$ surface is typically very smooth as it is a slowest etch rate plane in wet anisotropic etchant. It can easily be observed from Fig. 44. that the surface roughness in modified $\mathrm{KOH}$ solution affected marginally. A qualitative comparison of the effect of various kinds of additives on the etched surface of silicon in TMAH and $\mathrm{KOH}$ solution is presented in Tables 4 and 5 , respectively. It may be emphasized here that the etched surface morphology is a strong function of many parameters such as etching temperature, etchant concentration, types of additive, purity of the etchant, unwanted impurity incorporated during process, cleanliness of silicon surface, etc. Hence the etched surface morphology in same concentration etchant and etching temperature may vary from one experiment to another and one laboratory to another laboratory. 

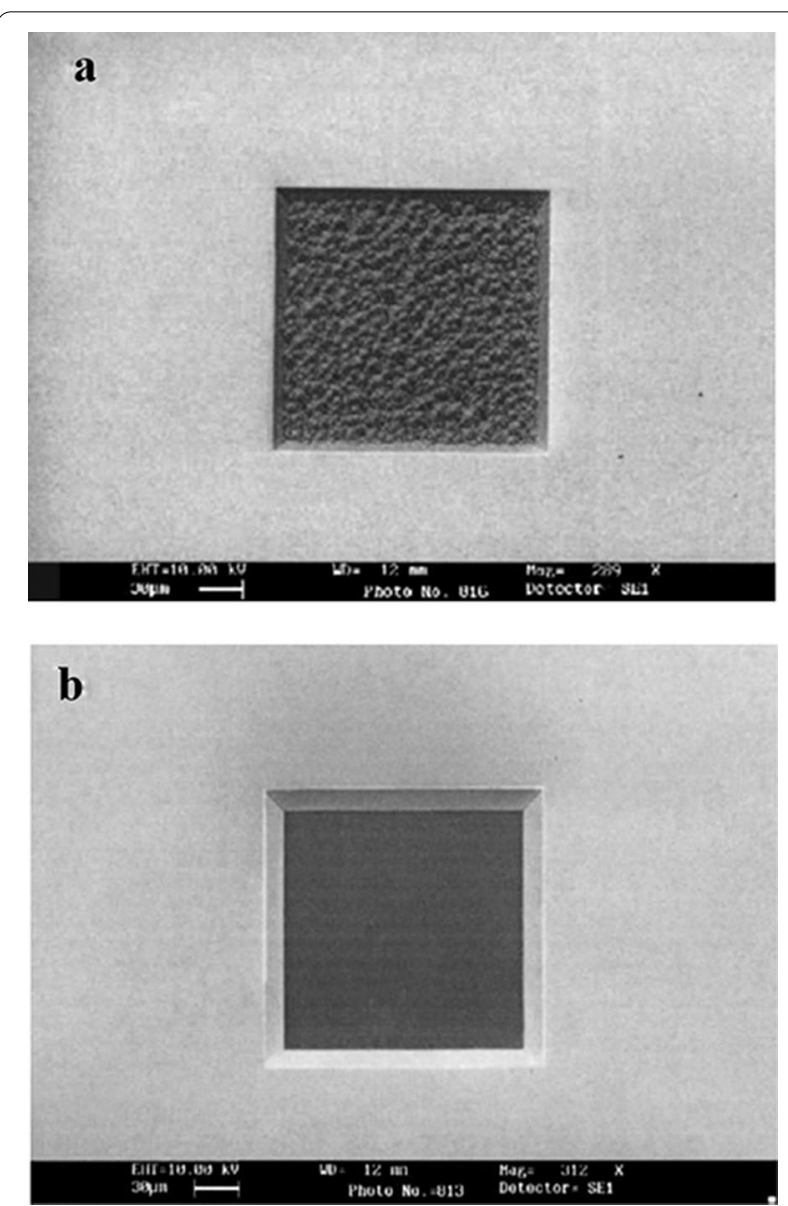

Fig. 36 SEM micrographs of etched silicon surfaces with dissolved $1.6 \mathrm{wt} \%$ silicon a without and $\mathbf{b}$ with $0.5 \mathrm{wt} \%\left(\mathrm{NH}_{4}\right)_{2} \mathrm{~S}_{2} \mathrm{O}_{8}$ in $5 \mathrm{wt} \%$ TMAH [106], @ 2001, Elsevier

As discussed previously in etch rate "Etch rate" section, the $\mathrm{NH}_{2} \mathrm{OH}$ is an unstable solution and decomposes in the presence of alkaline solutions. Therefore, the effect of etchant age on the etched surface roughness and morphology is investigated in the optimal composition of $\mathrm{NH}_{2} \mathrm{OH}$-added TMAH/KOH (i.e. $10 \% \mathrm{NH}_{2} \mathrm{OH}+5$ wt $\%$ TMAH and $15 \% \mathrm{NH}_{2} \mathrm{OH}-20$ wt $\% \mathrm{KOH}$ ), which provides the highest etch rate of silicon with improved etched surface morphology. To observe the aging effect, the same etchant solution is continuously used for one week and the experiments are performed at regular time interval. Figures 45, 46, 47 show the average surface roughness and the corresponding morphology of $\operatorname{Si}\{100\}, \operatorname{Si}\{110\}$ and $\mathrm{Si}\{111\}$, respectively in $\mathrm{NH}_{2} \mathrm{OH}$-added $\mathrm{TMAH}$, whereas Figs. 48, 49, 50 present the same for $\operatorname{Si}\{100\}$, $\mathrm{Si}\{110\}$ and $\mathrm{Si}\{111\}$, respectively, in $\mathrm{NH}_{2} \mathrm{OH}$-added $\mathrm{KOH}$
[50, 51, 60-65]. Although the etchant age influences the etched surface roughness and morphology, it is not significant like etch rate presented in previous section. The etch rate decreases with the age of the etchant. Hence it is recommended that the $\mathrm{NH}_{2} \mathrm{OH}$-added TMAH/KOH should be used immediately after preparation of the solution to achieve higher etch rate and better etched surface morphology.

\section{Undercutting}

The removal of bulk material at mask edges and convex corners is termed as undercutting. MEMS and NEMS (nanoelectromechanical systems)-based sensors and actuators usually employ freestanding structures like cantilevers, fixed-fixed beams, diaphragms, etc. To fabricate such structures, the phenomenon of undercutting is employed, which removes the underneath material of the masking layer and ultimately results in freestanding structures [1-6, 118-122]. In the case of a microstructure with free end, undercutting at the convex corner is inevitable. At the same time, convex corner undercutting is undesirable to fabricate mesa structures for applications in accelerometer and other sensors [118-123]. Various methods have been proposed to recess undercutting which includes altering the etching characteristics by addition of surfactants, employing corner compensation methods where the additional mask is provided at the convex corners to delay the etching at the convex corners, etc. $[118,119]$. To decrease the release time of suspended structure to improve industrial production and/or to minimize the exposure of structural layer in the etching solution, high undercutting is inevitable. Therefore, an etchant composition providing high undercutting is greatly desirable in silicon wet bulk micromachining. Undercutting length at convex corners $(l)$, etch depth $(d)$, and etch time $(t)$ are used to define the undercutting rate $(l / t)$, and undercutting ratio $(l / d)$, which are very important parameters to estimate the release time for the fabrication of overhanging structures using wet anisotropic etching $[118,119]$.

To study the undercutting at $\operatorname{Si}\{100\}$ surface, usually, rectangular shape mask pattern formed by $<110>$ directions is used as schematically presented in Fig. 51. To calculate the undercutting rate and undercutting ratio, the undercutting length is measured along $<110>$ directions (i.e., $\left.l_{<110\rangle}\right)$. As discussed in previous sections, the addition of Pyrazine, AP, and AHS in TMAH increases the etching rate effectively and improves the surface flatness. However, these additives do not affect undercutting significantly [109]. Figure 52 shows the undercutting at 


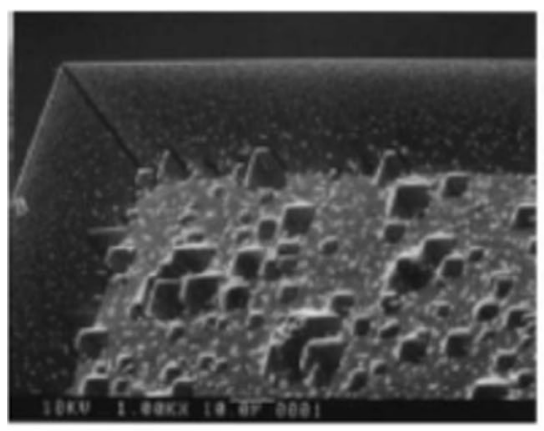

a

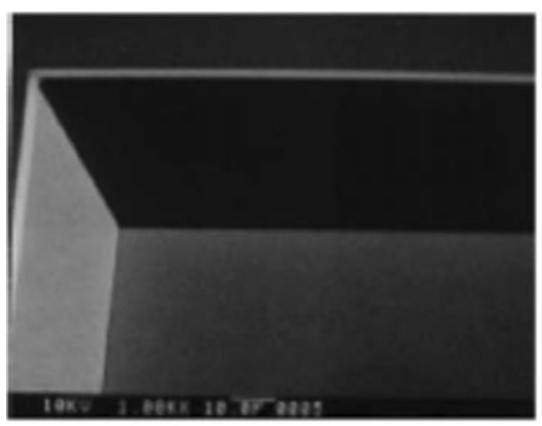

d

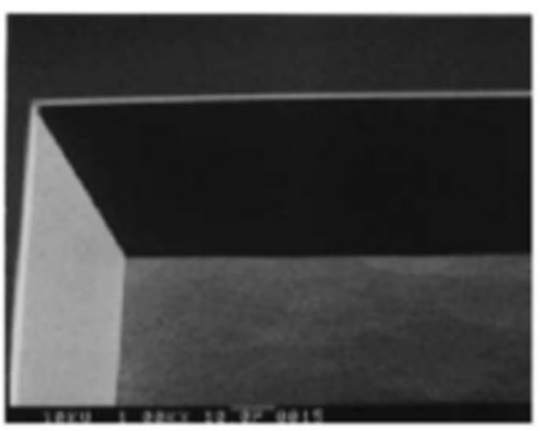

b

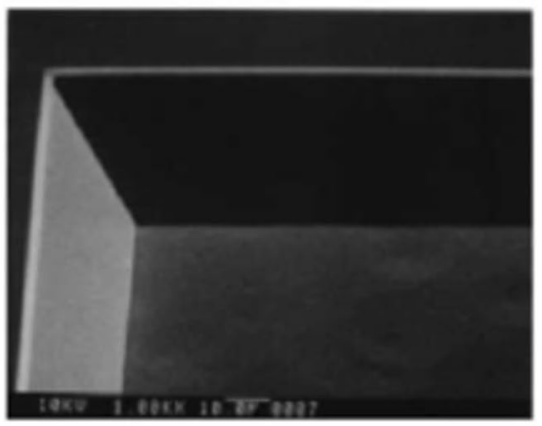

e

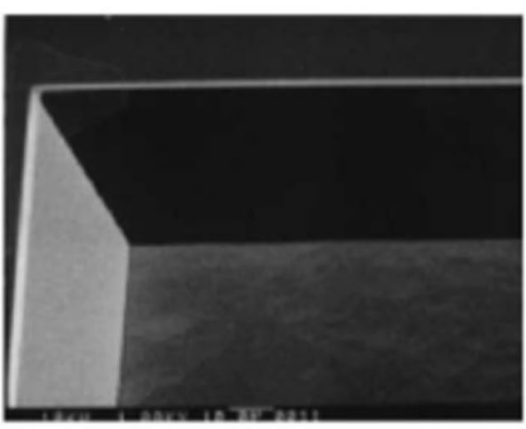

g

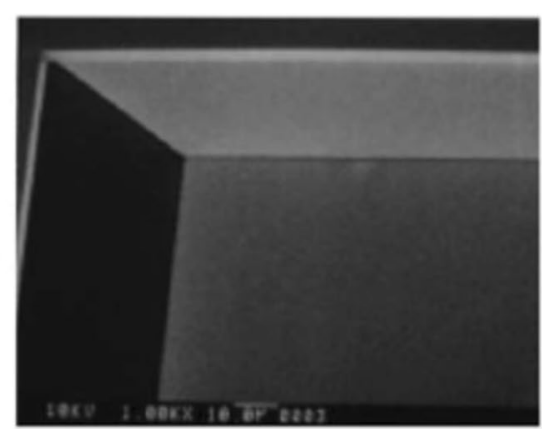

c

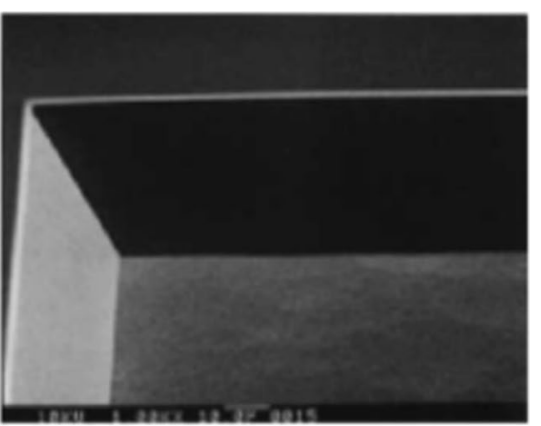

f

Fig. 37 SEM photographs of etched Si\{100\} in 3.2 wt.\% Si dissolving 10 wt. $\%$ TMAH at $80^{\circ} \mathrm{C}$ with addition of a 0 wt $\%$, b 0.2 wt $\%, \mathbf{c} 0.4$ wt $\%$, d 0.6 $w t \%$, e $0.8 \mathrm{wt} \%, \mathbf{f} 1.0 \mathrm{wt} \%, \mathbf{g} 1.2 \mathrm{wt} \%$, ammonium persulfate (AP) [108], ๑ 2004, Elsevier

convex corners on $\mathrm{Si}\{100\}$ surface without and with addition of various concentrations of ammonium persulfate (AP) in $10 \mathrm{wt} \% \mathrm{TMAH}$ at $70{ }^{\circ} \mathrm{C}[109]$. The undercutting ratio at $2.5 \mathrm{~g} / 500 \mathrm{~mL}$, at which the optimal etching rate and the surface roughness are achieved, is almost identical to that of the pure TMAH solution. Figures 53 and 54 present the undercutting rate $\left(l_{<110>} / \mathrm{t}\right)$ in pure and different concentrations of $\mathrm{NH}_{2} \mathrm{OH}$-added $5 \mathrm{wt} \% \mathrm{TMAH}$ and $20 \mathrm{wt} \% \mathrm{KOH}$, respectively. The undercutting rate increases with increase of $\mathrm{NH}_{2} \mathrm{OH}$ concentration and starts decreasing after certain concentration of $\mathrm{NH}_{2} \mathrm{OH}$. In the case of TMAH, it becomes maximum when
$\mathrm{NH}_{2} \mathrm{OH}$ concentration reaches $10 \%$ as can be seen in Fig. 53, while in $\mathrm{KOH}$ the highest value is achieved when $\mathrm{NH}_{2} \mathrm{OH}$ concentration reaches $15 \%$ as can be noticed in Fig. 54. The undercutting at convex corners occurs due to the appearance of high index planes during etching process $[3,118,119]$. Hence the increase in undercutting indicates that the etch rate of high index planes also dramatically improves when $\mathrm{NH}_{2} \mathrm{OH}$ is added into $\mathrm{TMAH} / \mathrm{KOH}$. The increment in undercutting is more than three times to that in pure $\mathrm{TMAH} / \mathrm{KOH}$, which is highly advantageous for the fast release of structure from substrate to minimize industrial manufacturing time. The 

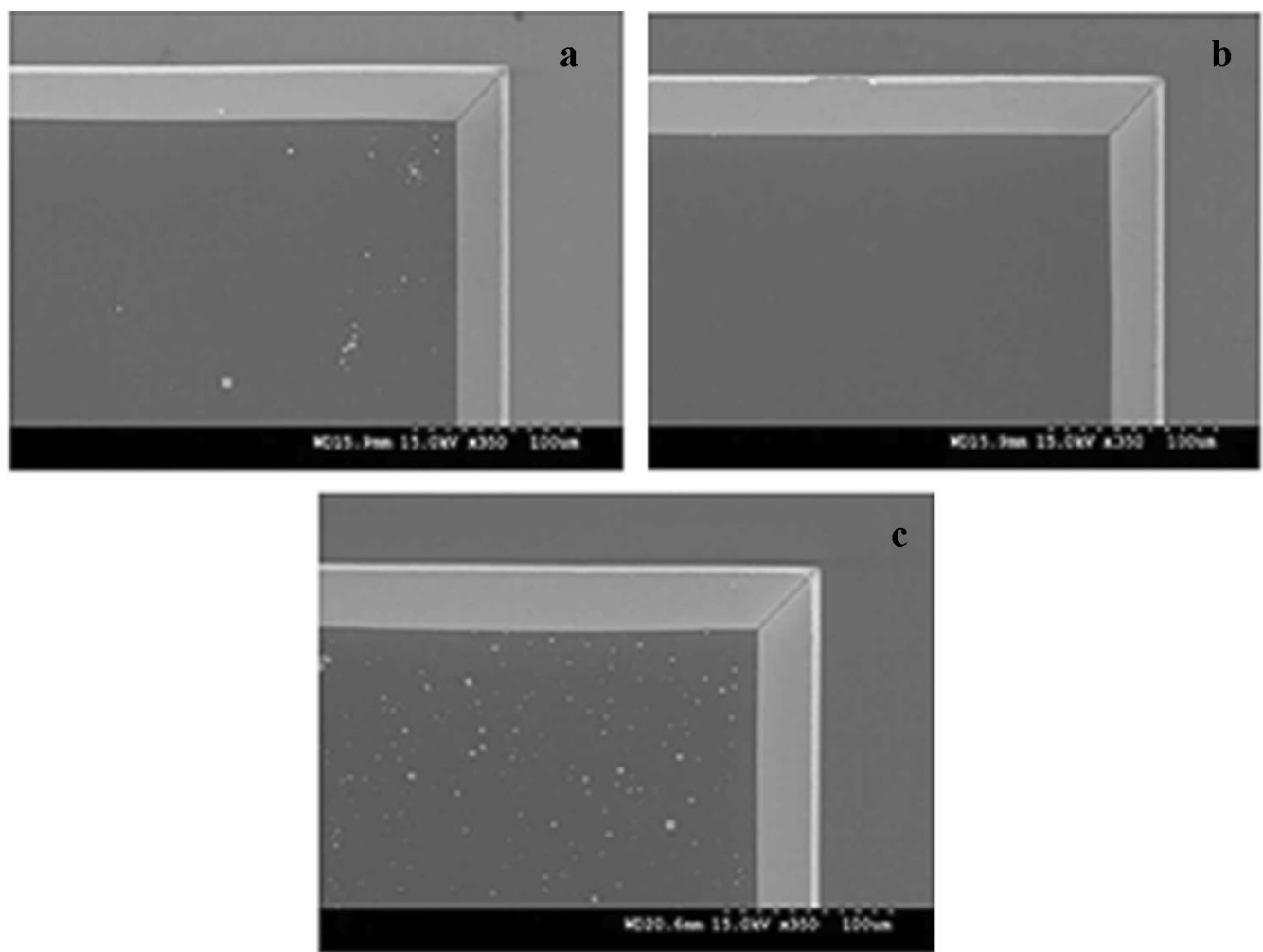

Fig. 38 SEM images of the etched Si\{100\} surface with various concentrations of ammonium persulfate (AP): a $1.0 \mathrm{~g} \mathrm{AP,} \mathrm{b} 2.5 \mathrm{~g}$ AP, c $5.0 \mathrm{~g}$ AP in per $500 \mathrm{~mL} 10 \mathrm{wt} \% \mathrm{TMAH}$ at $70{ }^{\circ} \mathrm{C}[109]$, @ 2015, Springer

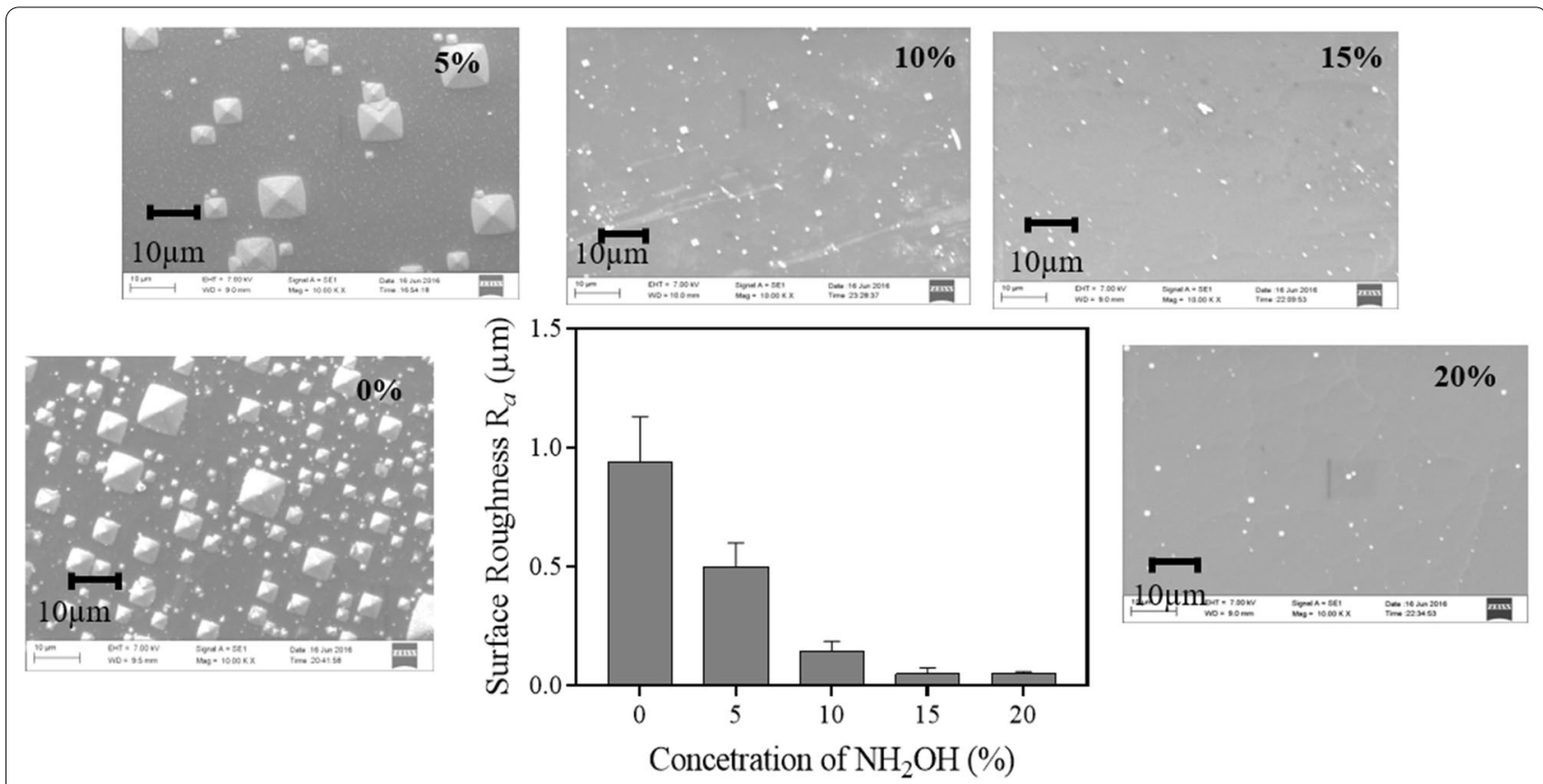

Fig. 39 Etched surface roughness $(\mathrm{Ra})$ and corresponding surface morphologies of $\mathrm{Si}\{100\}$ in pure and different concentrations of $\mathrm{NH}_{2} \mathrm{OH}$ added 5 wt $\%$ TMAH at $70 \pm 1{ }^{\circ} \mathrm{C}[50]$ 


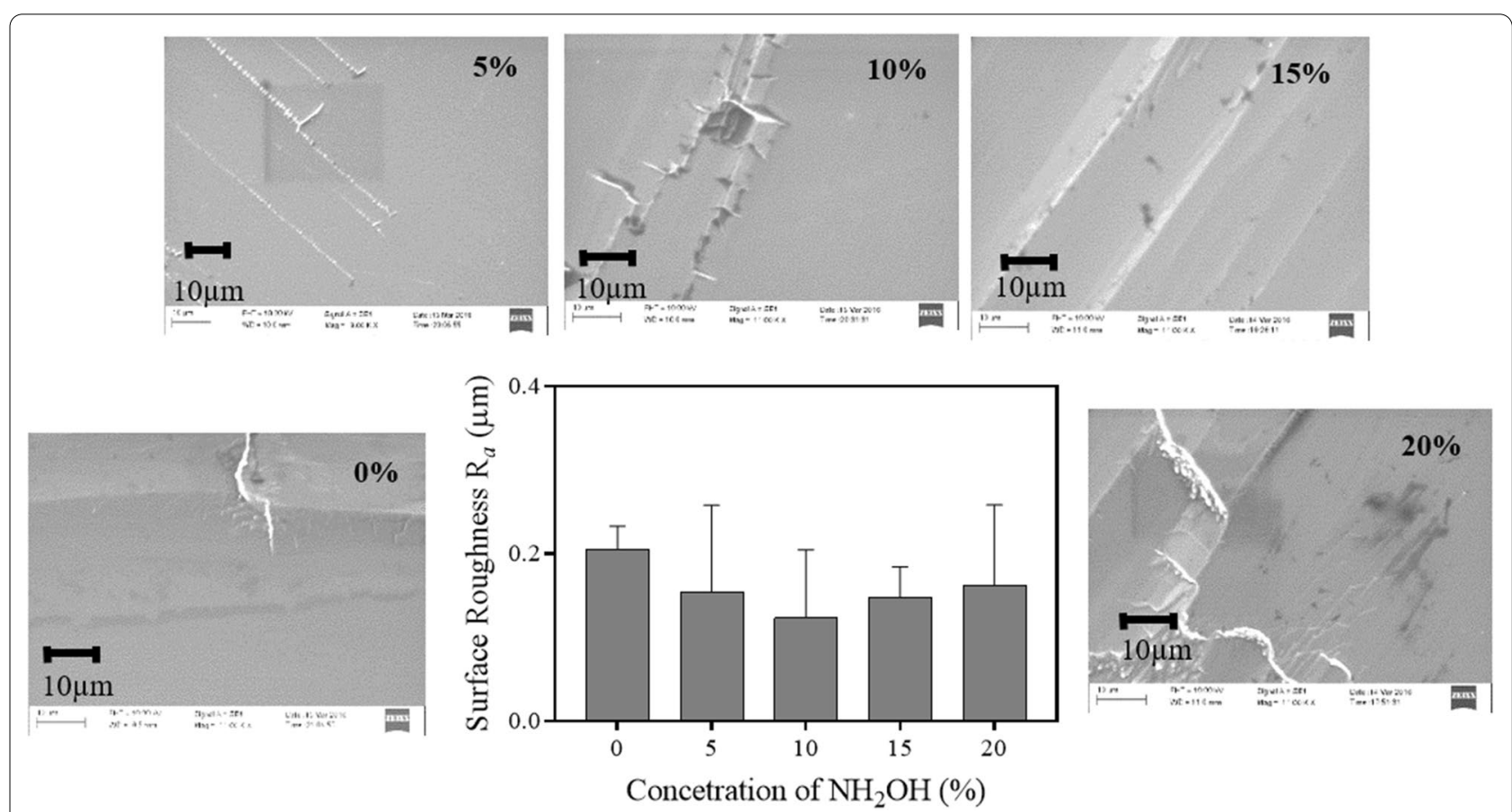

Fig. 40 Etched surface roughness (Ra) and corresponding surface morphologies of $\mathrm{Si}\{110\}$ in pure and different concentrations of $\mathrm{NH}_{2} \mathrm{OH}$ added 5 wt $\%$ TMAH at $70 \pm 1{ }^{\circ} \mathrm{C}[50]$

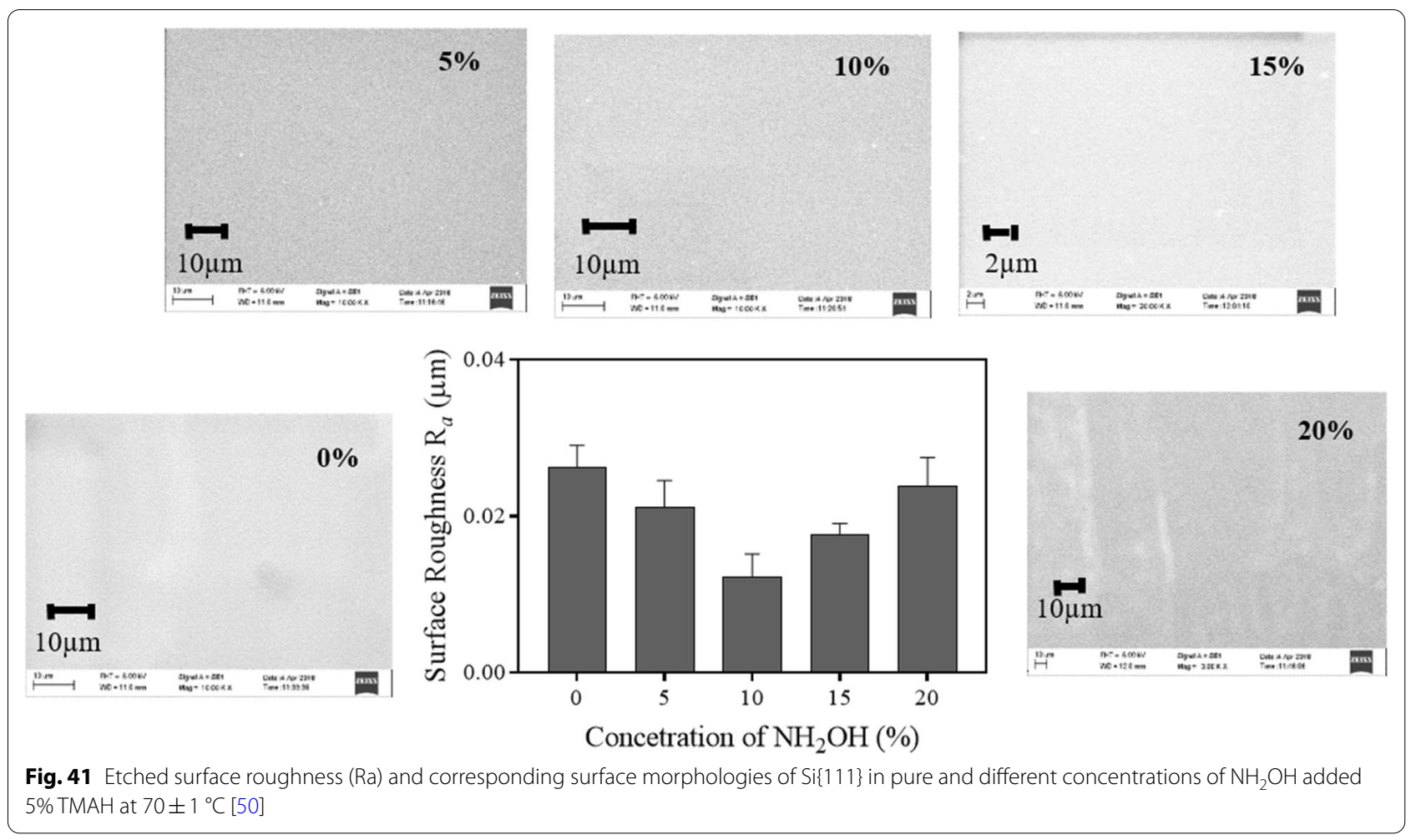




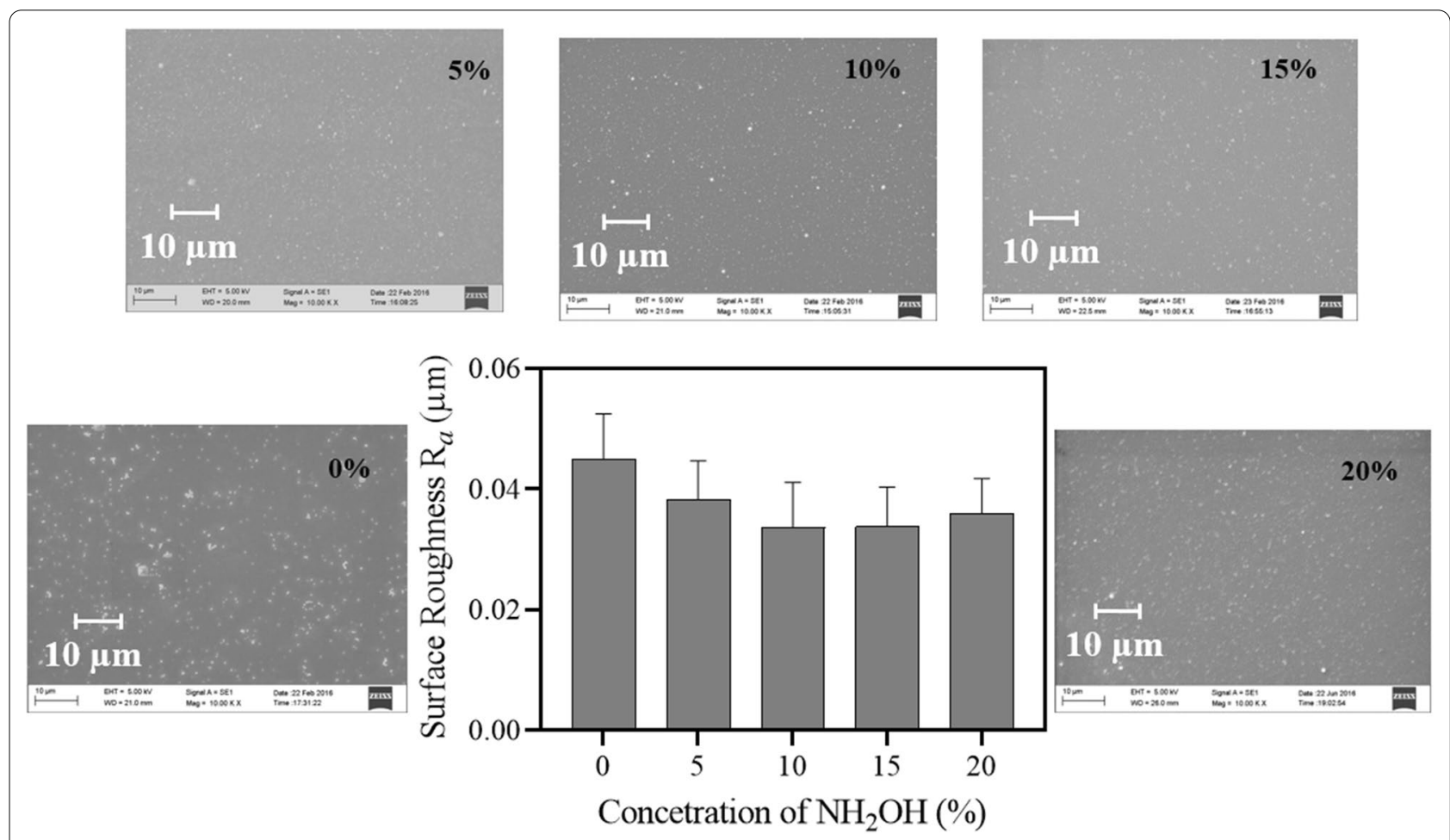

Fig. 42 Etched surface roughness $(\mathrm{Ra})$ and corresponding surface morphologies of $\mathrm{Si}\{100\}$ in pure and different concentrations of $\mathrm{NH}_{2} \mathrm{OH}$ added $20 \mathrm{wt} \% \mathrm{KOH}$ at $75 \pm 1{ }^{\circ} \mathrm{C}[51]$

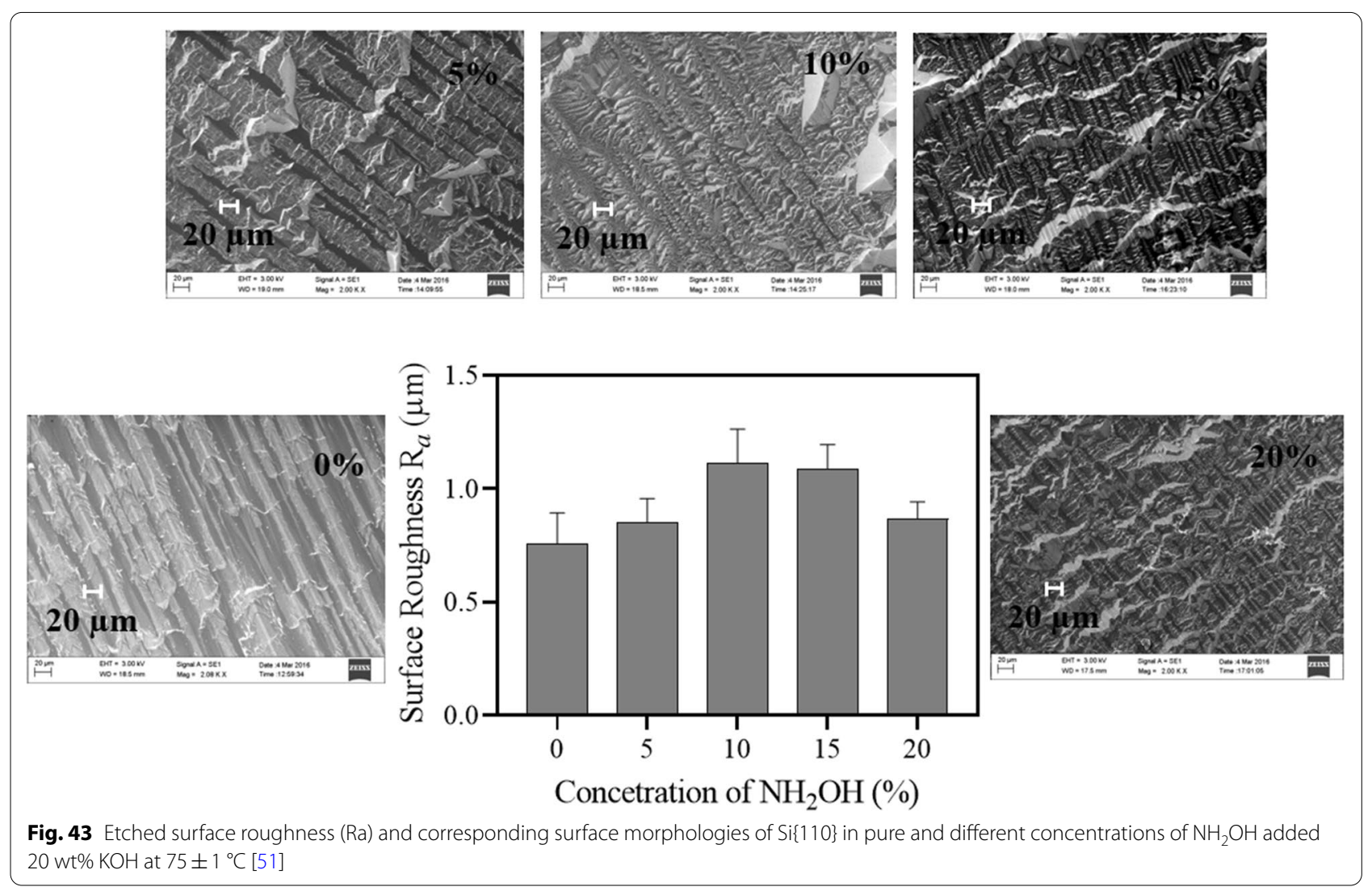




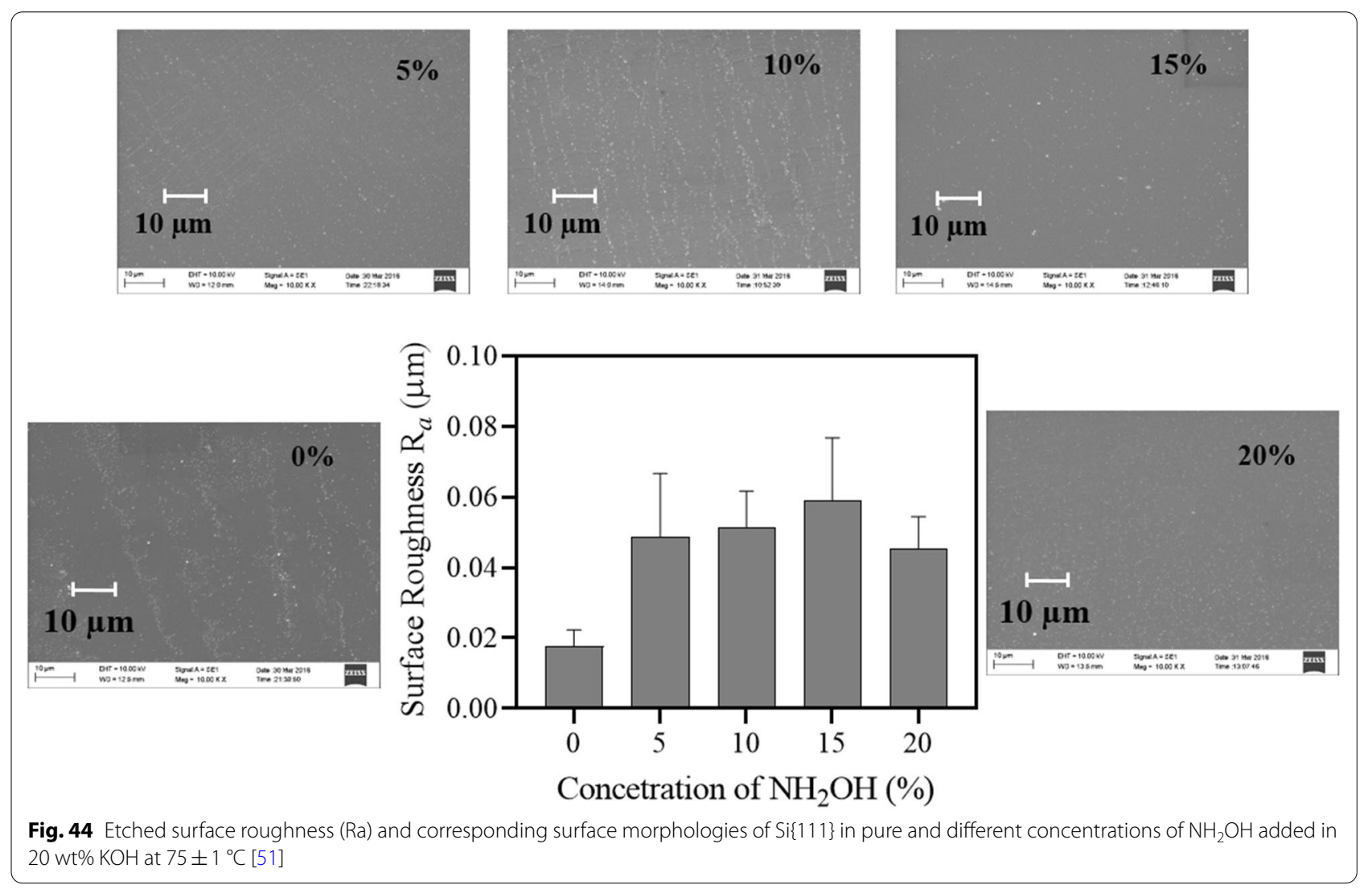

Table 4 The effect of various kinds of additives on etched surface roughness of silicon in TMAH solution

\begin{tabular}{|c|c|c|c|c|c|}
\hline Authors & Additive's name & Orientation of silicon & TMAH Conc & Temp. $\left({ }^{\circ} \mathrm{C}\right)$ & Surface roughness \\
\hline C-R Yang et al. [56] & $\begin{array}{l}\text { Anionic sodium dihexyl sulfos- } \\
\text { uccinate (SDSS) }\end{array}$ & $\{100\}$ & 10 wt.\% & $60-100$ & Increase \\
\hline GYan et al. [106] & Ammonium persulfate (AP) & $\{100\}$ & $5,10 w t \%$ & 85 & Decrease \\
\hline N Fujitsuka et al. [108] & Ammonium persulfate (AP) & $\{100\}$ & 10 wt.\% & 80 & Decrease \\
\hline K-H Jun et.al [109] & $\begin{array}{l}\text { Pyrazine, Ammonium persulfate } \\
\text { (AP) }\end{array}$ & $\{100\}$ & $10 w t \%$ & 70 & Decrease \\
\hline S. Birda et al. [107] & Ammonium persulfate (AP) & $\{100\}$ & $5-10$ wt.\% & $70-90$ & Decrease \\
\hline E.H. Klaassen et al. [111] & Ammonium peroxydisulfate & $\{100\}$ & 5 wt. $\%$ & $70-100$ & Not reported \\
\hline R. Sotoaka [55] & $\begin{array}{l}\text { Maltose, Glucose, } \mathrm{NH}_{2} \mathrm{OH} \text {, Cel- } \\
\text { lobiose }\end{array}$ & $\{100\}$ & $10 w t \%$ & 80 & Not reported \\
\hline V. Swarnalatha et al.[50, 60-62] & $\mathrm{NH}_{2} \mathrm{OH}$ & $\{100\},\{110\}$ and $\{111\}$ & $5 w t \%$ & 70 & $\begin{array}{l}\text { Surface roughness of }\{100\} \\
\text { decreases significantly, } \\
\text { while }\{110\} \text { and }\{111\} \text { are } \\
\text { not affected considerably }\end{array}$ \\
\hline
\end{tabular}


Table 5 The effect of various kinds of additives on the etched surface of silicon in KOH solution

\begin{tabular}{|c|c|c|c|c|c|}
\hline Authors & Additive's name & Orientation of $\mathrm{Si}$ & $\mathrm{KOH}$ Conc & Temp. $\left({ }^{\circ} \mathrm{C}\right)$ & Effect on surface roughness \\
\hline C. Moldovan et al. [52] & Redox + complexant & $\{100\}$ & $4.5 \mathrm{M}$ & 80 & Decrease \\
\hline C-R Yang et al. [56] & Anionic sodium dihexyl sulfosuccinate (SDSS) & $\{100\}$ & $30 \mathrm{wt} \%$ & $60-100$ & Decrease \\
\hline R. Sotoaka [55] & Maltose, Glucose, $\mathrm{NH}_{2} \mathrm{OH}$, Cellobiose & $\{100\}$ & $25 w t \%$ & 80 & Not reported \\
\hline $\begin{array}{l}\text { A. V. Narasimha Rao } \\
\text { et al. [51, 63-65] }\end{array}$ & $\mathrm{NH}_{2} \mathrm{OH}$ & $\{100\},\{110\}$ and $\{111\}$ & $20 w t \%$ & 75 & No significant change \\
\hline
\end{tabular}

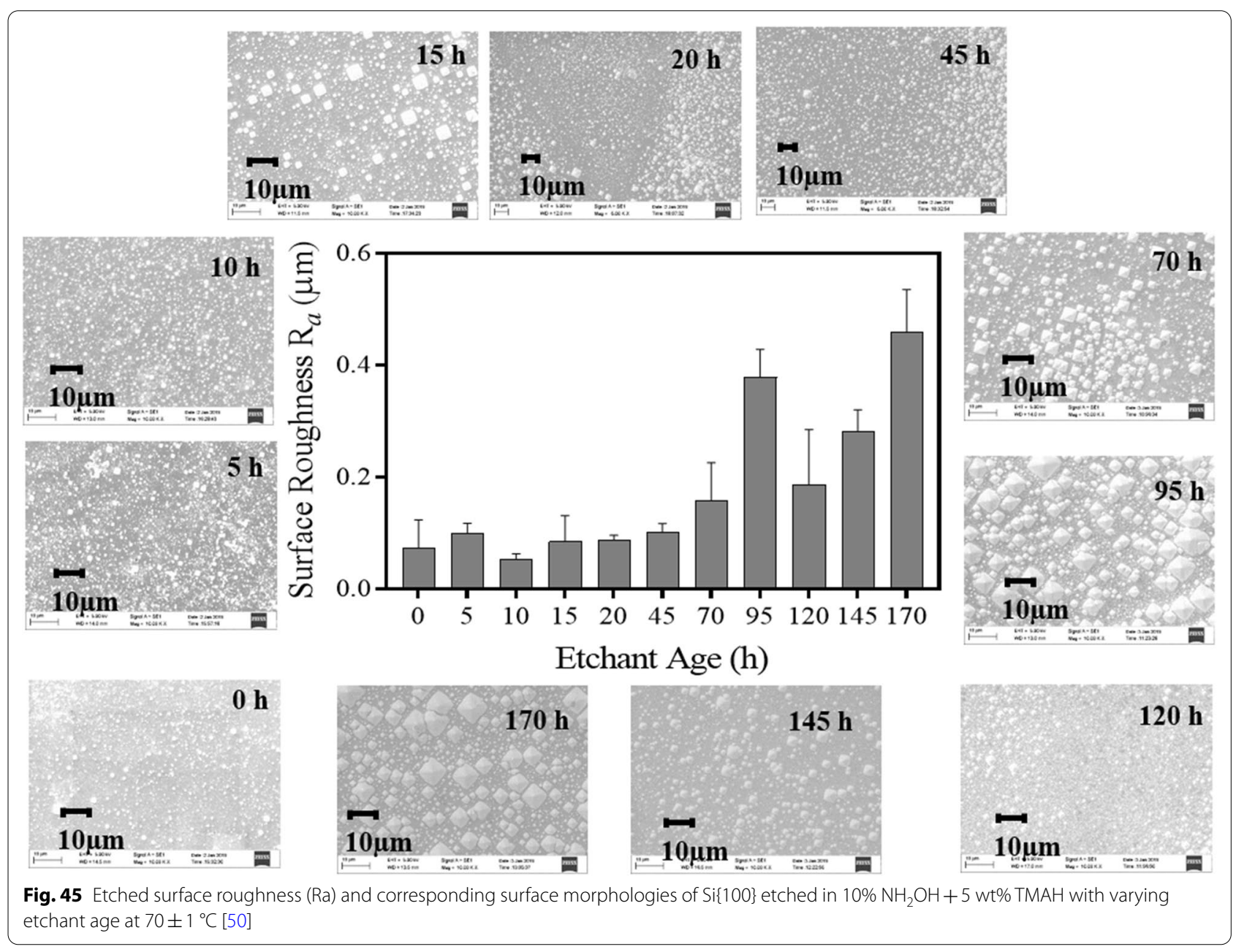

undercutting ratio $(l / d)$ can be calculated by dividing the undercutting ratio by etch rate.
$\mathrm{Si}\{110\}$ wafer is a primary choice when the microstructures with vertical sidewalls formed by $\{111\}$ planes are fabricated using wet anisotropic etching [124-131]. 


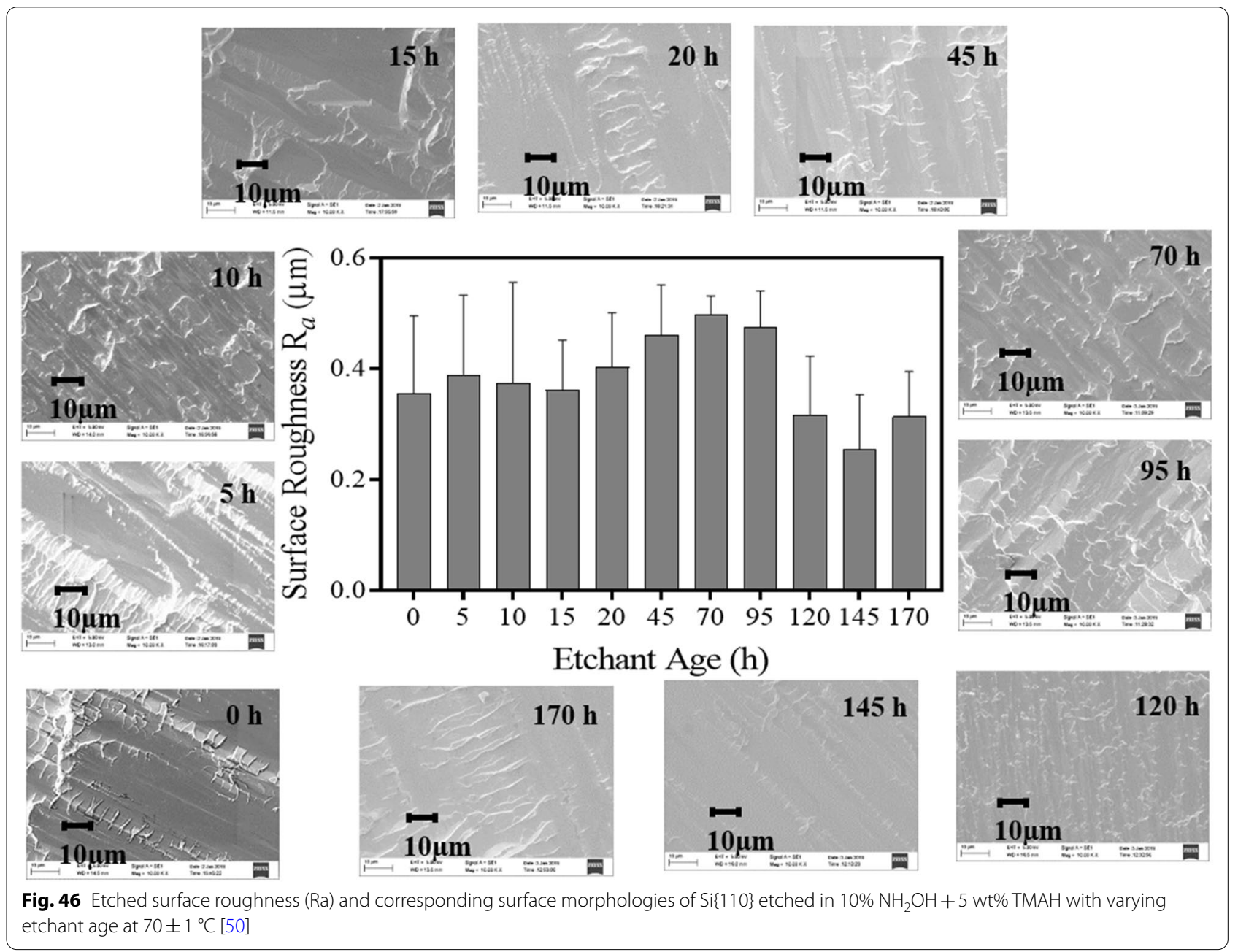

These vertical sidewalls appear at $<112>$ directions which form a rhombus shape structure containing two types of convex corners (acute and obtuse corners) as illustrated in Fig. 55. To study the undercutting in pure and $\mathrm{NH}_{2} \mathrm{OH}$-added $\mathrm{TMAH} / \mathrm{KOH}$, undercutting length along $<112>$ directions are measured on both acute and obtuse convex corners. The undercutting rates at acute $\left(l_{a} / t\right)$ and obtuse $\left(l_{o} / t\right)$ convex corners in different concentrations of $\mathrm{NH}_{2} \mathrm{OH}$-added TMAH are presented in Figs. 56 and 57, respectively. Figures 58 and 59 show the undercutting rates at acute $\left(l_{a} / t\right)$ and obtuse $\left(l_{o} / t\right)$ corners in various concentrations of $\mathrm{NH}_{2} \mathrm{OH}$-added $\mathrm{KOH}$, respectively. In both types of etchant compositions, undercutting rate at acute and obtuse corners significantly increases as the concentration of $\mathrm{NH}_{2} \mathrm{OH}$ increases and attains maximum value when $\mathrm{NH}_{2} \mathrm{OH}$ concentration reaches to a certain value. A qualitative comparison of the effect of different kinds of additives on the undercutting at convex corners in TMAH and $\mathrm{KOH}$ solution is presented in Tables 6 and 7, respectively.

$\mathrm{Si}\{111\}$ planes are slowest etching rate planes in all kinds of wet anisotropic etchants. Hence $\mathrm{Si}\{111\}$ wafer is rarely used for the fabrication of MEMS components if only wet anisotropic etching is used. However, it is very useful to fabricate complicated structures using deep reactive ion etching (DRIE) assisted wet 


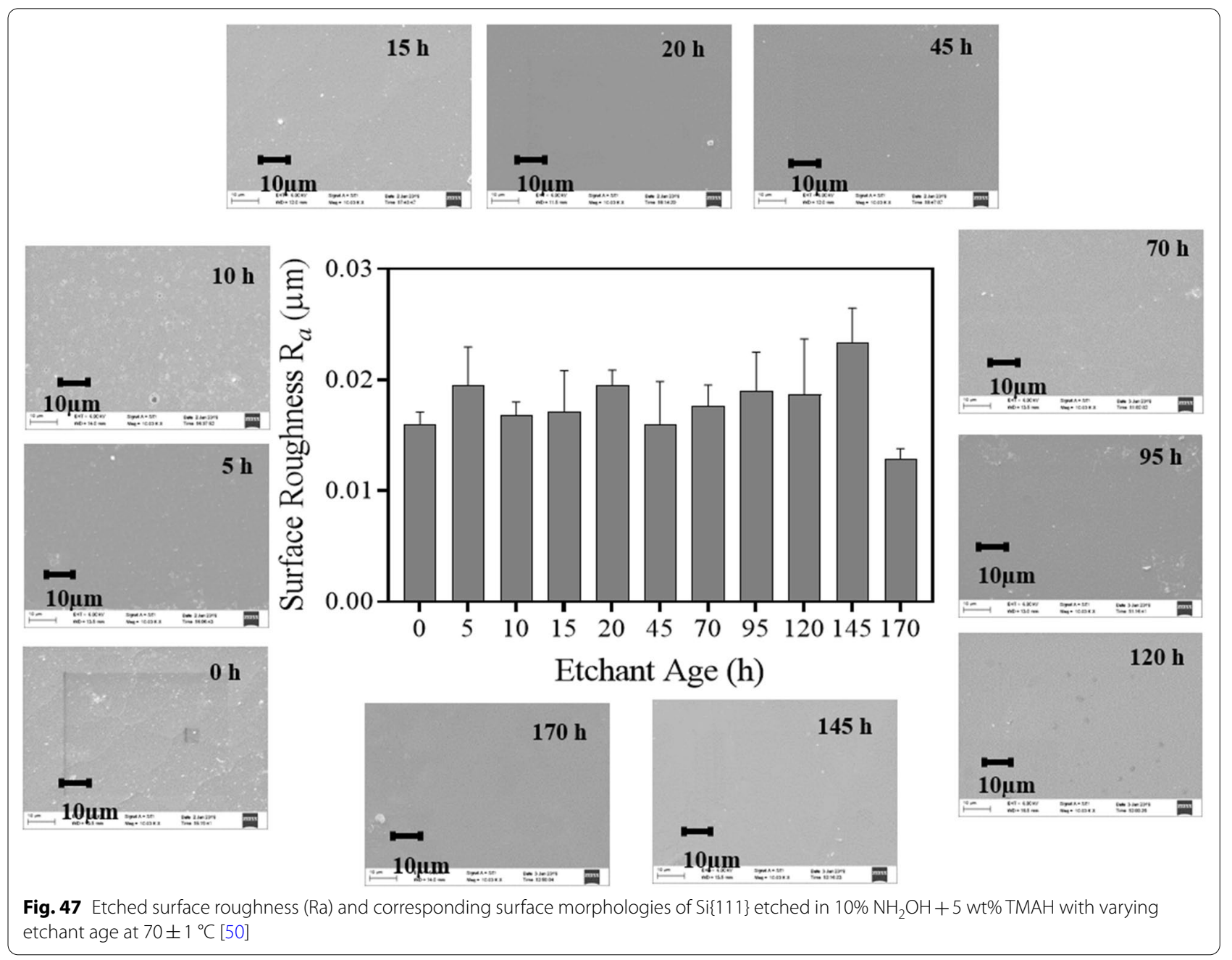

anisotropic etching [132-147]. The mask edges aligned along $<110>$ direction comprise $\{111\}$ planes. There are six $<110>$ directions on $\mathrm{Si}\{111\}$ surface at which $\{111\}$ planes emerge during etching. If the mask edges are aligned along non- $<110>$ direction, undercutting takes place which is desirable for the fabrication of suspended structures. In a rectangular shape formed by $<110>$ and $<112>$ direction on $\mathrm{Si}\{111\}$ wafer, the undercutting at $<112>$ direction proceed along $<110>$ direction at faster rate. Hence the study of undercutting at non- $<110>$ direction, specialty a direction perpendicular to $<110>$ direction (i.e. $<112>$ direction) is very important. To estimate the etch time to remove the underneath material for the fabrication of freestanding structures on $\mathrm{Si}\{111\}$ wafer, undercutting rate must be known. To investigate the undercutting rate along $<110>$ direction at $<112>$ mask edges, a mask pattern formed by $<110>$ and $<112>$ directions is employed as shown in Fig. 60. The lateral undercutting rate at $<112>$ mask edges along $<110>$ direction $\left(l_{<110>} / t\right)$ in TMAH and $\mathrm{KOH}$ based solution are presented Figs. 61 and 62 , respectively. The undercutting rate increases with increasing concentration of $\mathrm{NH}_{2} \mathrm{OH}$ in TMAH/ $\mathrm{KOH}$ and becomes highest when $\mathrm{NH}_{2} \mathrm{OH}$ concentration reaches $10 \%$ in TMAH and $15 \%$ in $\mathrm{KOH}$. This property of $\mathrm{NH}_{2} \mathrm{OH}$-added TMAH/KOH can be exploited 


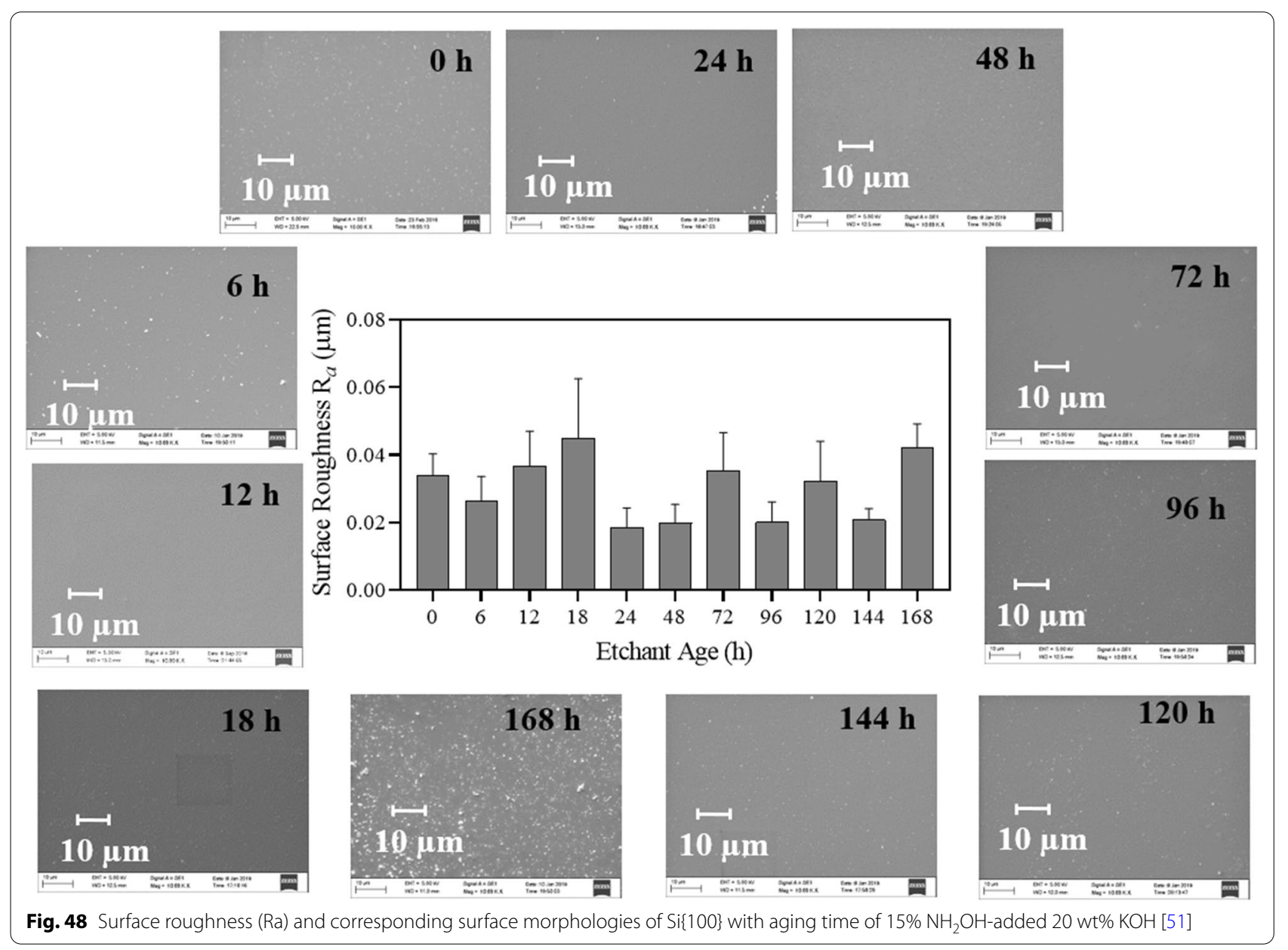

for the fast release of suspended microstructures on $\mathrm{Si}\{111\}$ wafer. The fast (or more) undercutting at mask edges takes place mainly due to the emergence of high index planes during etching process. As the etch rate of high index planes improve when $\mathrm{NH}_{2} \mathrm{OH}$ is added into $\mathrm{TMAH} / \mathrm{KOH}$, the undercutting rate at $<112>$ mask edges on $\mathrm{Si}\{111\}$ surface increases on the addition of $\mathrm{NH}_{2} \mathrm{OH}$ in TMAH/KOH. A solution providing high undercutting ratio is very useful to control the gap between freestanding structure and bottom surface such as bridges, combdrive structures, micro-gyroscope [140-147].

If the etch rate and undercutting rate results are considered together, $10 \%$ and $15 \% \mathrm{NH}_{2} \mathrm{OH}$ are optimal concentrations to achieve improved etching characteristics in $5 \mathrm{wt} \% \mathrm{TMAH}$ and $20 \mathrm{wt} \% \mathrm{KOH}$, respectively. The effect of aging is presented in Figs. 63 and 64 for TMAH and $\mathrm{KOH}$ based solutions, respectively. It can easily be observed from these results that the undercutting rate decreases with increase of etchant age. Hence, it is suggested to use the $\mathrm{NH}_{2} \mathrm{OH}$-added TMAH/KOH immediately after preparation to obtain high undercutting.

$\mathrm{NH}_{2} \mathrm{OH}$-added TMAH/KOH provides high etch rate, high undercutting, and high etch selectivity between silicon and $\mathrm{SiO}_{2}$. High etch rate is useful to form cavities/ grooves is less etching time, while high undercutting rate is extremely useful for the fast realization of suspended structures on silicon wafers. High etch selectivity 


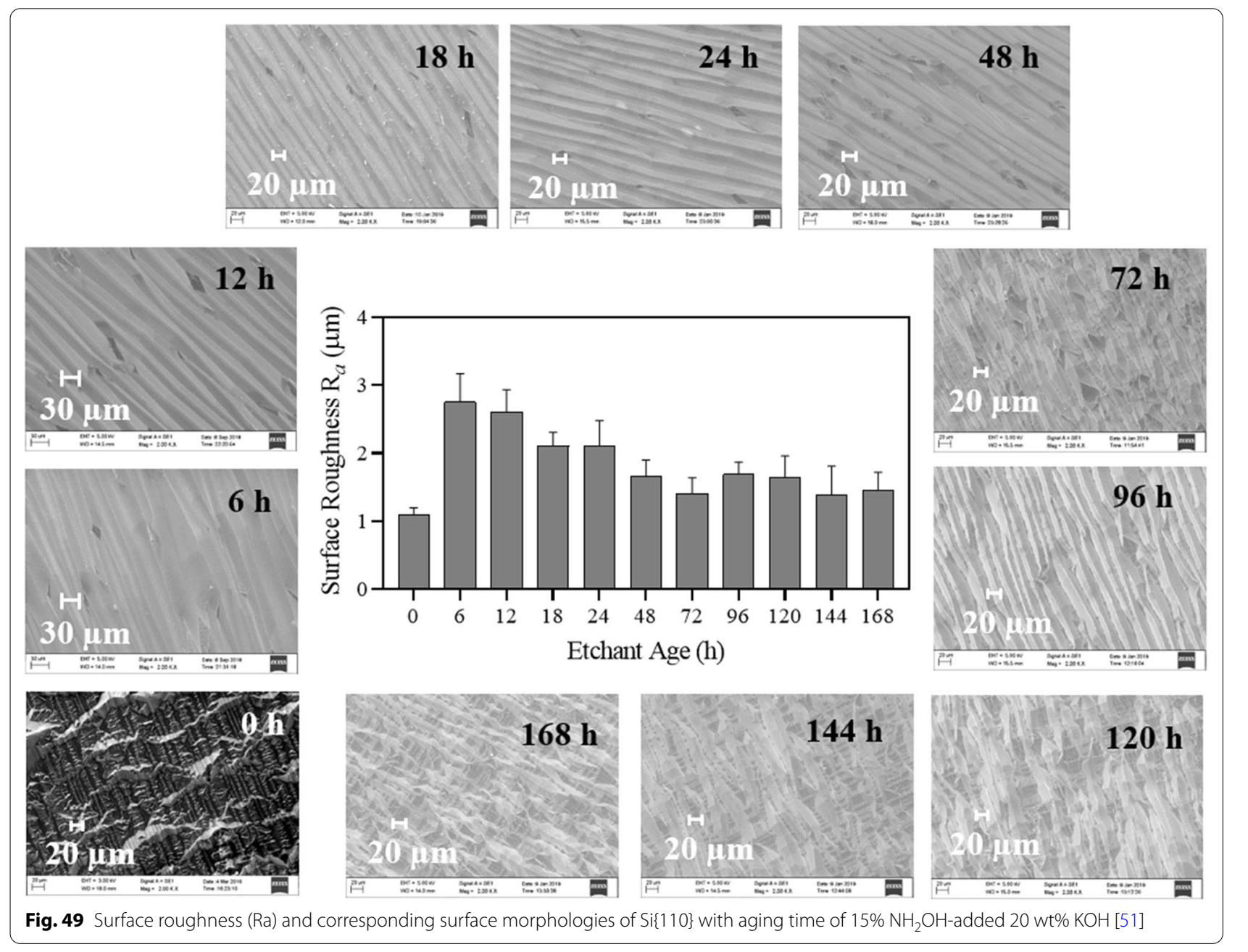

between silicon and $\mathrm{SiO}_{2}$ is highly advantageous to employ silicon dioxide as mask as well as structural layer. $\mathrm{NH}_{2} \mathrm{OH}$-added TMAH/KOH is exceedingly suitable for the formation of microstructures using $\mathrm{SiO}_{2}$ as etch mask and structural layer. The microstructures fabricated in optimal etchant compositions (i.e. $10 \% \mathrm{NH}_{2} \mathrm{OH}+5 \mathrm{wt} \%$ TMAH, $15 \% \mathrm{NH}_{2} \mathrm{OH}+20 \mathrm{wt} \% \mathrm{KOH}$ ) are presented in Figs. 65 and 66.

\section{Summary and conclusions}

Various methods to improve the etch rate of silicon have been reviewed and discussed systematically. Ultrasonic agitation during etching process improves the etch rate as well as etched surface morphology. However, due to mechanical sonic force applied to the device, the fragile structures may get damaged. Microwave irradiation significantly increases the etch rate, but experimental proofs 


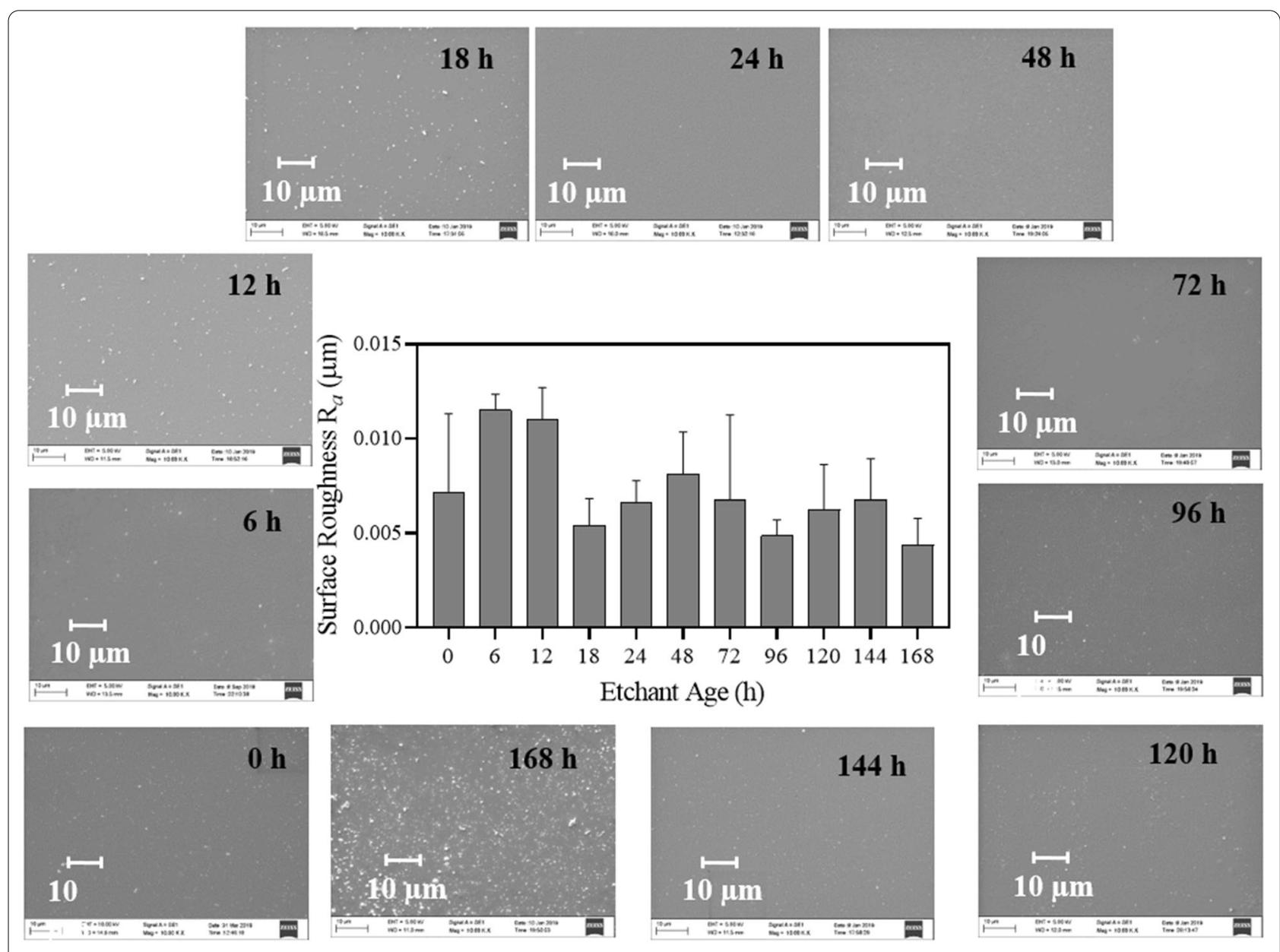

Fig. 50 Surface roughness $(\mathrm{Ra})$ and corresponding surface morphologies of Si\{111\} with aging time of 15\% $\mathrm{NH}_{2} \mathrm{OH}$-added $20 \mathrm{wt} \% \mathrm{KOH}$ [51]

are insufficient in terms of accuracy and repeatability of experimental data as no other research group confirmed (or carry forward) the effect of microwave irradiation on the etch rate of silicon.

The etchant concentration significantly affects the etch rate. There are two ways to reach local maximum in etch rate, both having pros and cons. The first approach is to etch Si using a diluted $\mathrm{KOH}$ or TMAH solutions. Typical concentrations are in a range of $10-20 \mathrm{wt} \%$ for $\mathrm{KOH}$ and
$2-5 \mathrm{wt} \%$ for TMAH. Pros are easiness to apply, cons are moderate increase of etch rate and inevitable etched surface roughness by an emergence of micro-pyramids. The second approach is etching at near boiling point typically at $145{ }^{\circ} \mathrm{C}$ using highly concentrated solution of $50 \mathrm{wt} \%$ $\mathrm{KOH}$. Pros are available etch rate of the order of $10 \mu \mathrm{m} /$ min, cons are lower etch selectivity between $\mathrm{Si}$ and oxide mask demanding alternative mask materials. 


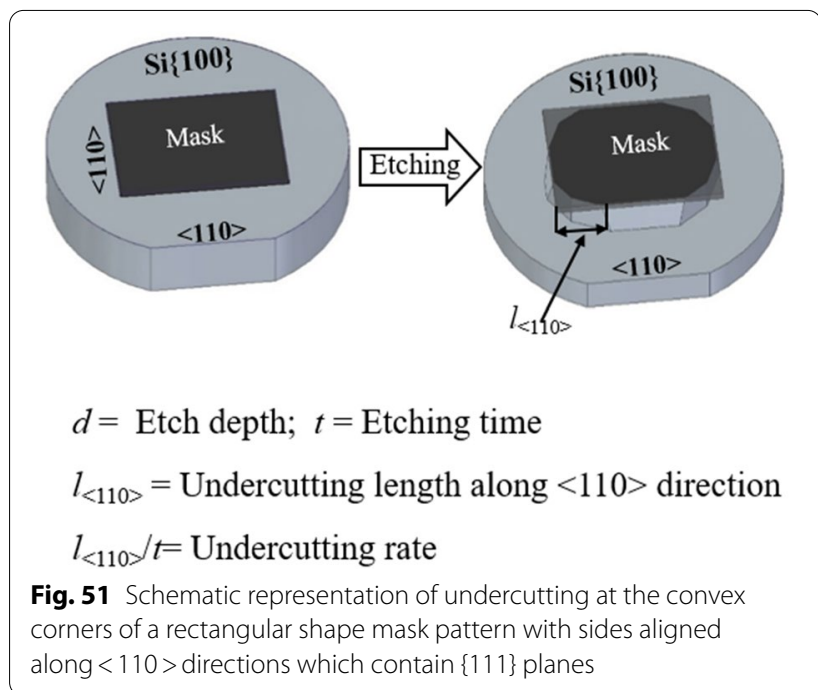

The etching characteristics are strongly influenced by different kinds of additives. Various additives have been investigated to improve the etch rate of silicon. The addition of redox system and complexant in $\mathrm{KOH}$ solution effectively increases the etch rate, but these additives are not studied further by other researchers and hence not very common in wet anisotropic etching.

The effects of various kinds of additives in TMAH solution to protect the $\mathrm{Al}$ layer during wet anisotropic etching step are investigated by several research groups. Ammonium peroxodisulfate (AP) is found as an optimal additive to obtain zero etch rate of $\mathrm{Al}$. The addition of AP supresses hillocks/pyramids and at the same time increase the etch rate of silicon.

The addition of $\mathrm{NH}_{2} \mathrm{OH}$ significantly influences the etching characteristics of TMAH/KOH and provides highest etch rate and undercutting, which are the desirable properties to increase the industrial throughput when the structures are fabricated using silicon wet bulk micromachining. In this paper, the effect of $\mathrm{NH}_{2} \mathrm{OH}$ concentration on the etching characteristics of TMAH/KOH (e.g. etch rate, etched surface morphology and undercutting) is methodologically presented. Moreover, the influence of etchant age on the etching characteristics is

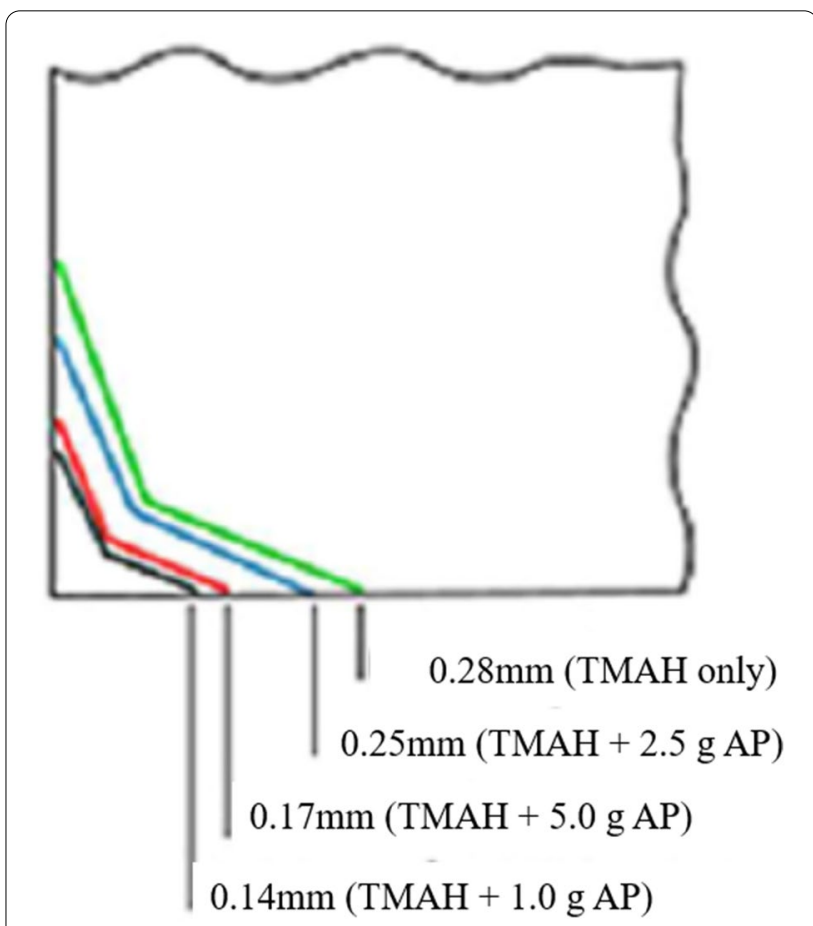

Fig. 52 Undercutting at convex corners on Si\{100\} surface without and with various concentrations of ammonium persulfate (AP) in 10 wt $\%$ TMAH at $70{ }^{\circ} \mathrm{C}$ [109], (c) 2015, Springer

systematically explained. The major conclusions pertaining to $\mathrm{NH}_{2} \mathrm{OH}$-added TMAH/KOH are as follows:

- The etch rate of silicon is increased when $\mathrm{NH}_{2} \mathrm{OH}$ is added to TMAH/KOH solution.

- $10 \%$ and $15 \%$ are the optimal concentrations of $\mathrm{NH}_{2} \mathrm{OH}$ to be incorporated in $5 \mathrm{wt} \%$ TMAH and 20 wt\% $\mathrm{KOH}$, respectively, to achieve the high etch rate of silicon.

- The etch selectivity between silicon and silicon dioxide (i.e. $\mathrm{Si} / \mathrm{SiO}_{2}$ ) improves substantially with the addition of $\mathrm{NH}_{2} \mathrm{OH}$. Therefore, $\mathrm{SiO}_{2}$ thin film can be used as a mask/structural layer for the fabrication of microstructures. 


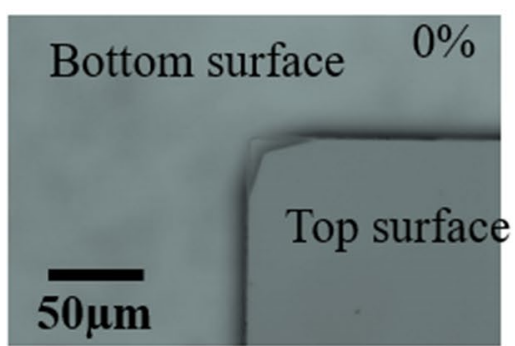

Etch time: $15 \mathrm{~min}$

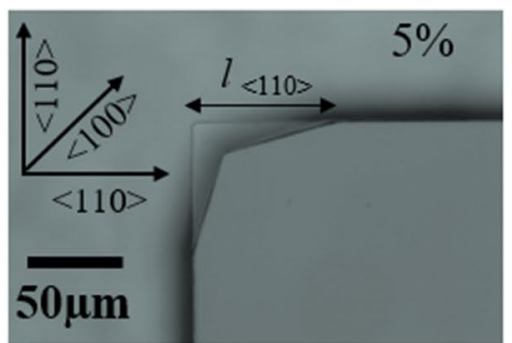

Etch time: $15 \mathrm{~min}$

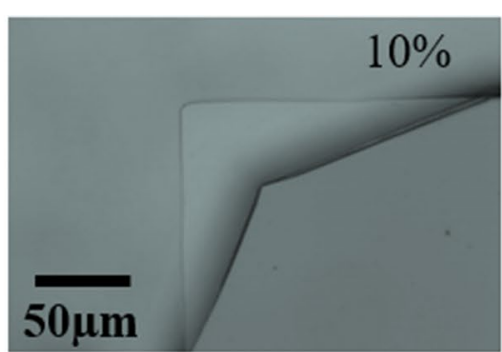

Etch time: $15 \mathrm{~min}$
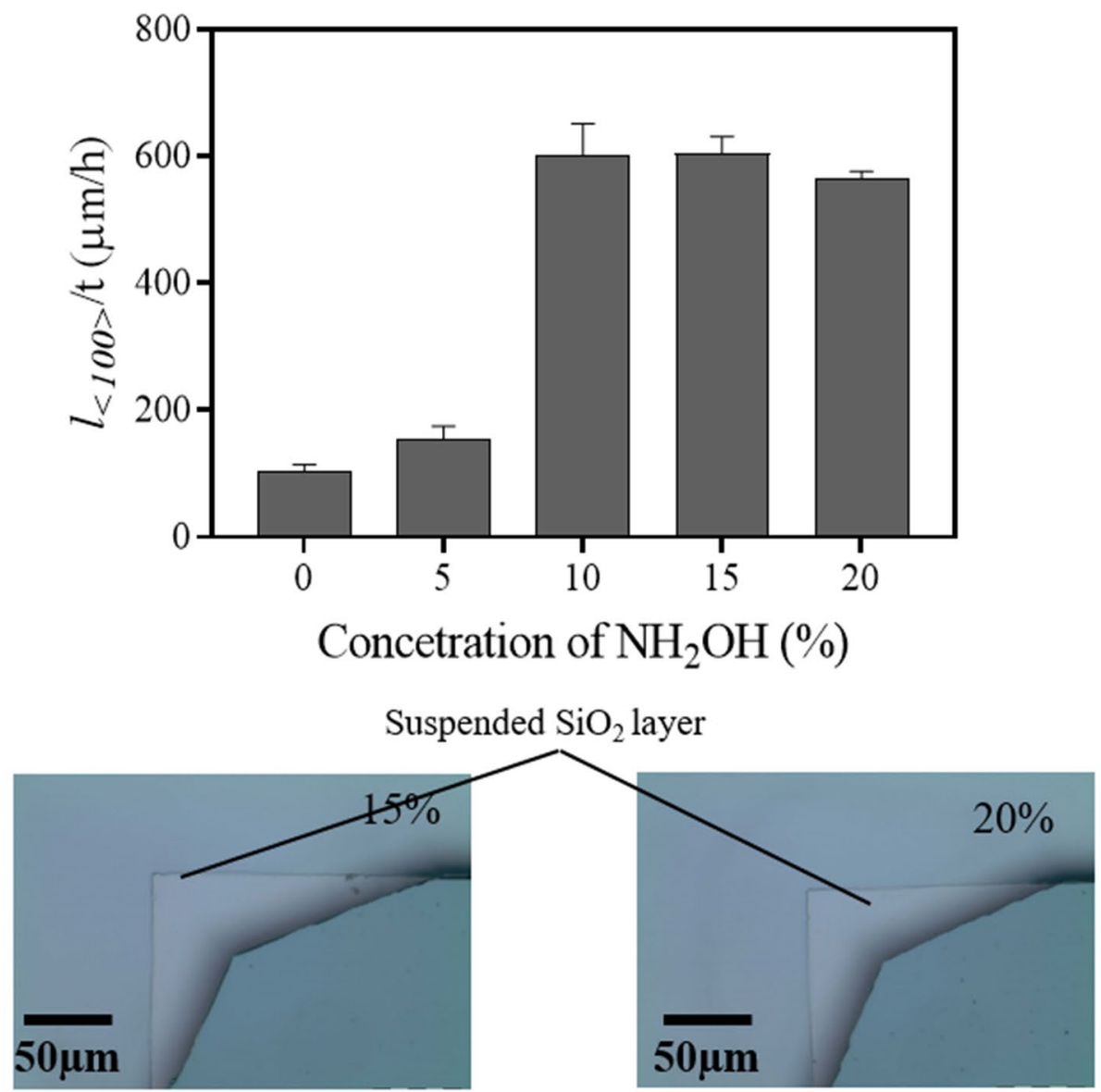

Etch time: $15 \mathrm{~min}$

Etch time: $15 \mathrm{~min}$

Fig. 53 Corner undercutting along $<110>$ direction in pure and different concentrations of $\mathrm{NH}_{2} \mathrm{OH}$-added 5 wt $\%$ TMAH at $70 \pm 1^{\circ} \mathrm{C}[50]$ 


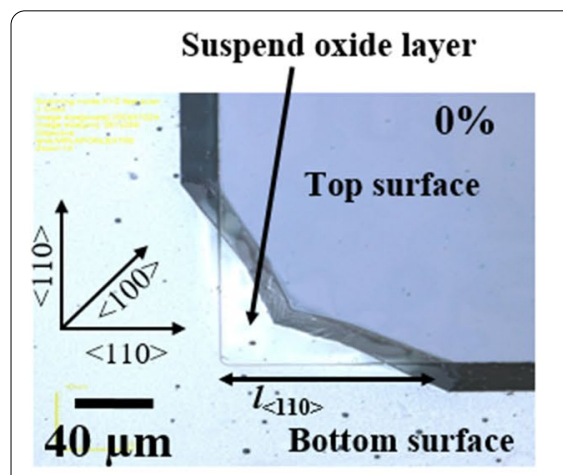

Etched time: $30 \mathrm{~min}$

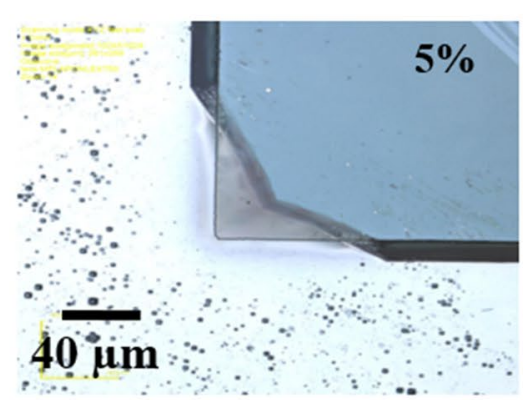

Etched time: $10 \mathrm{~min}$

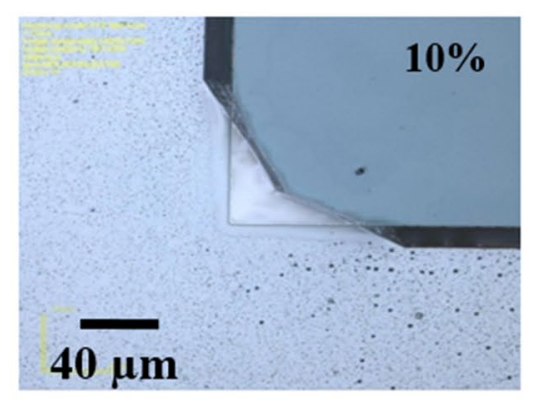

Etched time: 9 min

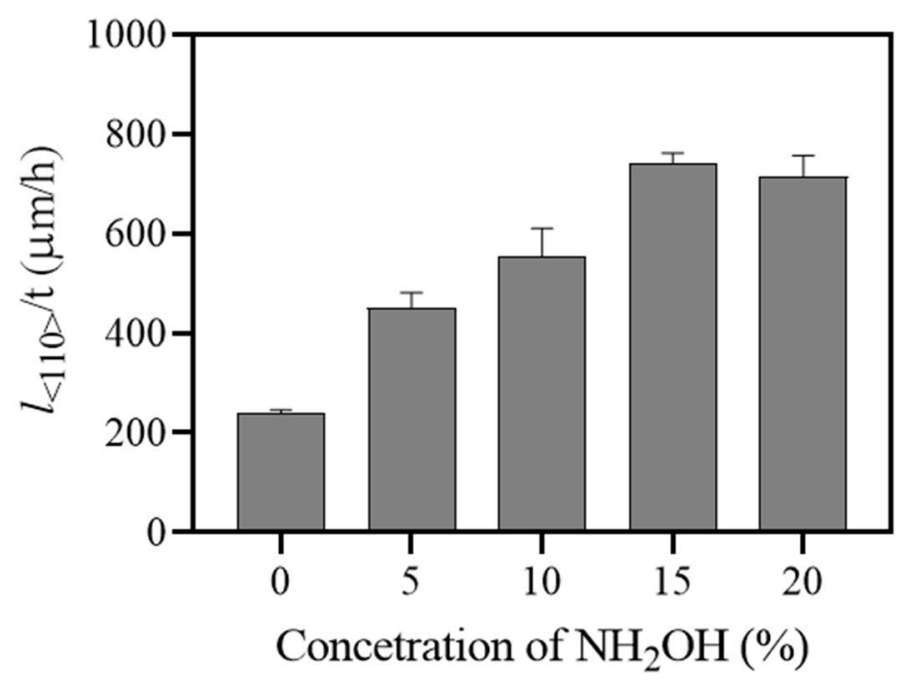

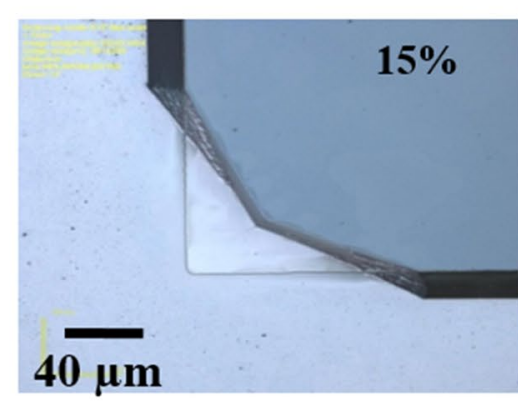

Etched time: $10 \mathrm{~min}$

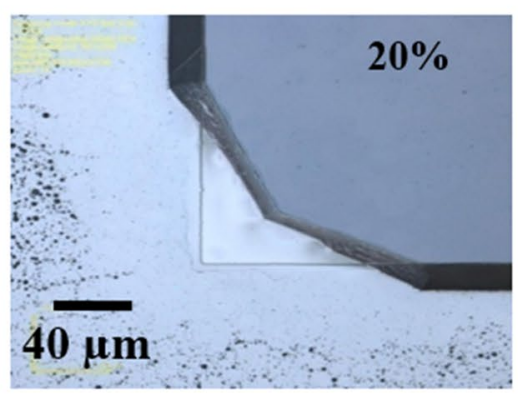

Etched time: $10 \mathrm{~min}$

Fig. 54 Etching characteristics at convex corner along $<110>$ direction on Si\{100\} wafer surface in various concentrations of $\mathrm{NH}_{2} \mathrm{OH}$-added 20 wt\% $\mathrm{KOH}$ at $75 \pm 1^{\circ} \mathrm{C}[51]$ 


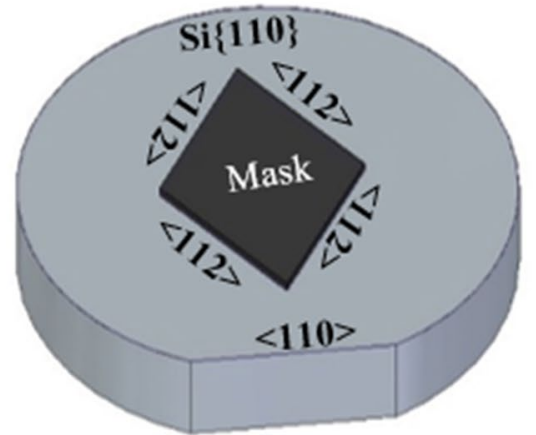

$\mathbf{a}$

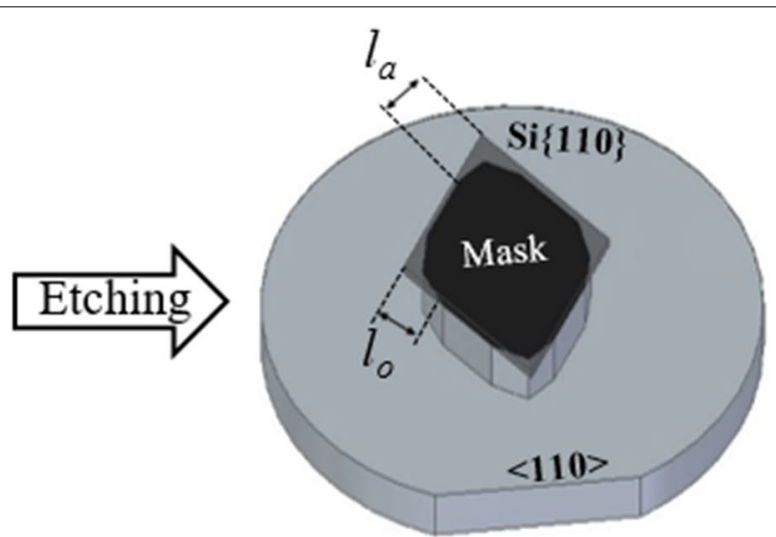

b

$\mathrm{d}=$ Etch depth; $\mathrm{t}=$ Etching time

$l_{a}=$ Undercutting length at acute corner along $<112>$ edge

$l_{d} / t=$ Undercutting rate at acute corner

$l_{o}=$ Undercutting length at obtuse corner along $<112>$ edge

$l_{0} / t=$ Undercutting rate at obtuse corner

Fig. 55 Schematic illustration of the undercutting at acute and obtuse convex corners of a rhombus shape mask pattern formed by $<112>$ directions on Si\{110\} wafer surface

- The etch rate of $\operatorname{Si}\{100\}, \operatorname{Si}\{110\}$ and $\operatorname{Si}\{111\}$ decreases significantly with etchant age. Hence it is recommended to use the etchant immediately after preparing the solution.

- In pure $\mathrm{TMAH} / \mathrm{KOH}, \mathrm{OH}^{-}$and $\mathrm{H}_{2} \mathrm{O}$ are the active species, while the addition of $\mathrm{NH}_{2} \mathrm{OH}$ increases the active species which are $\mathrm{NH}_{2} \mathrm{O}^{-}, \mathrm{OH}^{-}$and $\mathrm{H}_{2} \mathrm{O}$. The oxygen in $\mathrm{OH}^{-}$and $\mathrm{NH}_{2} \mathrm{O}^{-}$has high electronegativity and responsible for the high etch rate in $\mathrm{NH}_{2} \mathrm{OH}$-added TMAH/KOH solution.
- The addition of $\mathrm{NH}_{2} \mathrm{OH}$ affects the surface roughness and morphology, but the variation is not significant.

- The aging of etchant does not affect surface roughness considerably.

- Analogous to etch rate, $10 \%$ and $15 \%$ are the optimal concentrations of $\mathrm{NH}_{2} \mathrm{OH}$ to be added in $5 \mathrm{wt} \%$ TMAH and $20 \mathrm{wt} \% \mathrm{KOH}$, respectively, to obtain the highest undercutting rate, which is greatly beneficial for the fast release of the microstructures for application to develop MEMS-based devices. 


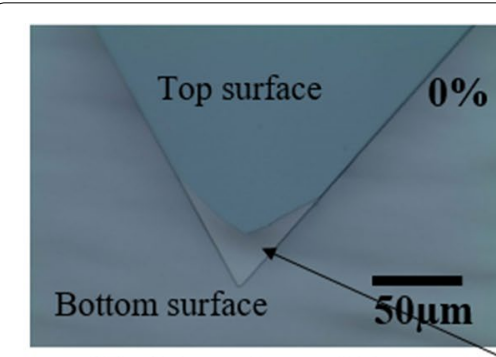

Etching time: $15 \mathrm{~min}$

Suspended $\mathrm{SiO}_{2}$

Etching time: $10 \mathrm{~min}$

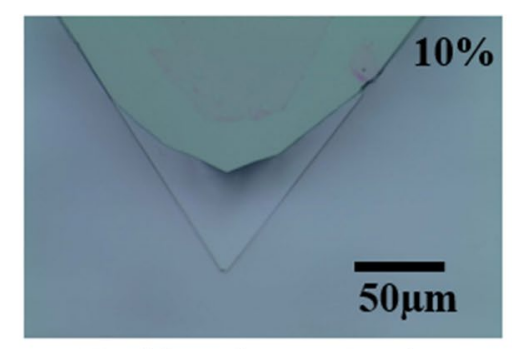

Etching time: $10 \mathrm{~min}$

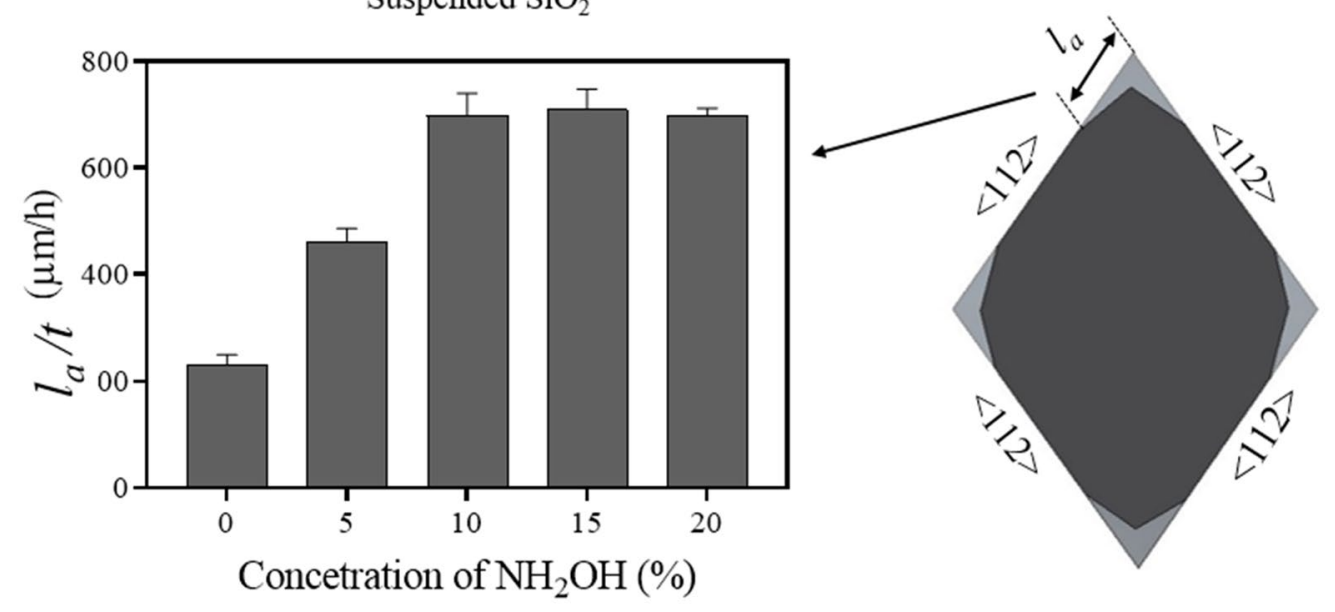

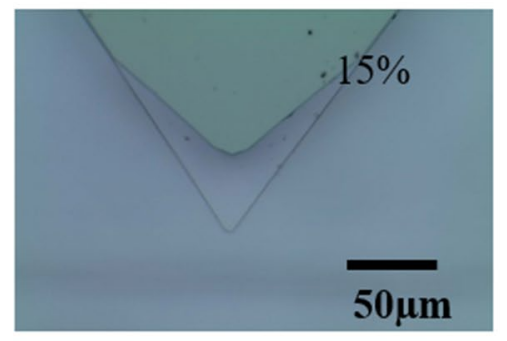

Etching time: $10 \mathrm{~min}$ $\mathrm{d}=$ Etch depth; $\mathrm{t}=$ Etching time

$l_{a}=$ Undercutting length at acute corner along $<112>$ edge $l_{a} / \mathrm{t}=$ Undercutting rate at acute corner

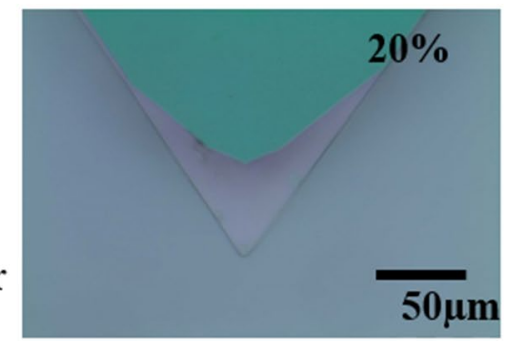

Etching time: $10 \mathrm{~min}$

Fig. 56 Undercutting at acute corners on Si\{110\} wafer surface in pure and different concentrations of $\mathrm{NH}_{2} \mathrm{OH}$-added $5 \mathrm{wt} \% \mathrm{TMAH}$ at $70 \pm 1{ }^{\circ} \mathrm{C}[50]$ 


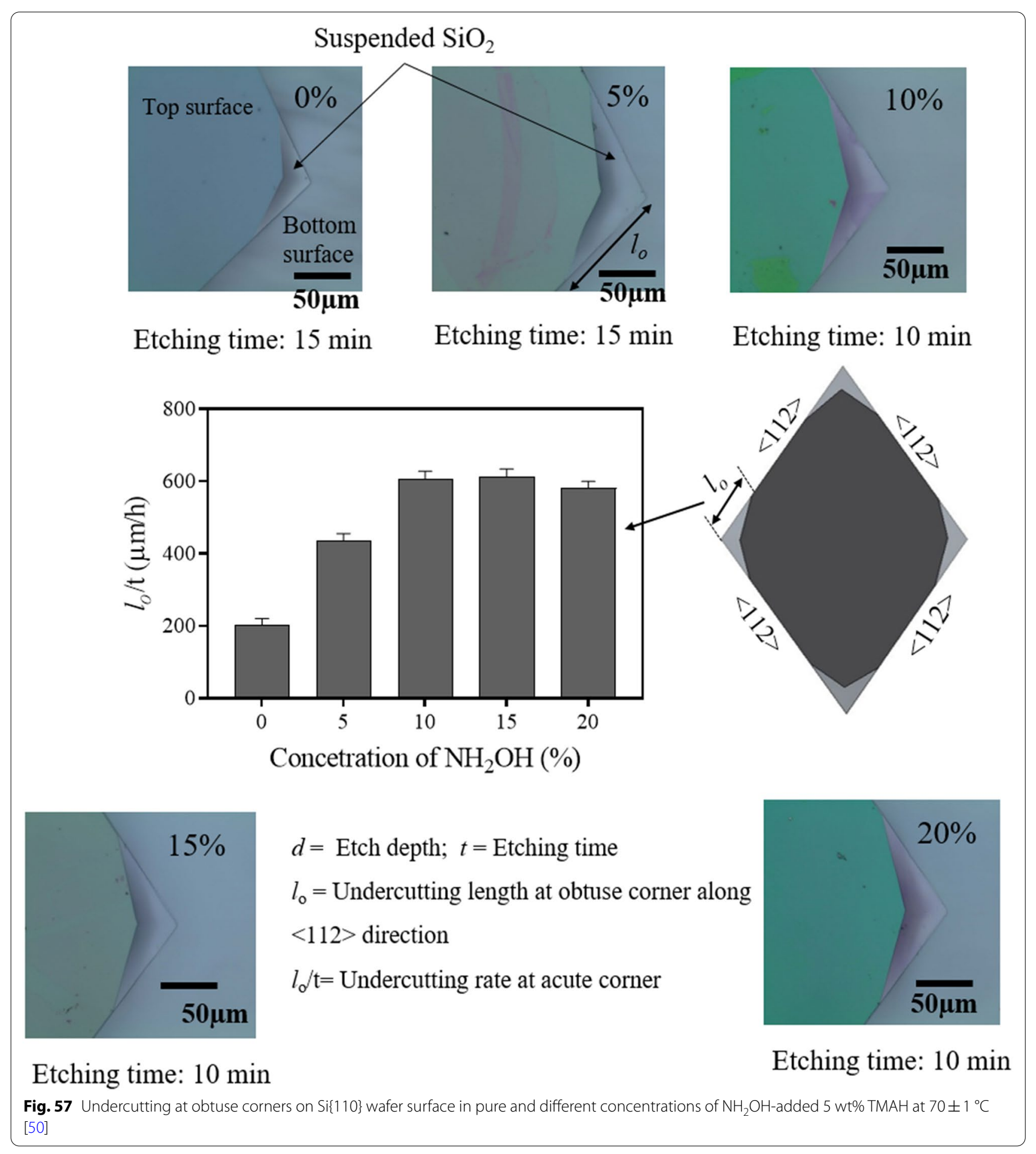




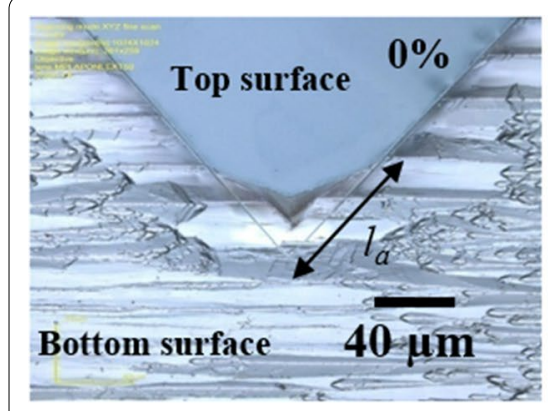

Etched time: $20 \mathrm{~min}$

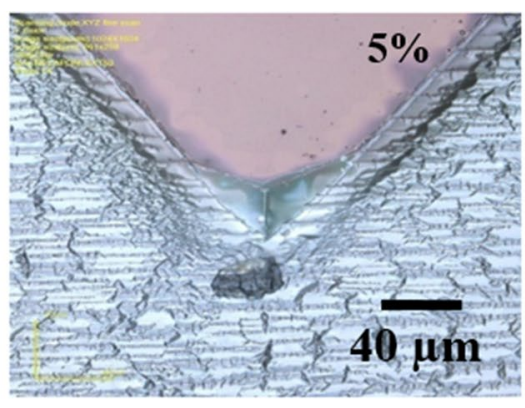

Etched time: $10 \mathrm{~min}$

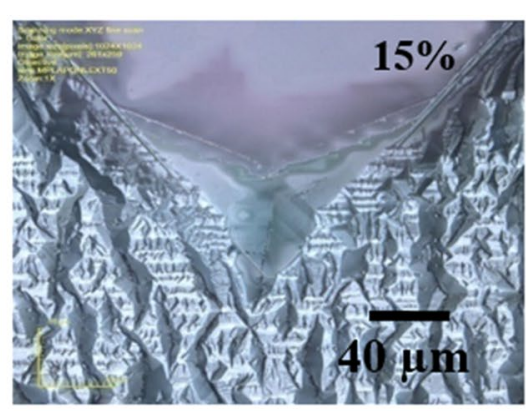

Etched time: $11 \mathrm{~min}$

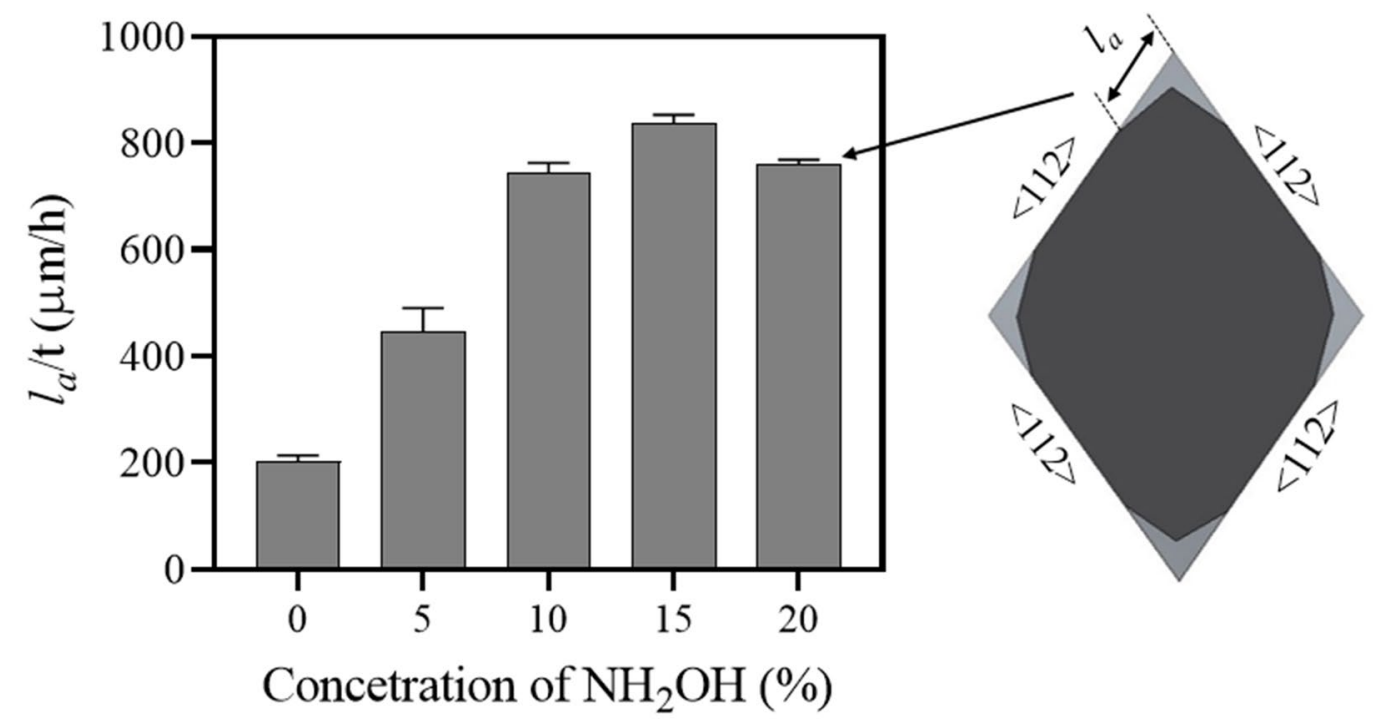

\footnotetext{
$t=$ etch time $\quad l_{a}=$ Undercutting length at acute corner along $<112>$ edge $d=$ etch depth $\quad l_{d} / t=$ Undercutting rate at acute corner
} 


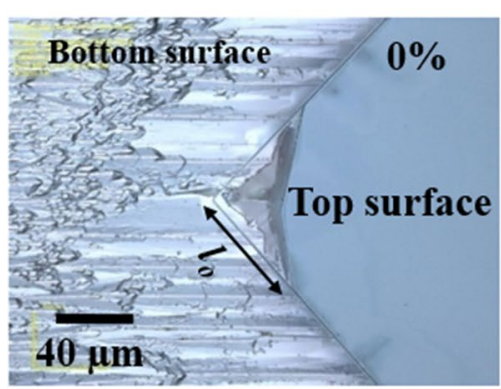

Etched time: $20 \mathrm{~min}$

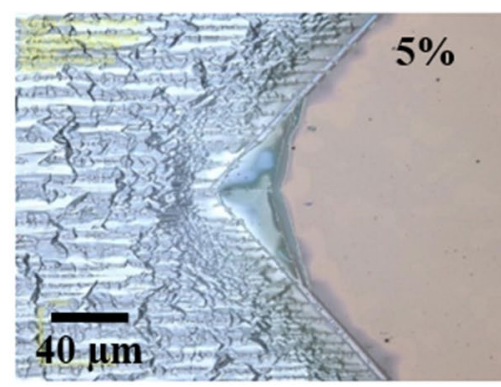

Etched time: $10 \mathrm{~min}$

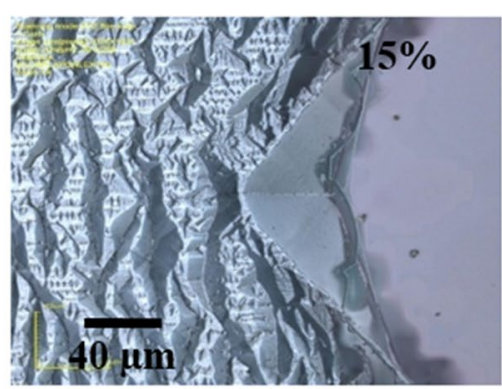

Etched time: $11 \mathrm{~min}$

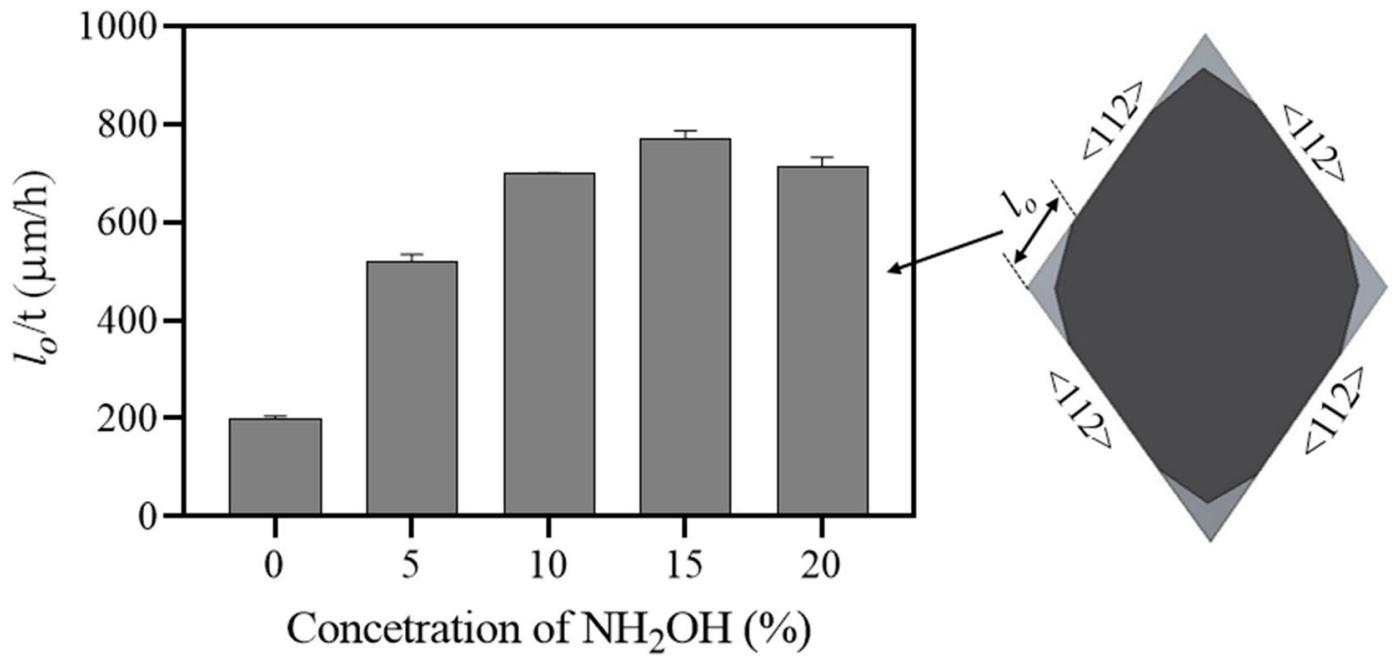

$$
\begin{array}{ll}
t=\text { etch time } & l_{o}=\text { Undercutting length at obtuse corner along }<112>\text { edge } \\
d=\text { etch depth } & l_{d} / d=\text { Undercutting rate at obtuse corner }
\end{array}
$$

Fig. 59 Undercutting at obtuse corners on Si\{110\} surface in pure and different concentrations of $\mathrm{NH}_{2} \mathrm{OH}$-added $20 \mathrm{wt} \% \mathrm{KOH}$ at $75 \pm 1{ }^{\circ} \mathrm{C}[51]$

\begin{tabular}{|c|c|c|c|c|c|}
\hline Authors & Additive's name & Orientation of silicon & TMAH Conc & Temp. $\left({ }^{\circ} \mathrm{C}\right)$ & Undercutting \\
\hline C-R Yang et al. [56] & $\begin{array}{l}\text { Anionic sodium dihexyl sulfosuccinate } \\
\text { (SDSS) }\end{array}$ & $\{100\}$ & 10 wt.\% & $60-100$ & Not reported \\
\hline G Yan et al. [106] & Ammonium persulfate (AP) & $\{100\}$ & $5,10 w t \%$ & 85 & Not reported \\
\hline N Fujitsuka et al. [108] & Ammonium persulfate (AP) & $\{100\}$ & 10 wt.\% & 80 & Not reported \\
\hline K-H Jun et.al [109] & Pyrazine, Ammonium persulfate (AP) & $\{100\}$ & $10 w+\%$ & 70 & Not affected significant \\
\hline S. Birda et al. [107] & Ammonium persulfate (AP) & $\{100\}$ & $5-10 w t . \%$ & $70-90$ & Not reported \\
\hline E.H. Klaassen et al. [111] & Ammonium peroxydisulfate & $\{100\}$ & 5 wt.\% & $70-100$ & Not reported \\
\hline R. Sotoaka [55] & Maltose, Glucose, $\mathrm{NH}_{2} \mathrm{OH}$, Cellobiose & $\{100\}$ & $10 w t \%$ & 80 & Not reported \\
\hline V. Swarnalatha et al.[50, 60-62] & $\mathrm{NH}_{2} \mathrm{OH}$ & $\{100\},\{110\}$ and $\{111\}$ & $5 w t \%$ & 70 & Significant increase \\
\hline
\end{tabular}

Table 6 The effect of various kinds of additives on the undercutting at convex corners in TMAH solution 
Table 7 The effect of various kinds of additives on the undercutting at convex corners in KOH solution

\begin{tabular}{|c|c|c|c|c|c|}
\hline Authors & Additive's name & Orientation of $\mathrm{Si}$ & $\mathrm{KOH}$ Conc & Temp. $\left({ }^{\circ} \mathrm{C}\right)$ & Effect on surface roughness \\
\hline C. Moldovan et al. [52] & Redox + complexant & $\{100\}$ & $4.5 \mathrm{M}$ & 80 & Not reported \\
\hline C-R Yang et al. [56] & Anionic sodium dihexyl sulfosuccinate (SDSS) & $\{100\}$ & $30 \mathrm{wt} \%$ & $60-100$ & Not reported \\
\hline R. Sotoaka [55] & Maltose, Glucose, $\mathrm{NH}_{2} \mathrm{OH}$, Cellobiose & $\{100\}$ & $25 \mathrm{wt} \%$ & 80 & Not reported \\
\hline $\begin{array}{l}\text { A. V. Narasimha Rao } \\
\text { et al. [51, 63-65] }\end{array}$ & $\mathrm{NH}_{2} \mathrm{OH}$ & $\{100\},\{110\}$ and $\{111\}$ & $20 w t \%$ & 75 & Significant increase \\
\hline
\end{tabular}

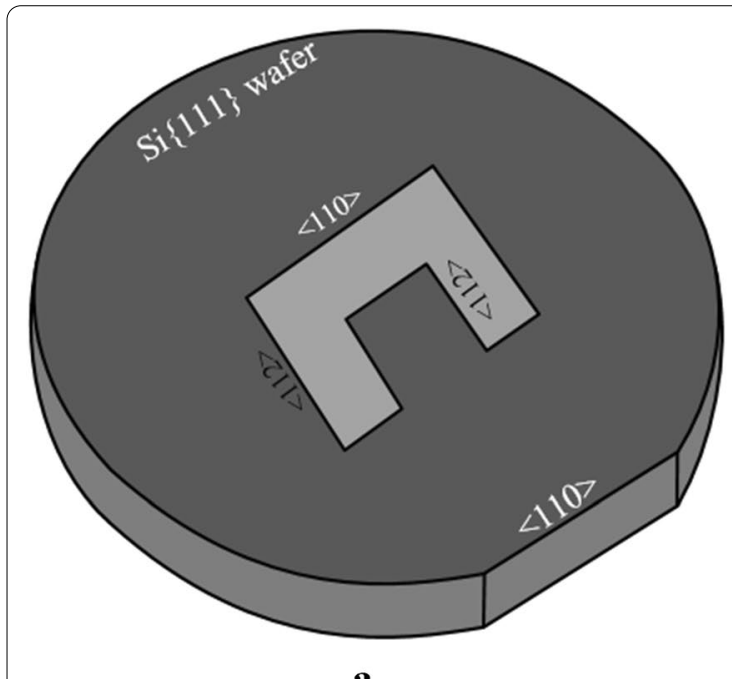

a

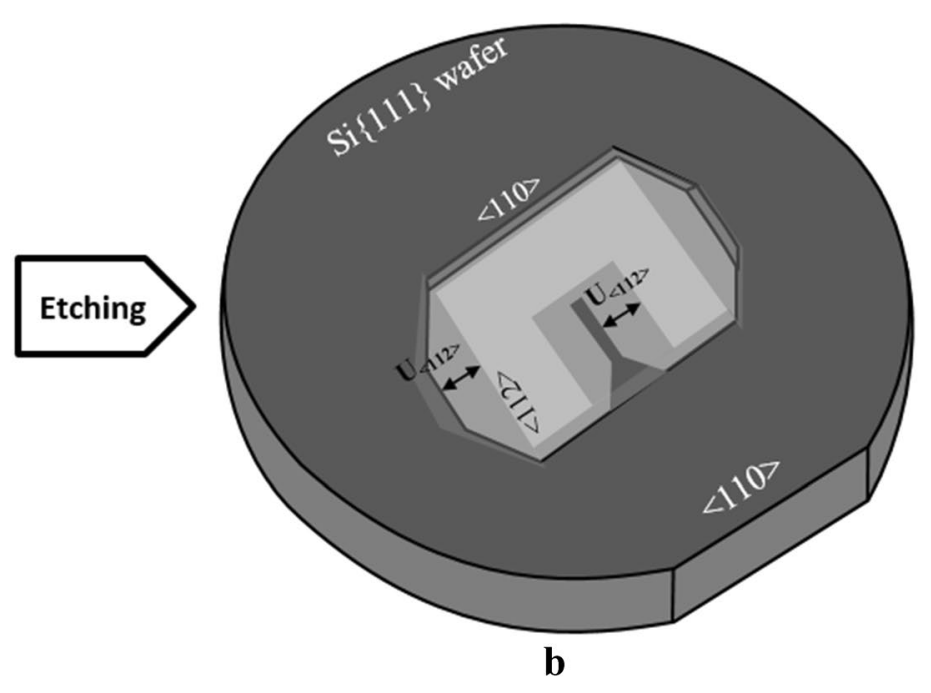

Mask suspended over undercut

Etched Si surface

$U_{<112>}$ : Lateral undercutting at mask edges aligned along $<112>$ directions

$t$ : etching time; $d$ : etch depth; $U_{<112>} / \mathrm{t}$ : Undercutting rate

Fig. 60 Schematic illustration of the undercutting at mask edges aligned along < 112> direction on Si\{111\} wafer: a mask pattern on wafer surface, b etched profile after wet anisotropic etching 


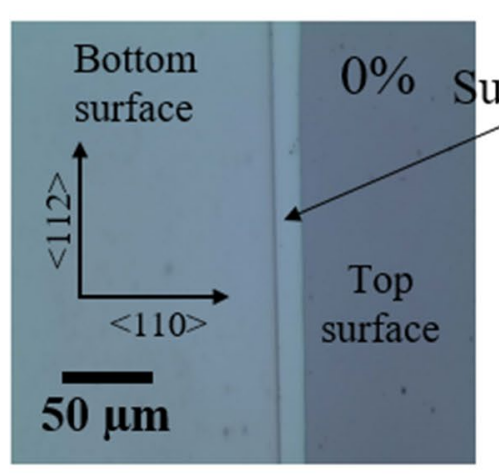

Etching time: $60 \mathrm{~min}$ uspended

$\mathrm{SiO}_{2}$

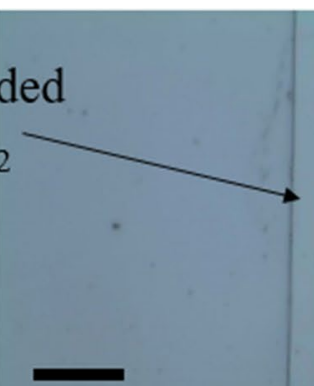

$50 \mu \mathrm{m}$

Etching time: $30 \mathrm{~min}$

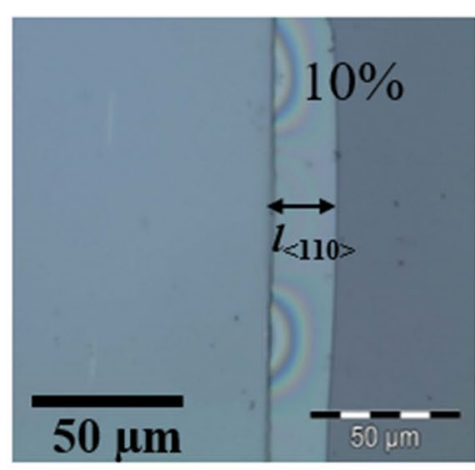

Etching time: $30 \mathrm{~min}$

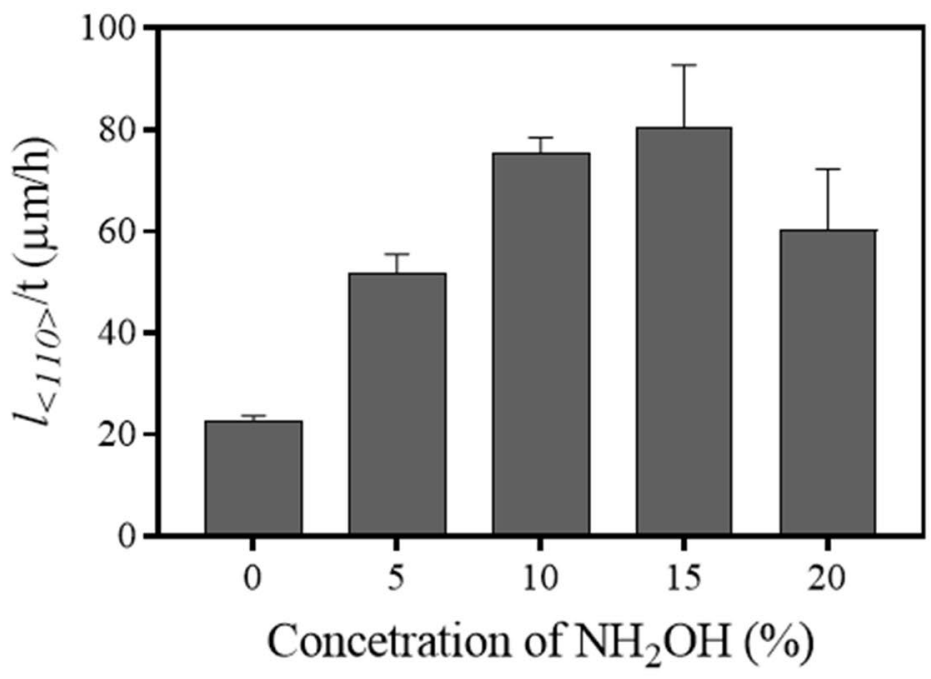

$t=$ Etch time $\quad l_{<110>}=$ Lateral undercutting along $<110>$ direction

$d=$ Etch depth $\quad l_{<110} J t=$ Undercutting rate

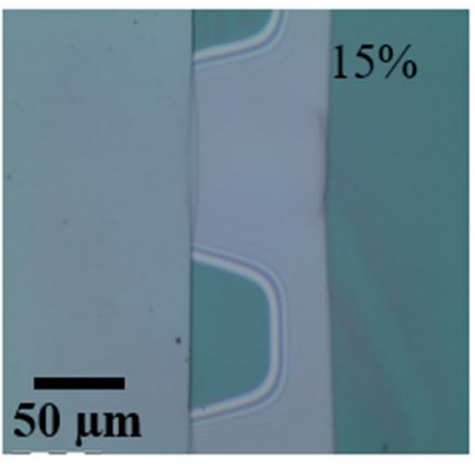

Etching time: $60 \mathrm{~min}$

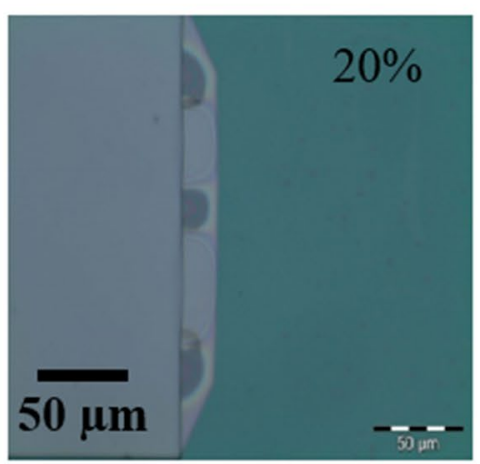

Etching time: $30 \mathrm{~min}$

Fig. 61 Lateral undercutting along $<110>$ direction at $<112>$ mask edges on Si\{111\} wafer in pure and different concentrations of $\mathrm{NH}_{2} \mathrm{OH}$-added 5 wt\% TMAH at $70 \pm 1{ }^{\circ} \mathrm{C}[50]$ 


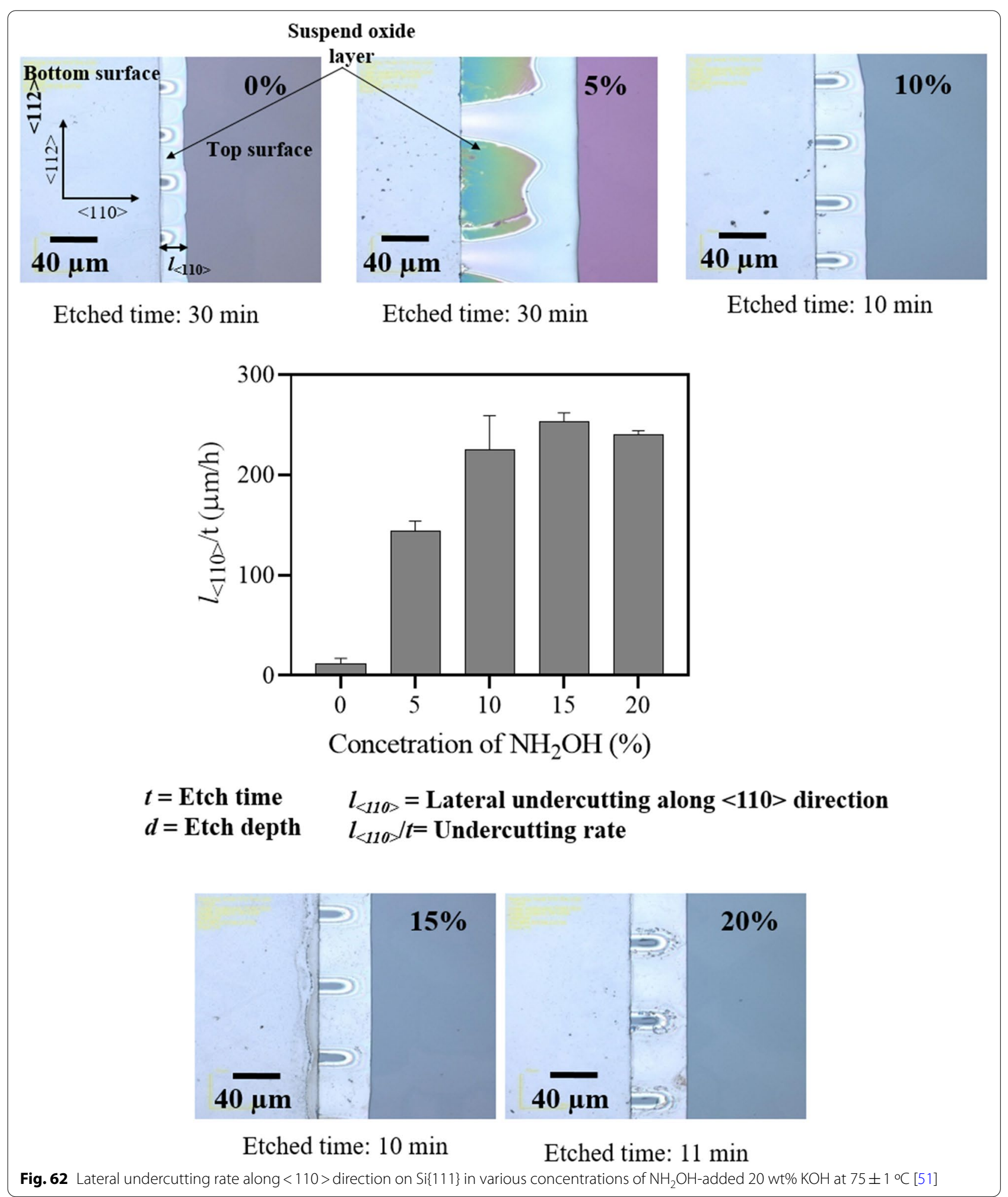



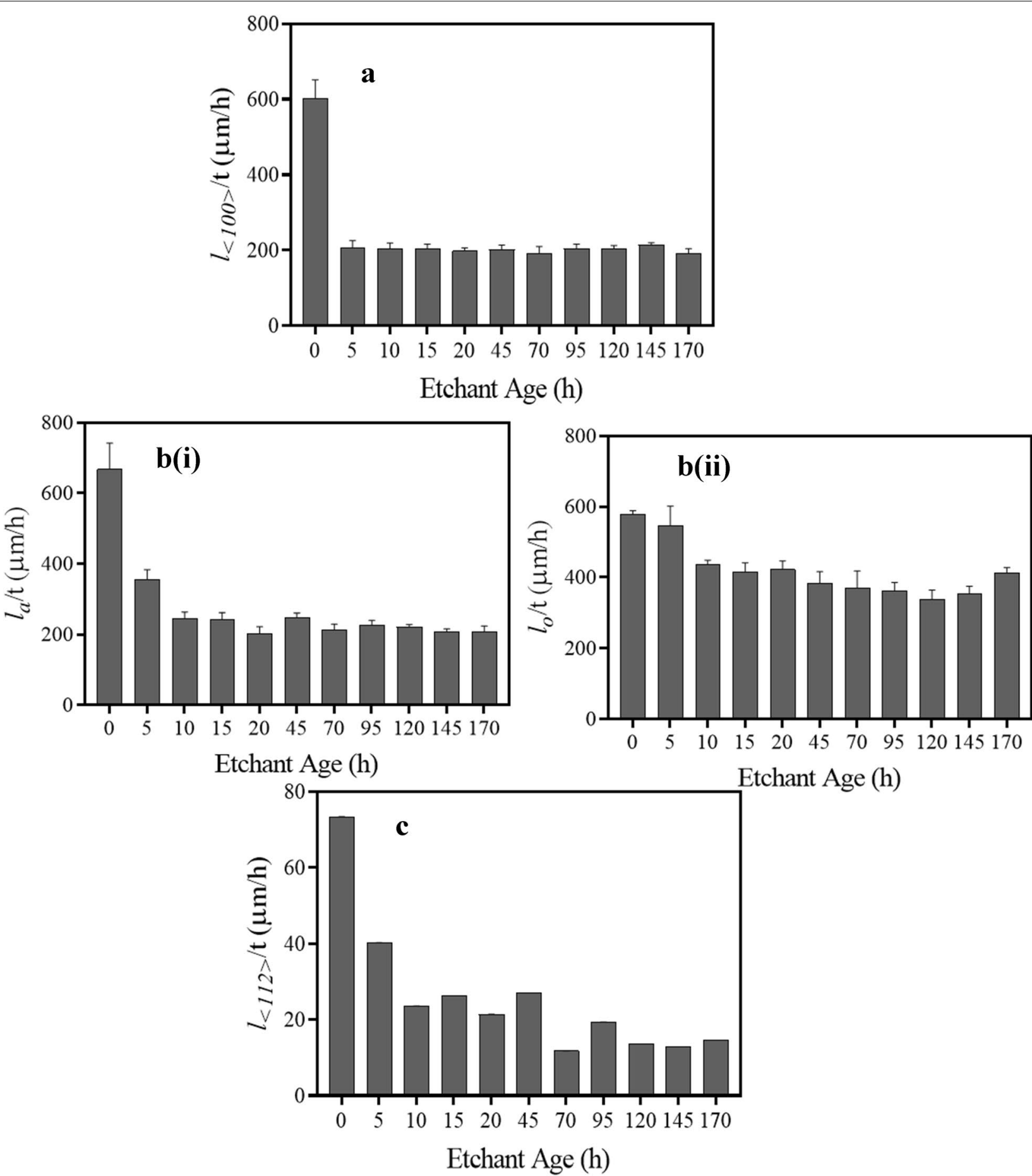

Etchant Age (h) 

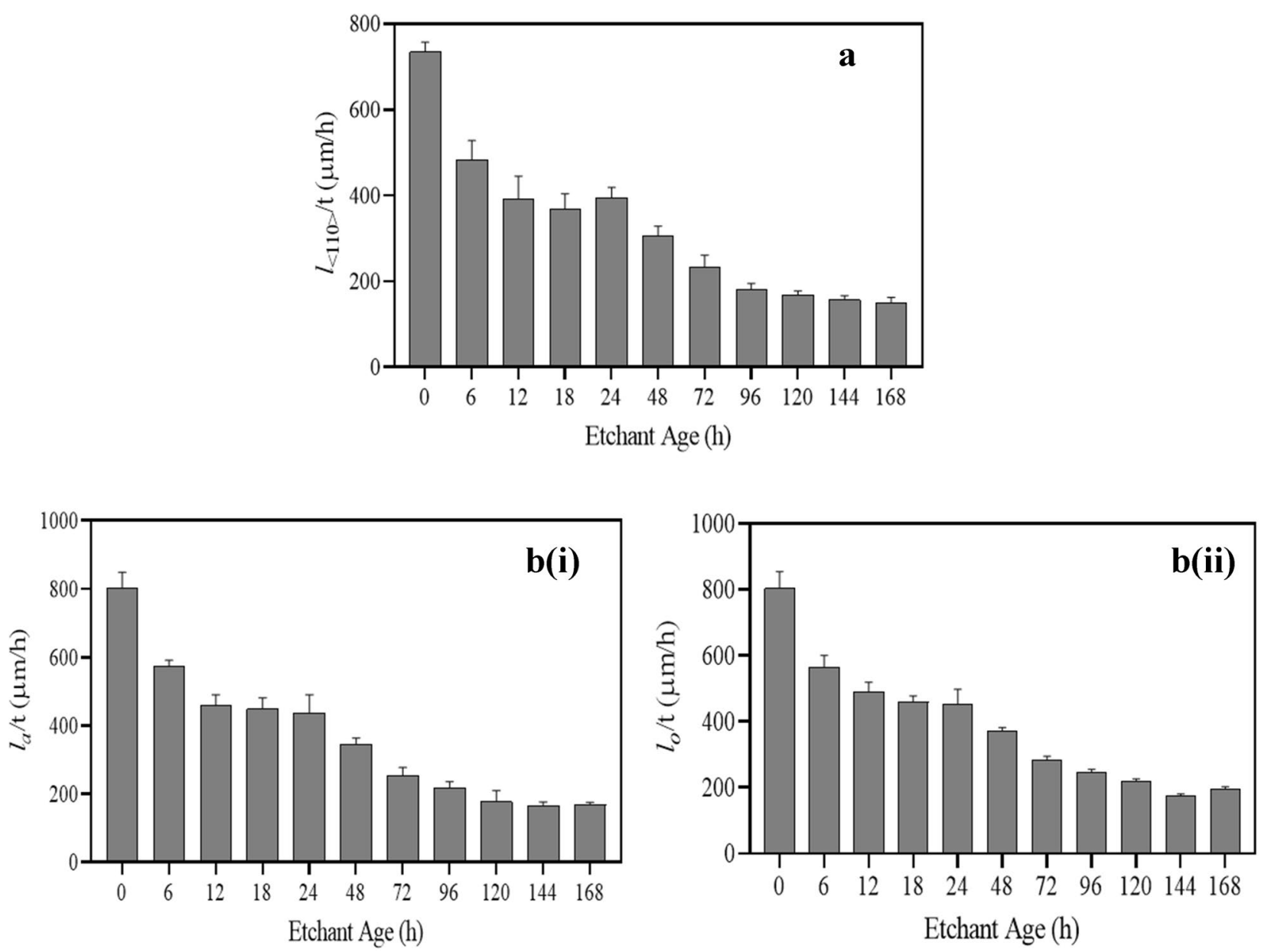

Fig. 64 Undercutting with varying etchant age on a Si\{100\}, b Si\{110\} ((i) acute corner and (ii) obtuse corner) in $20 \mathrm{wt} \% \mathrm{KOH}+15 \% \mathrm{NH}$ $75 \pm 1{ }^{\circ} \mathrm{C}$ [51] 


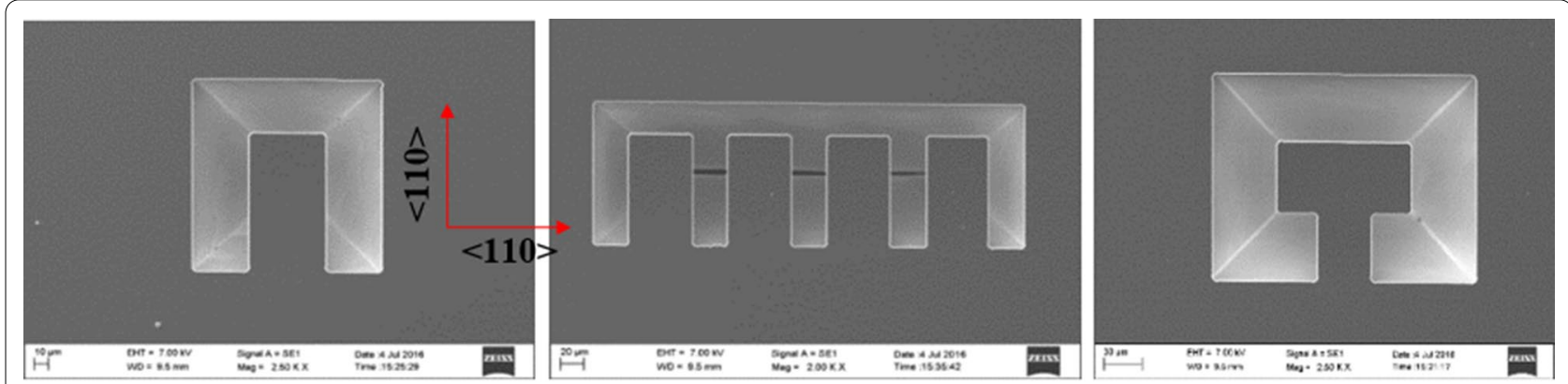

a Microstructures on $\operatorname{Si}\{100\}$ wafer

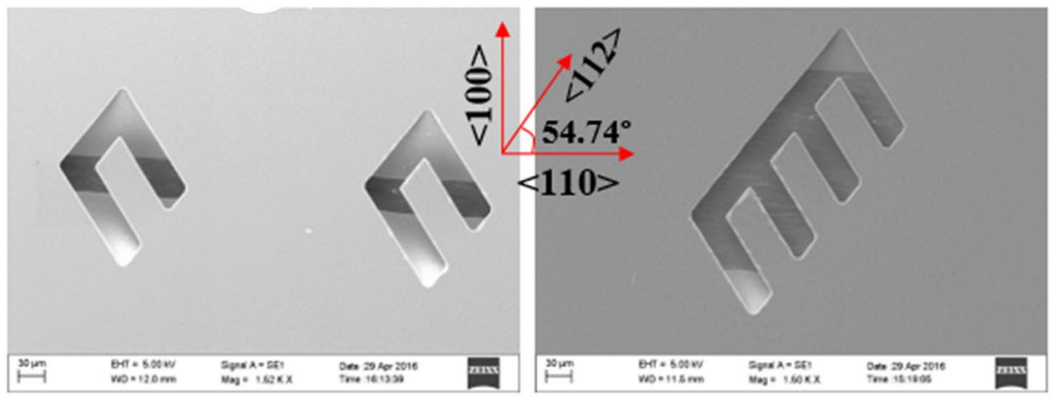

b Microstructures on $\operatorname{Si}\{110\}$ wafer
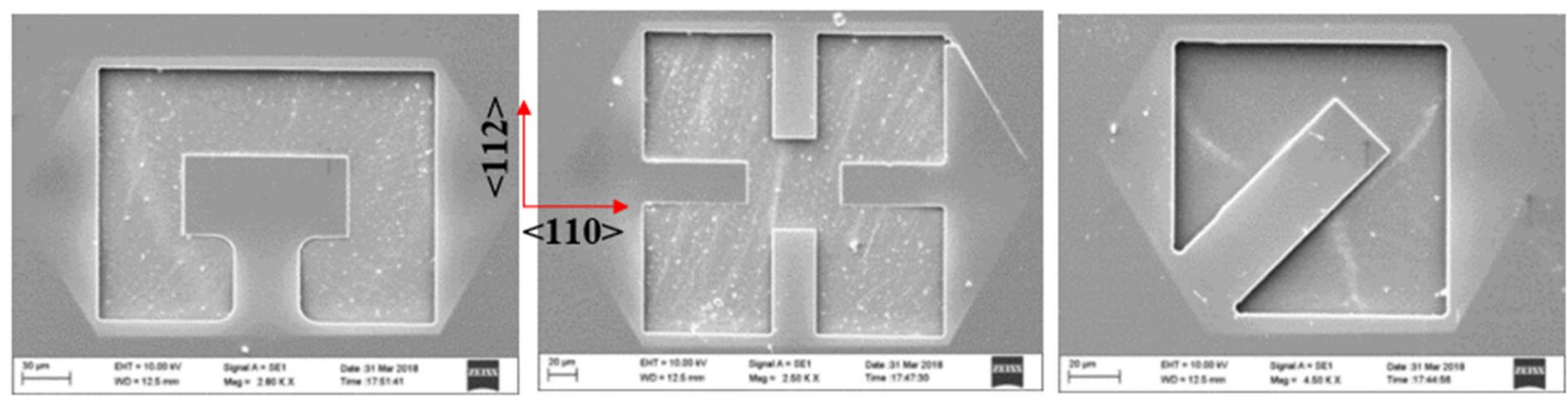

c Microstructures on $\operatorname{Si}\{111\}$ wafer

Fig. 65 SEM images of suspended $\mathrm{SiO}_{2}$ microstructures fabricated on a Si\{100\}, b Si\{110\}, and c Si\{111\} wafers in $\mathrm{NH}_{2} \mathrm{OH}$-added TMAH [50] 


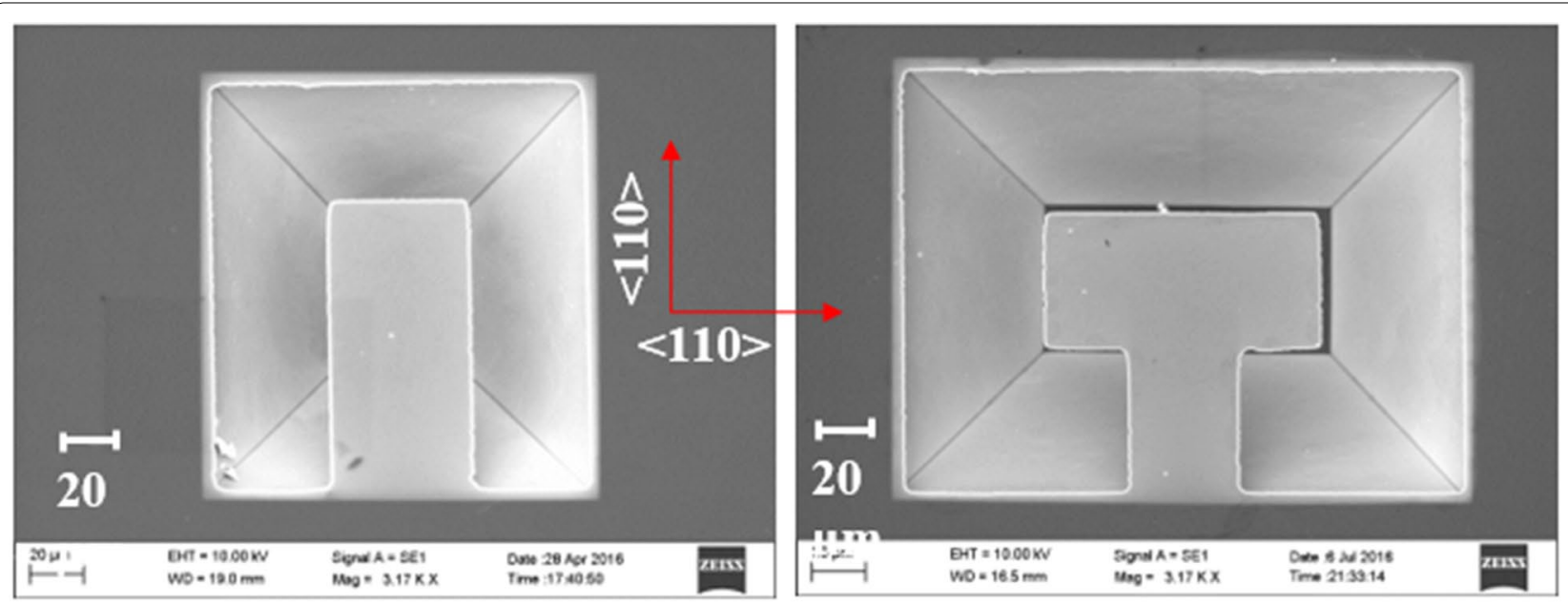

a Microstructures on $\operatorname{Si}\{100\}$ wafer

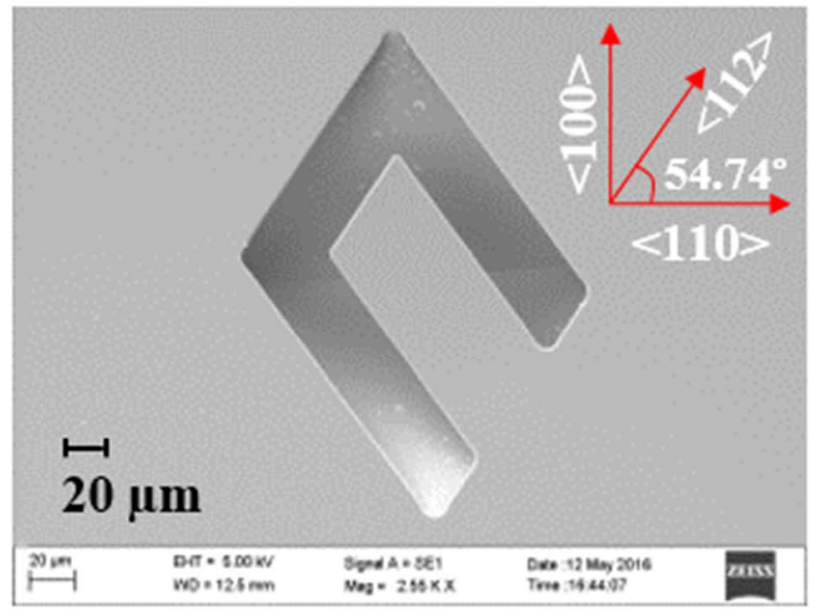

\section{b Microstructures on $\operatorname{Si}\{110\}$ wafer}

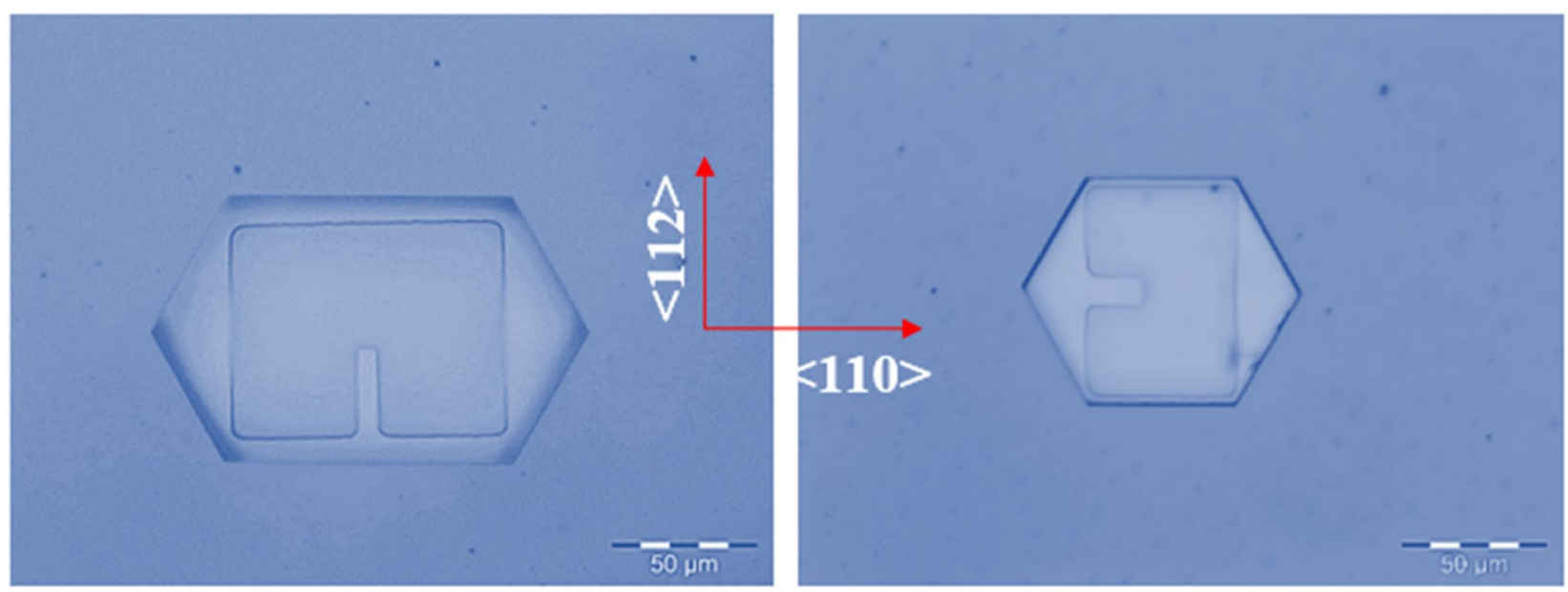

c Microstructures on $\operatorname{Si}\{111\}$ wafer

Fig. 66 Freestanding $\mathrm{SiO}_{2}$ microstructures fabricated on a Si\{100\}, b Si\{110\} and c Si\{111\} wafers in $\mathrm{NH}_{2} \mathrm{OH}$-added $\mathrm{KOH}$ [51] 
The $\mathrm{NH}_{2} \mathrm{OH}$ can be considered as a better additive for an alkaline solution to achieve improved etch rate of silicon, high etch selectivity between $\mathrm{Si}$ and $\mathrm{SiO}_{2}$, considerably high undercutting at convex corner. However, the major drawback of hydroxylamine $\left(\mathrm{NH}_{2} \mathrm{OH}\right)$ is that it is unstable in nature in the presence of alkaline solution, which decreases the etch rate with etchant age. Therefore, it should be used immediately after its preparation to obtain high etch and undercutting to minimize fabrication time.

The aging effect may be reduced by adding fresh $\mathrm{NH}_{2} \mathrm{OH}$ at regular intervals to obtain stable etch rate. However, it is not yet confirmed experimentally and therefore can be claimed firmly.

\section{Acknowledgements}

Financial support from the Council of Scientific and Industrial Research (CSIR), New Delhi, India is greatly acknowledged.

\section{Authors' contributions}

PP took the lead to prepare the manuscript and did literature survey, AVNR and VS helped in collecting data, plotting graphs, and drawing schematics, AKP, HT and KS wrote different parts of the manuscript and edited the manuscript. All authors read and approved the final manuscript.

\section{Funding}

This work was supported by research grant from the Council of Scientific and Industrial Research (CSIR, Ref: 22(0824)/19/EMR-II, 0527/NS), New Delhi, India.

\section{Availability of data and materials}

No extra data and material are used in this paper.

\section{Competing interests}

The authors declare that they have no competing interests.

\section{Author details}

1 MEMS and Micro/Nano Systems Laboratory, Department of Physics, Indian Institute of Technology Hyderabad, Hyderabad, India. ${ }^{2}$ Department of Mechanical and Aerospace Engineering, Indian Institute of Technology Hyderabad, Hyderabad, India. ${ }^{3}$ Deptartment of Mechanical Engineering, Aichi Institute of Technology, Toyota, Japan. ${ }^{4}$ Research Institute for Industrial Technology, Aichi Institute of Technology, Toyota, Japan.

Received: 24 August 2020 Accepted: 5 February 2021

Published online: 22 February 2021

\section{References}

1. Gad-el-Hak M (2002) The MEMS Handbook. CRC Press LLC, Boca Raton

2. Tilli M, Motooka T, Airaksinen VM, Franssila S, Krockel MP, Lindroos V (2015) Handbook of silicon based MEMS materials and technologies. William Andrew Publishing, United States

3. Pal P, Sato K (2017) Silicon Wet Bulk Micromachining for MEMS. Pan Stanford Publishing, Singapore

4. Elwenspoek M, Jansen H (1998) Silicon micromachining. Cambridge University Press, UK

5. Pal P, Chandra S (2004) Bulk-micromachined structures inside anisotropically etched cavity. Smart Mater Struct 3(6):1424-1429

6. Pal P, Gosalvez MA, Sato K (2010) Silicon micromachining based on surfactant-added tetramethyl ammonium hydroxide: etching mechanism and advanced application. Japan J Appl Phys 49:056702

7. Zubel I (2019) Anisotropic etching of Si. J Micromech Microeng 29(9):93002

8. Kovacs GT, Maluf NI, Petersen KE (1998) Bulk micromachining of silicon. IEEE Proc 86:1536-1551
9. Gupta A, Pal P, Sharma CS (2019) Surface texturing of Silicon 100 in an extremely low concentration TMAH for minimized reflectivity. ECS J Solid State Sci Technol 8(10):622-628

10. Solanki CS (2015) Solar photovoltaics: fundamentals, technologies and applications. India, PHI Learning Pvt. Ltd., p 16

11. Lee DB (1969) Anisotropic etching of silicon. J Appl Phys 40:4569-4575

12. Bean KE (1978) Anisotropic etching of silicon. IEEE Trans Electron Devices 25:1185-1193

13. Seidel H, Csepregi L, Heuberger A, Baumgartel H (1990) Anisotropic etching of crystalline silicon in alkaline solutions I: orientation dependence and behavior of passivation layers. J Electrochem Soc 137(11):3612-3626

14. Seidel H, Csepregi L, Heuberger A, Baumgartel H (1990) Anisotropic etching of crystalline silicon in alkaline solutions II: Influence of Dopants. J Electrochem Soc 137:3626-3632

15. Sato K, Shikida M, Matsushima Y, Yamashiro T, Asaumi K, Iriye Y, Yamamoto M (1998) Characterization of orientation-dependent etching properties of single-crystal silicon: effects of $\mathrm{KOH}$ concentration. Sens Actuators A 61:87-93

16. Sato K, Shikida M, Yamashiro T, Tsunekawa M, Ito S (1999) Roughening of single-crystal silicon surface etched by $\mathrm{KOH}$ water solution. Sens Actuators A 73:122-130

17. Powell O, Harrison HB (2001) Anisotropic etching of 100 and 110 planes in (100) silicon. J Micromech Microeng 11:217-220

18. Tanaka H, Yamashita S, Abe Y, Shikida M, Sato K (2004) Fast etching of silicon with a smooth surface in high temperature ranges near the boiling point of $\mathrm{KOH}$ solution. Sens Actuators A 114:516-520

19. Matsuoka M, Yoshida Y, Moronuki M (1992) Preparation of silicon thin diaphragms free from micropyramids using anisotropic etching in $\mathrm{KOH}$ solution. J Chem Eng 25:735-740

20. Baryeka I, Zubel I (1995) Silicon anisotropic etching in $\mathrm{KOH}$-isopropanol etchant. Sens Actuators A 48:229-238

21. Shikida M, Sato K, Tokoro K, Uchikawa D (2000) Differences in anisotropic etching properties of $\mathrm{KOH}$ and TMAH solutions. Sens Actuators A 80:179-188

22. Backlund Y, Rosengren L (1992) New shapes in (100) Si using KOH and EDP etches. J Micromech Microeng 27:5-9

23. Pal P, Ashok A, Haldar S, Xing Y, Sato K (2015) Anisotropic etching in low concentration $\mathrm{KOH}$ : effects of surfactant concentration. Micro Nano Lett 10(4):224-228

24. Gosalvez MA, Pal P, Ferrando N, Hida H, Sato K (2001) Experimental procurement of the complete 3D etch rate distribution of $\mathrm{Si}$ in anisotropic etchants based on vertically micromachined wagon wheel samples. J Micromech Microeng 21(12):125007

25. Tabata O, Asahi R, Funabashi H, Shimaoka K, Sugiyama S (1992) Anisotropic etching of silicon in TMAH solutions. Sens Actuators A 34(1):51-57

26. Sato K, Shikida M, Yamashiro T, Asaumi K, Iriye Y, Yamamoto M (1999) Anisotropic etching rates of single-crystal silicon for TMAH water solution as a function of crystallographic orientation. Sens Actuators A 73:131-137

27. Cheng D, Gosalvez MA, Hori T, Sato K, Shikida M (2006) Improvement in smoothness of anisotropically etched silicon surfaces: Effects of surfactant and TMAH concentrations. Sens Actuators A 125:415-421

28. Pal P, Sato K, Gosalvez MA, Tang B, Hida H, Shikida M (2011) Fabrication of novel microstructures based on orientation dependent adsorption of surfactant molecules in TMAH solution. J Micromech Microeng 21(1):015008

29. Pal P, Sato K (2010) Fabrication methods based on wet etching process for the realization of silicon MEMS structures with new shapes. Microsyst Technol 16(7):1165-1174

30. Gosalvez MA, Tang B, Pal P, Sato K, Kimura Y, Ishibashi K (2009) Orientation and concentration dependent surfactant adsorption on silicon in aqueous alkaline solutions: explaining the changes in the etch rate, roughness and undercutting for MEMS applications. J Micromech Microeng 19(12):125011

31. Gosalvez MA, Pal P, Ferrando N, Sato K (2011) Reliability assessment of the complete $3 \mathrm{D}$ etch rate distribution of $\mathrm{Si}$ in anisotropic etchants based on vertically micromachined wagon wheel samples. J Micromech Microeng 21(12):125008 
32. Chen PH, Peng HY, Hsieh CM, Chyu MK (2001) The characteristic behavior of TMAH water solution for anisotropic etching on both silicon substrate and $\mathrm{SiO}_{2}$ layer. Sens Actuators A 93(2):132-137

33. Tellier CR, Charbonnieras AR (2003) Characterization of the anisotropic chemical attack of (hhl) silicon plates in a TMAH $25 \mathrm{wt} \%$ solution: micromachining and adequacy of the dissolution slowness surface. Sens Actuators A 105:62-75

34. Zhang J, Hon WC, Leung LLW, Chen KJ (2005) CMOS-compatible micromachining techniques for fabricating high-performance edgesuspended RF/microwave passive components on silicon substrates. J Micromech Microeng 15:328-335

35. Steinsland E, Finstad T, Hanneborg A (2000) Etch rates of (100), (111), and (110) single-crystal silicon in TMAH measured in situ by laser reflectance interferometry. Sens Actuators A 86:73-80

36. Pal P, Gosalvez MA, Sato K (2012) Etched profile control in anisotropic etching of silicon by TMAH+Triton. J Micromech Microeng 22(6):065013

37. Wu MP, Wu QH, Ko WH (1986) A study on deep etching of silicon using ethylenediamine-pyrocatechol-water. Sens Actuators A 9:333-343

38. Reisman A, Berkenblit M, Chan SA, Kaufmann FB, Green DC (1979) The controlled etching of silicon in catalyzed ethylene-diamine-pyrochatechol-water solutions. J Electrochem Soc: Solid-State Sci Technol 126:1406-1415

39. Dutta S, Imran Md, Kumar P, Pal R, Datta P, Chatterjee R (2011) Comparison of etch characteristics of $\mathrm{KOH}$, TMAH and EDP for bulk micromachining of silicon (110) Microsyst. Technol 17:1621-1628

40. Declercq MJ, Gerzberg L, Meindl JD (1975) Optimization of the hidrazine-water solution for anisotropic etching of silicon in integrated circuit technology. J Electrochem Soc Solid State Science 122:545-552

41. Gajda MA, Ahmed H, Shaw JEA, Putnis A (1994) Anisotropic etching of silicon in hydrazine. Sens Actuators A 40:227-236

42. Schnakenberg U, Benecke W, Lochel B, Ullerich S, Lange P (1991) $\mathrm{NH}_{4} \mathrm{OH}$-based etchants for silicon micromachining: influence of additives and stability of passivation layers. Sens Actuators A 25-27:1-7

43. Schnakenberg U, Benecke W, Lochel B (1990) $\mathrm{NH}_{4} \mathrm{OH}$-based etchants for silicon micromachining. Sens Actuators A 23:1031-1035

44. Clarck LD, Lund JL, Edell DJ (1988) Cesium hydroxide (CsOH): A useful etchant for micromachining silicon. In: Tech. Digest, IEEE Solid State Sensor and Actuator Workshop (Hilton Head Island, SC, 1988) pp 5-8.

45. Pal P, Sato K (2009) Complex three dimensional structures in Si\{100\} using wet bulk micromachining. J Micromech Microeng 19:105008

46. Pal P, Sato K (2009) Various shapes of silicon freestanding microfluidic channels and microstructures in one step lithography. J Micromech Microeng 19(5):055003

47. Pal P, Sato K (2009) Suspended Si microstructures over controlled depth micromachined cavities for MEMS based sensing devices. Sensor Lett 7(1):11-16

48. Zubel I, Kramkowska M (2005) Possibilities of extension of 3D shapes by bulk micromachining of different $\mathrm{Si}(h \mathrm{k} /)$ substrates. J Micromech Microeng 15:485-493

49. https://en.wikipedia.org/wiki/Wafer_(electronics)

50. Swarnalatha V (2019) TMAH based high speed silicon bulk micromachining, PhD thesis, Indian Institute of Technology Hyderabad, India.

51. Rao AVN (2019) Investigation of high speed silicon wet bulk micromachining in $\mathrm{KOH}$-based solution, PhD thesis, Indian Institute of Technology Hyderabad, India.

52. Moldovan C, losub R, Dascalu D, Nechifor G (1999) Anisotropic etching of silicon in a complexant redox alkaline system. Sens Actuators B Chem 58(1):438-449

53. Van den Meerakker JEAM (1990) The reduction of hydrogen peroxide at silicon in weak alkaline solutions. Electrochim Acta 35(8):1267-1272

54. Van den Meerakker JEAM, Van der Straaten MHM (1990) A mechanistic study of silicon etching in $\mathrm{NH}_{3} / \mathrm{H}_{2} \mathrm{O}_{2}$ cleaning solutions. J Electrochem Soc 137(4):1239-1243

55. Sotoaka R (2008) New etchants for high speed anisotropic etching of silicon. J Surf Finish Soc Japan 59(2):104

56. Yang CR, Chen PY, Yang CH, Chiou YC, Lee RT (2005) Effects of various ion-typed surfactants on silicon anisotropic etching properties in $\mathrm{KOH}$ and TMAH solutions. Sens Actuators A 119(1):271-281

57. Hein A, Dorsch O, Obermeier E (1997) Effects of metallic impurities on anisotropic etching of silicon in aqueous $\mathrm{KOH}$-solutions. IEEE In
Solid State Sensors and Actuators, TRANSDUCERS'97 (Chicago, U.S), pp 687-690.

58. Tanaka H, Cheng D, Shikida M, Sato K (2006) Characterization of anisotropic wet etching properties of single crystal silicon: effects of ppblevel of $\mathrm{Cu}$ and $\mathrm{Pb}$ in $\mathrm{KOH}$ solution. Sens Actuators A 128(1):125-131

59. Menon PK, Rao AVN, Murthy AL, Pandey AK, Pal P (2020) Study of high speed etching of silicon in $\mathrm{KOH}+\mathrm{NH}_{2} \mathrm{OH}$ Solution at lower temperatures for the fabrication of through holes in silicon wafer. Micro Nano Lett 15(6):365-369

60. Swarnalatha V, Rao AVN, Ashok A, Singh SS, Pal P (2017) Modified TMAH based etchant for improved etching characteristics on Si $\{100\}$ wafer. J Micromech Microeng 27(8):085003

61. Swarnalatha V, Rao AVN, Pal P (2018) Effective improvement in the etching characteristics of Si\{110\} in low concentration TMAH solution. Micro Nano Lett 13(8):1085-1089

62. Swarnalatha V, Pal P, Pandey AK, Rao AVN, Xing Y, Tanaka H, Sato K (2020) Systematic study of the etching characteristics of Si\{111\} in modified TMAH. Micro Nano Lett 15(1):52-57

63. Rao AVN, Swarnalatha V, Ashok A, Singh SS, Pal P (2017) Effect of $\mathrm{NH}_{2} \mathrm{OH}$ on etching characteristics of Si\{100\} in $\mathrm{KOH}$ solution. ECS I Solid State Sci Technol 6(9):609-614

64. Rao AVN, Swarnalatha V, Pal P (2017) Etching characteristics of Si\{110\} in $20 \mathrm{wt} \% \mathrm{KOH}$ with addition of hydroxylamine for the fabrication of bulk micromachined MEMS. Micro Nano Syst Lett 5(23):1-9

65. Rao AVN, Pal P, Swarnalatha V, Pandey AK, Menon PK, Tanaka H, Sato K (2019) Aging effects of $\mathrm{KOH}+\mathrm{NH}_{2} \mathrm{OH}$ solution on the etching characteristics of silicon. ECS J Solid State Sci Technol 8(1 1):685-692

66. Chen J, Liu L, Li Z, Tan Z, Jiang Q, Fang H, Xu Y, Liu Y (2002) Study of anisotropic etching of (100) Si with ultrasonic agitation. Sens Actuators A 96(2):152-156

67. Dziuban JA (2000) Microwave enhanced fast anisotropic etching of monocrystalline silicon. Sens Actuators A 185(1):133-138

68. Dziuban JA, Walczak R (2001) Etching microwave silicon [EMSi]-microwave enhanced fast deep anisotropic etching of silicon for microelectromechanical systems [MEMS]. Sens materials 13(1):41-55

69. Tang B, Sato K, Zhang D, Cheng Y (2014) Fast Si(100) etching with a smooth surface near the boiling temperature in surfactant-modified tetramethylammonium hydroxide solutions. Micro Nano Lett 9(9):582-584

70. Palik ED, Bermudez VM, Glembocki OJ (1985) Ellipsometric study of orientation dependent etching of silicon in aqueous $\mathrm{KOH}$. J Electrochem Soc 132(4):871-884

71. Seidel H, Csepregi L, Heuberger A, Baumgärtel H (1990) Anisotropic etching of crystalline silicon in alkaline solutions I. Orientation dependence and behavior of passivation layers. J Electrochem Soc 137(11):3612-3626

72. Raley NF, Sugiyama Y, Van Duzer T (1984) (100) Silicon etch rate dependence on boron concentration in ethylenediamine pyrocatechol water solutions. J Electrochem Soc 131:161-171

73. Elwenspoek M (1993) On the mechanism of anisotropic etching of silicon. J Electrochem Soc 140(7):2075-2080

74. Allongue P, Brune $H$, Gerischer H (1992) In situ STM observations of the etching of $\mathrm{n}$-Si (111) in $\mathrm{NaOH}$ solutions. Surface Sci 275(3):414-423

75. Allongue P, Costa Kieling V, Gerischer $\mathrm{H}$ (1993) Etching of silicon in $\mathrm{NaOH}$ solutions II. Electrochemical studies of n Si (111) and (100) and mechanism of the dissolution. J Electrochem Soc 140(4):1018-1026

76. Gosalvez MA (2003) Atomistic modeling of anisotropic etching of crystalline silicon. PhD Thesis, Dissertation 123, Dissertations of Laboratory of Physics, Helsinki University of Technology.

77. Bressers PMMC, Kelly JJ, Gardeniers JGE, Elwenspoek M (1996) Surface morphology of p-type (100) silicon etched in aqueous alkaline solution. J Electrochem Soc 143:1744-1750

78. Palik ED, Glembocki OJ, Heard I, Burno PS, Tenerz L (1991) Etching roughness for (100) silicon surfaces in aqueous $\mathrm{KOH}$. J Appl Phys 70:3292-3300

79. Campbell SA, Cooper K, Dixon L, Earwaker R, Port SN, Schiffrin DJ (1995) Inhibition of pyramid formation in the etching of $\mathrm{Si} P(100)$ in aqueous potassium hydroxide isopropanol. J Micromech Microeng 5:209-218

80. Baum T, Schiffrin DJ (1997) AFM study of surface finish improvement by ultrasound in the anisotropic etching of $\mathrm{Si}<100>$ in $\mathrm{KOH}$ for micromachining applications. J Micromech Microeng 7:338-342 
81. Elwenspoek M (1999) Stationary hillocks on etching silicon. J Micromech Microeng 9:180-185

82. Veenendaal E, Sato K, Shikida M, Nijdam AJ, Suchtelen J (2001) Micromorphology of single crystalline silicon surfaces during anisotropic wet chemical etching in $\mathrm{KOH}$ : velocity source forests. Sens Actuators A 93:232-242

83. Ohwada K, Negoro Y, Konaka Y, Oguchi T (1995) Groove depth uniformization in (10) Si anisotropic etching by ultrasonic wave and application to accelerometer fabrication. In: Proc. IEEE MEMS Conference (Amsterdam, 29 Jan-2 Feb 1995), 100-105.

84. Walczak R, Dziuban JA (2004) Microwave enhanced wet anisotropic etching of silicon utilizing a memory effect of $\mathrm{KOH}$ activation-a remote E2MSi process. Sens Actuators A 116:161-170

85. Tanaka $\mathrm{H}$ (2005) High-speed anisotropic wet etching of silicon and the effects of metal impurities in $\mathrm{KOH}$ solution. Ph.D thesis, Nagoya University Japan.

86. Sundaram KB, Vijayakumar A, Subramanian G (2005) Smooth etching of silicon using TMAH and isopropyl alcohol for MEMS applications. Microelectron Eng 77:230-241

87. Merlos A, Acero M, Bao MH, Bausells J, Esteve J (1993) TMAH/IPA anisotropic etching characteristics. Sens Actuators A 37:737-743

88. Zubel I (2000) Silicon anisotropic etching in alkaline solutions III: On the possibility of spatial structures forming in the course of $\mathrm{Si}(100)$ anisotropic etching in $\mathrm{KOH}$ and $\mathrm{KOH}+\mathrm{IPA}$ solutions. Sens Actuators A 84(1-2):116-125

89. Zubel I, Kramkowska M (2001) The effect of isopropyl alcohol on etching rate and roughness of (100) Si surface etched in $\mathrm{KOH}$ and TMAH solutions. Sens Actuators A 93:138-147

90. Tang B, Pal P, Gosalvez MA, Shikida M, Sato K, Amakawa H, Itoh S (2009) Ellipsometry study of the adsorbed surfactant thickness on Si\{110\} and Si\{100\} and the effect of pre-adsorbed surfactant layer on etching characteristics in TMAH. Sens Actuators A 156:334-341

91. Resnik D, Vrtacnik D, Aljancic U, Mozek M, Amon S (2005) The role of Triton surfactant in anisotropic etching of 110 reflective planes on (100) silicon. J Micromech Microeng 15:1174-1183

92. Pal P, Sato K, Gosalvez MA, Shikida M (2007) Study of rounded concave and sharp edge convex corners undercutting in CMOS compatible anisotropic etchants. J Micromech Microeng 17:2299-2307

93. Yang CR, Yang CH, Chen PY (2005) Study on anisotropic silicon etching characteristics in various surfactant-added tetramethyl ammonium hydroxide water solutions. J Micromech Microeng 15:2028-2037

94. Sato K, Uchikawa D, Shikida M (2001) Change in orientation-dependent etching properties of single-crystal silicon caused by a surfactant added to TMAH solution. Sens Mater 13:285-291

95. Sekimura M (1999) Anisotropic etching of surfactant-added TMAH solution. In: Proc. 21th IEEE Micro-Electro-Mech. Syst. Conf. (Orlando, Florida, Jan. 1999) pp17-21.

96. Sarro PM, Brida D, van der Vlist W, Brida S (2000) Effect of surfactant on surface quality of silicon microstructures etched in saturated TMAHW solutions. Sens Actuators A 85:340-345

97. Zubel I, Kramkowska M, Rola K (2012) Silicon anisotropic etching in TMAH solutions containing alcohol and surfactant additives. Sens Actuators A 178:126-135

98. Menon PK, Ashok A, Rao AVN, Pandey AK, Pal P (2020) Effect of concentration change of $0.1 \%$ Triton added $25 \mathrm{wt} \%$ TMAH during Fabrication of deep cavities with mesa structures in SOI wafer. Microelectronic Eng 227:111313

99. Ashok A, Pal P (2017) Silicon micromachining in 25 wt\% TMAH without and with surfactant concentrations ranging from ppb to ppm. Microsyst Technol 23(1):47-54

100. Tang B, Yao MQ, Tan G, Pal P, Sato K, Su W (2014) Smoothness control of wet etched Si\{100\} surfaces in TMAH+Triton. Key Eng Materials 609:536-541

101. Pal P, Sato K, Gosalvez MA, Kimura Y, Ishibashi K, Niwano M, Hida H, Tang B, Itoh S (2009) Surfactant adsorption on single crystal silicon surfaces in TMAH solution: orientation-dependent adsorption detected by insitu infra-red spectroscopy. J Microelectromech Syst 18:1345-1356

102. Cho WJ, Chin WK, Kuo CT (2004) Effects of alcoholic moderators on anisotropic etching of silicon in aqueous potassium hydroxide solutions. Sens Actuators A 116:357-368
103. Zubel I, Kramkowska M (2004) Etch rates and morphology of silicon (hkl) surfaces etched in $\mathrm{KOH}$ and $\mathrm{KOH}$ saturated with isopropanol solutions. Sens Actuators A 115:549-556

104. Philipsen HGG, Kelly JJ (2009) Influence of chemical additives on the surface reactivity of $\mathrm{Si}$ in $\mathrm{KOH}$ solution. Electrochim Acta 54:3526-3531

105. Xu YW, Michael A, Kwok CY (2011) Formation of ultra-smooth 45o micromirror on (100) silicon with low concentration TMAH and surfactant: Techniques for enlarging the truly 450 portion. Sens Actuators A 166:164-171

106. Yan G, Chan Philip CH, Hsing IM, Sharma RK, Sin JKO, Wang Y (2001) An improved TMAH Si-etching solution without attacking exposed aluminum. Sens Actuators A 89:135-141

107. Brida S, Faes A, Guarnieri V, Giacomozzi F, Margesin B, Paranjape M, Pignatel GU, Zen M (2000) Microstructures etched in doped TMAH solutions. Microelectronic Eng 53:547-551

108. Fujitsuka N, Hamaguchi K, Funabashi H, Kawasaki E, Fukada T (2004) Silicon anisotropic etching without attacking aluminum with Si and oxidizing agent dissolved in TMAH solution. Sens Actuators A 114:510-515

109. Jun KH, Kim BJ, Kim JS (2015) Effect of Additives on the anisotropic etching of silicon by using a TMAH based solution. Electron Mater Lett 11:871-880

110. Tsaur JJ, Du CH, Lee C (2001) Investigation of TMAH for front-side bulk micromachining process from manufacturing aspect. Sens Actuators A 92:375-383

111. Klaassen EH, Reay RJ, Storment C, Kovacs GTA (1997) Micromachined thermally isolated circuits. Sens Actuators A 58:43-50

112. Chunyang W (2006) Thermal runaway reaction hazard and decomposition mechanism of the hydroxylamine system. Doctoral dissertation, Texas A \& M University.

113. Cisneros LO, Rogers WJ, Mannan MS (2004) Comparison of the thermal decomposition behavior for members of the hydroxylamine family. Thermochim Acta 414:177-183

114. Hughes MN, Nicklin HG (1971) Autoxidation of hydroxylamine in alkaline solutions. J Chem Soc A 164-168.

115. Wei C, Saraf SR, Rogers WJ, Mannan MS (2004) Thermal runaway reaction hazards and mechanisms of hydroxylamine with acid/base contaminants. Thermochim Acta 421:1-9

116. Cisneros LO, Wu X, Rogers WJ, Mannan MJ, Park J, North SW (2003) Decomposition products of 50 mass\% hydroxylamine/water under runaway reaction conditions. Process Saf Environ Prot 81(2):121-124

117. Swarnalatha V, Vismaya KT, Rao AVN, Pal P, Pandey AK, Tanaka H, Sato K (2020) Etching mechanism behind the high speed etching of silicon in $\mathrm{NH}_{2} \mathrm{OH}$-added alkaline solutions. IEEJ Transaction on Sensors and Micromachines 140(1):24-30

118. Pal P, Sato K, Chandra S (2007) Fabrication techniques of convex corners in a (100)-silicon wafer using bulk micromachining: a review. J Micromech Microeng 17:R1-R23

119. Pal P, Sato K (2015) A comprehensive review on convex and concave corners in silicon bulk micromachining based on anisotropic wet chemical etching. Micro and Nano Syst Lett 3(6):1-42

120. Pal P, Haldar S, Singh SS, Ashok A, Xing Y, Sato K (2014) A detailed investigation and explanation to the appearance of different undercut profiles in $\mathrm{KOH}$ and TMAH. J Micromech Microeng 24:095026

121. Pal P, Sato K, Shikida M, Gosalvez MA (2009) Study of corner compensating structures and fabrication of various shapes of MEMS structures in pure and surfactant added TMAH. Sens Actuators A 154:192-203

122. Pal P, Singh SS (2013) A simple and robust model to explain convex corner undercutting in wet bulk micromachining. Micro Nano Systems Lett 1(1):1-6

123. Pal P, Chandra S (2004) Recessed microstructures with perfect convex corners for accelerometers. Sensor Lett 2:226-231

124. Kolesar JES, Carver MW (1989) Deep anisotropic etching of tapered channels in (110)-oriented silicon. Chem Mater 1(6):634-639

125. Lee D, Yu K, Krishnamoorthy U, Solgaard O (2009) Vertical mirror fabrication combining $\mathrm{KOH}$ etch and DRIE of (110) silicon. J Microelectromech Syst 18(1):217-227

126. Holke A, Henderson HT (1999) Ultra-deep anisotropic etching of (110) silicon. J Micromech Microeng 9(1):51-57 
127. Pal P, Gosalvez MA, Sato K, Hida H, Xing Y (2014) Anisotropic etching on Si\{110\}: Experiment and simulation for the formation of microstructures with convex corners. J Micromech Microeng 24:125001

128. Uenishi Y, Tsugai M, Mehregany M (1995) Micro-opto-mechanical devices fabricated by anisotropic etching of (110) Silicon. J Micromech Microeng 5(4):305-312

129. Pal P, Singh SS (2013) A new model for the etching characteristics of corners formed by $\mathrm{Si}\{111\}$ planes on $\mathrm{Si}\{110\}$ wafer surface. Engineering 5(11):1-8

130. Kim SH, Lee SH, Lim HT, Kim YK, Lee SK (1997) Anisotropic bulk etching of (110) Silicon with high aspect ratio. IEEJ Trans Sens Micromach 118(1):32-36

131. Krause P, Obermeier E (1995) Etch rate and surface roughness of deep narrow U-grooves in (110)-oriented silicon. J Micromech Microeng 5(2):112-114

132. Kim J, Cho DI, Muller RS (2001) Why is (111) silicon a better mechanical material for MEMS?. In: Transducers' 01 Eurosensors XV Springer Berlin Heidelberg 662-665.

133. Yu X, Wang Y, Zhou H, Liu Y, Wang Y, Li T, Wang Y (2013) Top-down fabricated silicon-nanowire-based field-effect transistor device on a (111) silicon wafer. Small 9(4):525-530

134. Oosterbroek RE, Berenschot JW, Jansen HV, Nijdam AJ, Pandraud G, Van Den Berg A, Elwenspoek MC (2000) Etching methodologies in $<111>$-oriented silicon wafers. J Microelectromech Syst 9(3):390-398

135. Shah IA, Van Enckevort WJP, Vlieg E (2010) Absolute etch rates in alkaline etching of silicon (111). Sens Actuators A 164(1):154-160

136. Koo Kl, Chung H, Yu Y, Seo J, Park J, Lim JM, Paik SJ, Park S, Choi HM, Jeong MJ, Kim GS (2006) Fabrication of pyramid shaped three-dimensional $8 \times 8$ electrodes for artificial retina. Sens Actuators A 130:609-615

137. Pandraud G, Veldhuis G, Berenschot JW, Nijdam AJ, Hoekstra HJWM, Parriaux O, Lambeck PV (2000) Micromachining of high-contrast optical waveguides in [111] silicon wafers. IEEE Photon Technol Lett 12(3):308-310
138. Ensell G (1995) Free standing single-crystal silicon microstructures. J Micromech Microeng 5(1):1-4

139. Rao AVN, Swarnalatha V, Pandey AK, Pal P (2018) Determination of precise crystallographic directions on Si $\{111\}$ wafers using self-aligning pre-etched pattern. Micro Nano Syst Lett 6(4):1-9

140. Lee S, Park S, Cho DI (1999) A new micromachining technique with (111) silicon. Jpn J Appl Phy 38(5R):2699-2703

141. Fleming JG (1998) Combining the best of bulk and surface micromachining using $\mathrm{Si}(111)$ substrates. Micromach Microfabrication Proc Technol IV Int Soc Optics Photonics 3511:162-169

142. Cho DI, Choi BD, Lee S, Paik SJ, Park S, Park J, Park Y, Kim J, Jung IW (2003) Dry and wet etching with (111) silicon for high-performance micro and nano systems. Int J Comput Eng Sci 4(02):181-187

143. Park S, Lee S, Yi S, Cho DI (1999) Mesa-supported, single-crystal microstructures fabricated by the surface/bulk micromachining process. Jpn J Appl Phy 38(7R):4244-4249

144. Chou BC, Chen CN, Shie JS (1999) Micromachining on (111)-oriented silicon. Sens Actuators A 75(3):271-277

145. Lee S, Park S, Kim J, Lee S, Cho DI (2000) Surface/bulk micromachined single-crystalline-silicon micro-gyroscope. J Microelectromech Syst 9(4):557-567

146. Hu HH, Lin HY, Fang W, Chou BC (2001) The diagnostic micromachined beams on (111) substrate. Sens Actuators A 93(3):258-265

147. Lee S, Park S, Cho DI (1999) The surface/bulk micromachining (SBM) process: a new method for fabricating released MEMS in single crystal silicon. J Microelectromech Syst 8(4):409-416

\section{Publisher's Note}

Springer Nature remains neutral with regard to jurisdictional claims in published maps and institutional affiliations.

\section{Submit your manuscript to a SpringerOpen ${ }^{\circ}$ journal and benefit from:}

- Convenient online submission

- Rigorous peer review

- Open access: articles freely available online

- High visibility within the field

- Retaining the copyright to your article

Submit your next manuscript at $\boldsymbol{\nabla}$ springeropen.com 